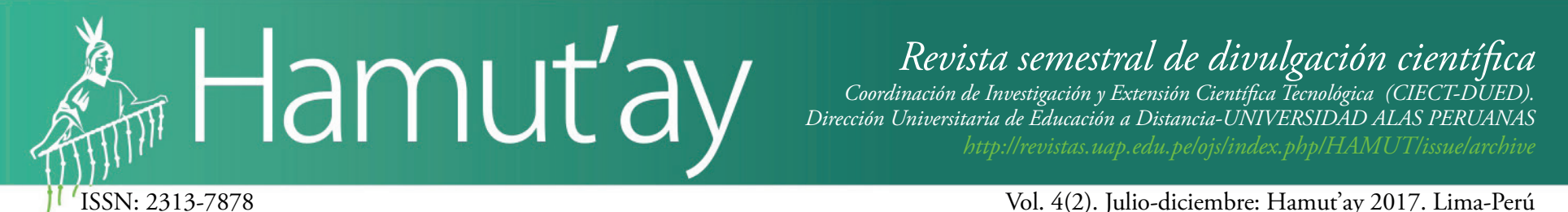

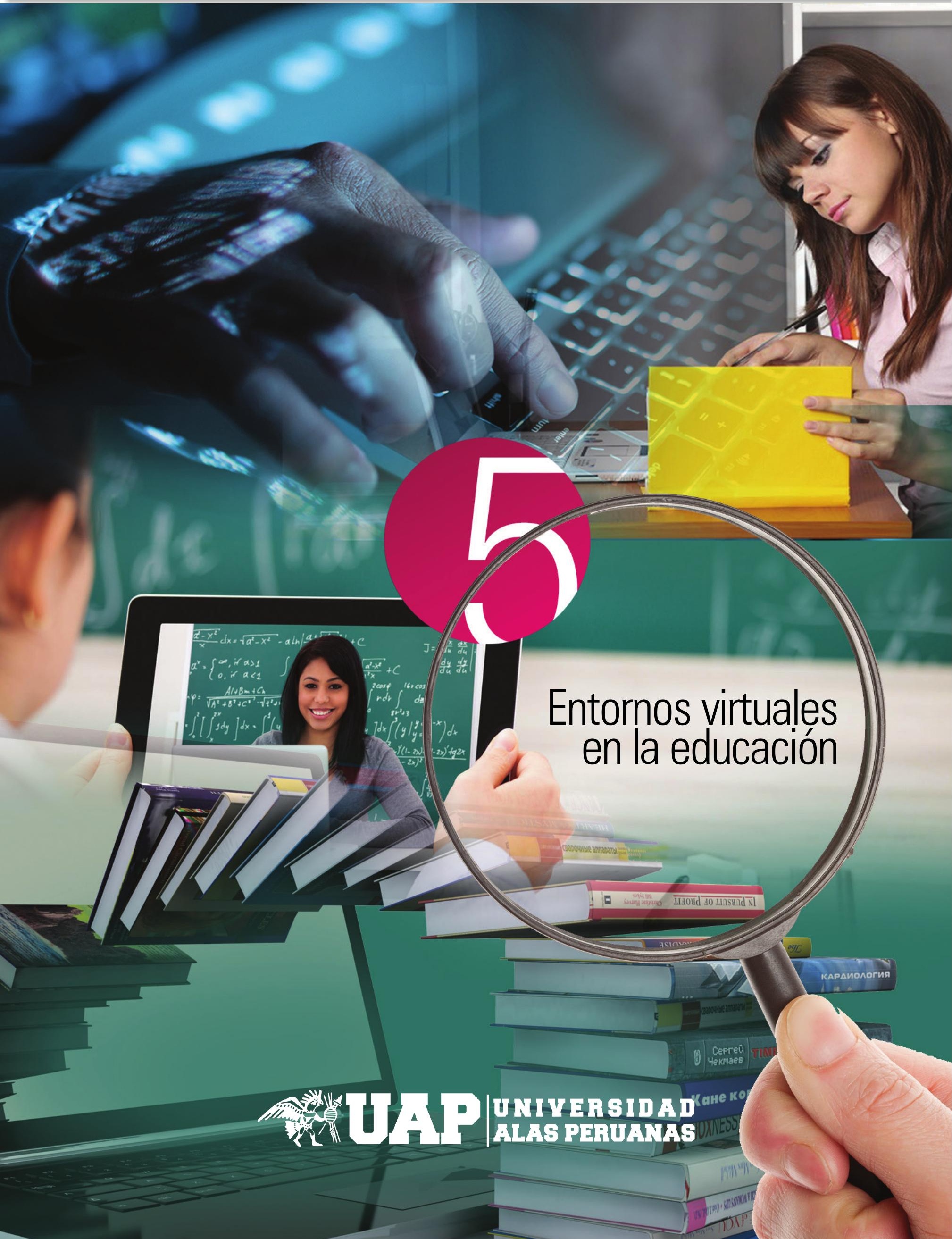




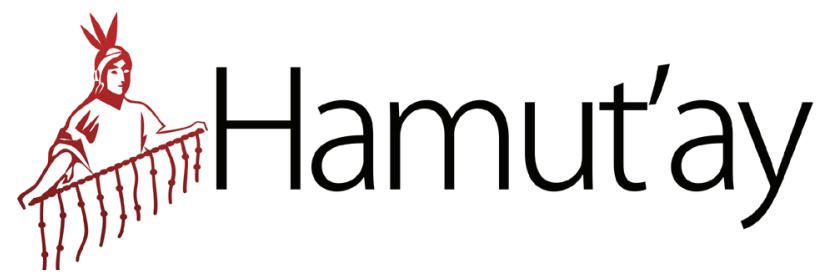

Revista semestral de divulgación científica publicada por la Coordinación de Investigación y Extensión Científica Tecnológica (CIECT-DUED) de la Dirección Universitaria de Educación a Distancia. Universidad Alas Peruanas. Lima, Perú.

Título clave: Hamut’ay
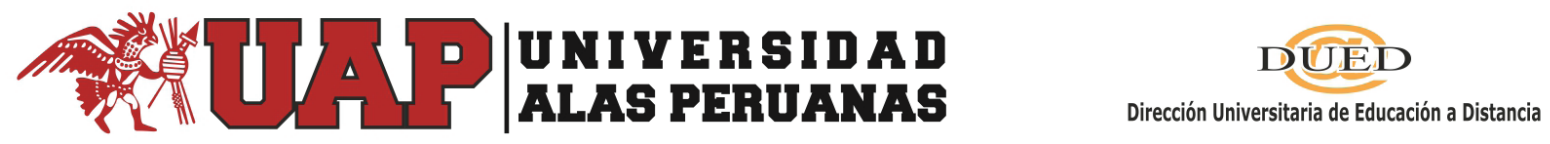

http://revistas.uap.edu.pe/ojs/index.php/HAMUT/issue/archive correo electrónico: revistahamutay@uap.edu.pe 
UNIVERSIDAD ALAS PERUANAS

Fidel Ramirez Prado Phd. Rector

Dr. Enrique Bedoya Sánchez Vicerrector Académico

Dr. Manuel Coronado Aguilar

Vicerrector Administrativo

Dr. Jorge Lazo Arrasco

Vicerrector de Investigacion e Innovación Tecnológica

Dr. José Soberon Bolaños

Vicerrector de Planificación y Economía

Dra. Rosabel Alarcón Ramírez

Directora, Dirección Universitaria de Educación a Distancia

EDITOR EN JEFE

Dra. Cleofé Genoveva Alvites Huamaní

Universidad Alas Peruanas, Perú

CONSEJO EDITORIAL

Dra. Constanza Abadia Garcia

Universidad Nacional Abierta a Distancia, Colombia

Dra. Cynthia Zaira Vega Valero

Universidad Nacional Autónoma de México

Dr. José Bernardo Peña Arcila

Universidad Politécnica Territorial del estado

Aragua. Venezuela. Integrante del Grupo internacional de investigación TEIS, Universidad de Granada, España.

Dr. Pere Marqués Graells

Universidad Autónoma de Barcelona, España

Dr. Ramfis Miguelena

Universidad Tecnológica de Panamá

Dr. José Ernesto Mancera Pineda

Universidad Nacional de Colombia

Dr. Philip Desenne

Harvard University, EE. UU.

Dr. Pedro Agustín Pernías Peco

Universidad de Alicante, España

M.Sc. Plinio Puello Marrugo

Universidad de Cartagena, Colombia

Ing. David Antonio Franco Borré

Universidad de Cartagena, Colombia

\section{COMITÉ EDITORIAL}

Dr. Pedro Martínez Geijo

Universidad Nacional de Educación a Distancia, España

Miguel Ángel García-Ruiz, PhD.

Algoma University, Canadá

Adriana P. Herrera. PhD.

Universidad de Cartagena, Colombia

Dr. Arturo Silva Rodríguez

Universidad Nacional Autónoma de México

Dra. Sonia Concari

Universidad Nacional de Rosario, Argentina

Dr. Omar O. López Sinisterra

Universidad de Panamá, Panamá

Maestro Óscar Pérez Mora

Universidad de Guadalajara, México

Ricardo Filipe Martins, PhD

GrupoPEDAGO, Instituto Superior de Ciências

Educativas ISCE / ISCE Douro, Portugal

M.D.C. Martha Amalia Ávalos Medina

Jefa, Educación Superior del Estado de Michoacán, México

Lilian R. Daset, Ph.D.

Universidad Católica del Uruguay, Uruguay

Dr. Miguel Angel Vargas-Lombardo

Universidad Tecnológica de Panamá

Ing. Katia Ruiz

Universidad Alas Peruanas, Perú

Mag. Liliana Larrea

Universidad Alas Peruanas, Perú

SOPORTE TÉCNICO

$\mathrm{Mg}$. Jorge Olaya Rodríguez

DIAGRAMACIÓN Y ARTES FINALES

Ing. Víctor Raúl Millán Salazar

CORRECCIÓN DE ESTILO

Dr. Néstor Fernández Sánchez

TRADUCCIÓN

Mg. Magaly Ugarte Sebastián

\section{DIRECCIÓN}

Av. Guillermo Prescott 520, San Isidro, Lima, Perú. Teléfono 4714545

http://revistas.uap.edu.pe/ojs/index.php/HAMUT/issue/archive Email: revistahamutay@uap.edu.pe

\section{REVISTA ARBITRADA}

Se permite la copia y distribución por cualquier medio siempre que se mantenga el reconocimiento de los autores y no se realice modificaciones.

Los artículos publicados expresan las opiniones personales de sus autores y no necesariamente las de la Universidad Alas Peruanas. 


\section{Índice}

Editorial

Contraste de Estudiantes Universitarios Presenciales y en Línea en un

Curso Autogestivo: El Papel de la Autoeficacia y la Motivación

Contrast of University Students Face-To-Face and Online in a Self-

Management Course: The Role of Self-Efficacy and Motivation

Sistema Inteligente de Tutoría para entrenamiento procedimental apoyado en un diálogo adaptado al contexto

Intelligent Tutoring System for procedural training supported in a dialogue adapted to the context

Capital Intelectual, Gestión del Conocimiento en la Interacción

Gobierno y Gestión de la Tecnologías de la Información desde perspectiva COBIT 5

Intellectual capital, knowledge management in the interaction government and management of information technologies from COBIT 5 perspective

Blog, Correo Electrónico y Foros Temáticos: su Uso, Dominio y

Actitud en Estudiantes de Educación Medio Superior de México.

Blog, Electronic Mail and Thematic Forums: its Use, Domain and Attitude in Mexico's Higher Education Students

Juegos Online: Una Mirada desde el Juego Patológico

Online Games: A Look from the Pathological game

Propuesta de práctica investigativa con la Webquest. Estrategia pedagógica de comprensión del concepto e importancia del "bosque" Proposal of investigative practice with the Webquest. Pedagogic strategy of understanding of the concept and importance of the "forest"

Despliegue de una Red Inalámbrica Libre Comunitaria: Un Ejercicio de Soberanía Digital en el Barrio Villa Del Río (Bogotá, Colombia)

Deploying an Open Community Wireless Network: An Exercise on Digital Sovereignty on Villa Del Rio Neighborhood (Bogotá, Colombia) 


\section{Editorial}

Cita recomendada: Alvites-Huamaní, C. (2017). Investigación y Tecnología. Hamut’ay 4(2), 5-6. Recuperado de: http://dx.doi.org/10.21503/hamu.v4i2.1466

\section{INVESTIgACIÓN Y TeCNOLOgÍA}

Investigación y tecnologías, aunque son términos diferentes, existe una estrecha relación complementaria entre ellos por la multitud de funciones que la tecnología respalda en la diversidad de ámbitos de la investigación. A su vez, la investigación aporta elementos que favorecen el uso apropiado y conveniente de las tecnologías. La progresiva versatilidad e incesante desarrollo que durante estos años ha caracterizado a las tecnologías permite recibir, intercambiar, representar, manejar, analizar, interpretar y acceder a la producción de conocimiento científicos en una diversidad de vertientes y en una amplia gama de especialidades académicas y niveles educativos; esta situación promueve el desarrollo de una serie de descubrimientos útiles para la humanidad, sin dejar de mencionar el aporte que estas dos simples palabras están haciendo a la ciencia, tecnología y desarrollo sustentable de los países en beneficio de su desarrollo económico. Tal es el caso de Perú, país en vías de desarrollo, donde la investigación y las tecnologías están haciendo que, aunque no esté en un lugar privilegiado, su nombre sea reconocido como uno de los países de Latinoamérica que está apostando por darle un mayor énfasis a la investigación, junto con la apropiación de las tecnologías.

Este binomio investigación tecnología no pueden dejar de lado el rol que cumplen las instituciones de educación superior y sus docentes al abonar en el proceso de complementariedad de la investigación y la tecnología, ya que parte de las funciones sustantivas de toda universidad es generar nuevos conocimientos a través de la investigación y de la tecnología, enmarcados desde un carácter científico y tecnológico; por su parte, el cuerpo docente promueve el desarrollo de la investigación formativa apoyándose en la tecnología, como una de las funciones inherentes a su cargo. Desde esta

\section{Research and Technology}

Research and technologies, although they are different terms, there is a close complementary relationship between them, due to the number of functions that technology supports in the diversity of research fields. Additionally, research provides elements that support the appropriate and convenient use of technologies. The progressive versatility and continuous development that has characterized these technologies during these years allows us to receive, exchange, represent, manage, analyze, interpret and access to the production of scientific knowledge in a variety of perspectives and in a wide range of academic specialties and educational levels. This situation promotes the development of a series of useful discoveries for humanity, not to mention the contribution that these two simple words are making to the science, technology and sustainable development of the countries for the benefit of their economic growth. Such is the case of Peru, a developing country, where research and technologies are making it possible, even if it is not in a privileged place yet, that its name is recognized as one of the countries in Latin America that is committed to giving greater emphasis to research, together with the appropriation of technologies.

This binomial technology - research cannot disregard the role of higher education institutions and their professors for contributing in the process of complementarity of research and technology, since some of the most important functions of any university is to generate new knowledge through research and technology, outlined in a scientific and technological framework. Furthermore, faculty professors promote the development of formative research based on technology, as one of the functions inherent to their position. From this perspective, Hamut'ay journal publishes 
perspectiva la revista Hamut'ay divulga artículos científicos para dar a conocer cómo se están dando los avances en las diversas áreas de especialidad donde está inmersa la tecnología y la investigación. scientific articles to show how advances are being made in the several areas of expertise where technology and research are immersed.

Dra. Cleofé Genoveva Alvites Huamaní Editor Jefe de la revista cientifica Hamut'ay I Editor in Chief of the Hamut'ay journal

\section{DUED}

Dirección Universitaria de Educación a Distancia 


\title{
Contraste de Estudiantes Universitarios Presenciales y en Línea en un Curso Autogestivo: el Papel de la Autoeficacia y la Motivación
}

\section{Contrast of university students face-to-face and online in a self-management course: the role of self-efficacy and motivation}

\author{
Sandra Ivonne Muñoz Maldonado ${ }^{1}$ \\ Ricardo Sánchez Medina ${ }^{2}$ \\ David Javier Enríquez Negrete ${ }^{3}$ \\ Consuelo Rubi Rosales Piña ${ }^{4}$ \\ Universidad Nacional Autónoma de México
}

Recibido: 20-09-2017

Aceptado: 09-11-2017

\section{Cita Recomendada}

Muñoz, S., Sánchez, R., Enríquez, D. y Rosales, C. (2017) Contraste de estudiantes universitarios presenciales y en línea en un curso autogestivo: El papel de la autoeficacia y la motivación. Hamut'ay, 4 (2), 7-16. Recuperado de: http://dx.doi.org/10.21503/hamu.v4i2.1467

\section{RESUMEN}

Ante el auge de cursos en línea autogestivos y masivos, se ha revelado la necesidad de evaluar e identificar las habilidades de los estudiantes que retoman este tipo de opciones educativas para actualizarse o formarse. La evidencia empírica coincide en que las habilidades de autorregulación, la percepción de autoeficacia y la motivación son factores indispensables en los estudiantes, sobre todo en aquellos que ya han estudiado bajo esta modalidad y han terminado exitosamente; por ello es que el objetivo de esta investigación fue identificar si existen diferencias en las habilidades antes mencionadas en estudiantes que provienen de un sistema en línea o de un sistema presencial al participar en un curso en línea autogestivo. Se trata de un estudio descriptivo, comparativo, transversal, con un muestreo no aleatorio de tipo voluntario en el que participaron 80 estudiantes de la licenciatura en psicología y a los que se les aplicó la Escala de Autopercepción de la Motivación Académica Personal, así como la Escala sobre Autoeficacia y Autorregulación. Los resultados del análisis estadístico T- Student muestran diferencias significativas en algunas de las escalas de los instrumentos aplicados. Los estudiantes que provenían del sistema a distancia presentaron mayores puntajes en las estrategias de autorregulación relacionadas con el esfuerzo diario, la verificación de las acciones de aprendizaje efectivas y el procesamiento activo de la información. Al comparar los resultados entre estudiantes

1 Profesora en la Universidad Nacional Autónoma de México. Facultad de Estudios Superiores Iztacala. Sistema de Universidad Abierta y Educación a Distancia. Grupo de Investigación en Procesos Psicológicos y Sociales. Correo: sandra.munoz@ired.unam.mx 2 Profesor en la Universidad Nacional Autónoma de México. Facultad de Estudios Superiores Iztacala. Sistema de Universidad Abierta y Educación a Distancia. Grupo de Investigación en Procesos Psicológicos y Sociales. Correo: ricardo.sanchez@ired.unam.mx

3 Profesor en la Universidad Nacional Autónoma de México. Facultad de Estudios Superiores Iztacala. Sistema de Universidad Abierta y Educación a Distancia. Grupo de Investigación en Procesos Psicológicos y Sociales. Correo: david.enriquez@ired.unam.mx

4 Profesora en la Universidad Nacional Autónoma de México. Facultad de Estudios Superiores Iztacala. Sistema de Universidad Abierta y Educación a Distancia. Grupo de Investigación en Procesos Psicológicos y Sociales. Correo: rubi.rosales@ired.unam.mx 
que finalizan o no el curso, no se encontraron diferencias en las estrategias de autorregulación entre ambos grupos. Estos hallazgos muestran que los estudiantes en línea tienen un mejor manejo del tiempo y recursos propios; con estas características y las estrategias de aprendizaje ejercidas es más probable terminar exitosamente un curso autogestivo en línea.

Palabras Clave: Autoeficacia, autorregulación, motivación, aprendizaje autogestivo, tecnologías.

\section{Abstract}

Due to the boom of self-managed and massive online courses, it is now clear the necessity to assess and identify the skills of students who enroll in this type of educational options to update or study. The empirical evidence agrees that self-regulation skills, the perception of self-efficacy and motivation are indispensable factors in students, especially in those who have already studied under this modality and have successfully completed a course; that is why the objective of this research was to identify if there are any differences in the previously mentioned abilities in students who come from an online or a face-to-face system when participating in a self-managed online course. It is a descriptive, comparative, cross-sectional study, with a voluntary non-random sampling in which 80 undergraduate Psychology students participated and to which the Self-Perception Scale of Personal Academic Motivation was applied, as well as the Scale on Self-efficacy and Self-regulation. The results of the T-Student statistical analysis show significant differences in some of the scales of the instruments applied. Students that came from the distance system presented higher scores in the self-regulation strategies related to daily effort, the verification of the effective learning actions and the active processing of information. When comparing the results among students who completed the course or not, no differences were found in the self-regulation strategies between both groups. These findings show that online students have a better management of their time and own resources; with these characteristics and the learning strategies applied, it is more likely to successfully complete a self-managed online course.

Keywords: Self-efficacy, self-regulation, motivation, self-managed learning, technologies.

\section{INTRODUCCIÓN}

Ante el crecimiento y propagación a gran escala que está teniendo la educación en línea y cursos en línea autogestivos y masivos, se ha evidenciado que es necesario investigar más sobre las habilidades que debe poseer el estudiante que tome como opción la educación en esta modalidad para favorecer su éxito.

En particular, una investigación realizada por Chiecher et al (2015) los estudiantes que se perciben más motivados por aprender y con una alta valoración de las tareas tienden a obtener mejor rendimiento que sus pares menos motivados; este último factor es fundamental en los cursos autogestivos ya que promueven la implementación de las estrategias de aprendizaje autorregulado, debido a que los estudiantes gestionan su aprendizaje $\mathrm{y}$ avancen de acuerdo a sus tiempos y metas propuestas.

Aquellos que estudian en un sistema a distancia se caracterizan por tener mayores niveles de orientación a la tarea, mayor valor a la tarea de aprendizaje, mejores creencias de control de aprendizaje y autoeficacia para el aprendizaje; emplean además estrategias cognitivas de repetición, organización y autorregulación metacognitiva. A diferencia de los estudiantes presenciales, los de educación a distancia se interesan más por aprender y dominar la tarea, y se consideran más capaces de poder controlar el proceso de aprendizaje. 
Ante el panorama descrito es que el presente estudio buscó identificar las posibles diferencias entre la autoeficacia y la motivación de los estudiantes que provienen de un sistema presencial y de un sistema a distancia, quienes participaron en un curso en línea autogestivo para aprender el tema de construcción de instrumentos.

\section{Autoeficacia}

La teoría Cognitivo Social de Bandura (1993) establece que la autoeficacia percibida tiene un rol relevante en el aprendizaje, de tal forma que los juicios que los estudiantes realizan de sus propias capacidades y medios para poder realizar una actividad pueden determinar el éxito para alcanzar las metas académicas. La autoeficacia se relaciona de forma significativa con el aprendizaje autorregulado.

Existen investigaciones que afirman que un estudiante autorregulado tiene mayor autoeficacia y emplea estrategias de aprendizaje más adecuadas para resolver cada una de las tareas académicas que se le presentan (Komarraju \& Nadler, 2013). Así mismo, la motivación se ha mostrado como un predictor robusto de la autoeficacia y el desempeño en diferentes contextos y poblaciones (Mega, Ronconi, \& De Beni, 2014). En este sentido la autoeficacia se relaciona con la autorregulación, en los estudiantes universitarios.

Investigaciones como la de Garello y Rinaudo (2012) señalan que los procesos de autorregulación son fundamentales; ellos argumentan que, si se cuenta con habilidad para el manejo, control y monitoreo de las propias metas, estrategias, motivaciones y emociones relacionadas con la finalización de las tareas académicas, entonces se tendrán estudiantes con mayor éxito académico.

La autoeficacia en una tarea o área específica que puede potenciar la motivación y el desempeño de aprendizaje. Por ejemplo, en Taiwán un grupo de investigadores estudió el efecto de la autoeficacia en el uso de Internet en la motivación del estudiante y su desempeño. Los resultados mostraron que aquellos estudiantes universitarios que reportaban mayor autoeficacia en el uso de Internet se mostraron más confiados en su habilidad para completar un curso en línea, además de que los varones presentan mayores puntajes que impac- tan en la atención, relevancia, confianza y motivación (Lee, Choi \& Kim, 2013).

\section{Autorregulación}

La autorregulación es definida como los esfuerzos realizados por el estudiante para controlar sistemáticamente el proceso de aprendizaje orientándose a alcanzar las metas planteadas (Zimmerman \& Schunk, 2011).

Diferentes perspectivas coinciden en que los elementos fundamentales de este constructo son la orientación a las metas, autoeficacia académica y la regulación en diferentes contextos. La perspectiva Social Cognitiva afirma que la autorregulación es el resultado de la interacción recíproca entre la persona, conducta y ambiente; al respecto, Pintrich (2000) propone que la autorregulación se divide en cuatro factores en un contexto académico, estos son: planeación, monitoreo, control y reflexión.

Azevedo (2014) afirma que los estudiantes que priorizan el conocimiento y monitorean sus conductas de aprendizaje están relacionados con un modelo mental más sofisticado; asimismo, afirma que el monitoreo es la clave del aprendizaje autorregulado.

En una investigación se estudió el rol de los intereses individuales en el proceso de autorregulación y encontraron que existe una trayectoria directa entre el interés personal y la autorregulación académica, de tal manera que el interés en un tópico específico o un área de conocimiento en la cual se quiere profundizar para predecir una mejor autorregulación (Lee, Lee \& Bong, 2014). Al respecto, Pintrich (2004) afirma que los estudiantes que desarrollan mejores habilidades cognitivas de autorregulación tienden a estar académicamente más motivados y aprenden más que aquellos que no las han desarrollado.

\section{Motivación}

Otro factor deseable en la educación a distancia es la motivación, que se relaciona con una menor deserción en este tipo de educación. La motivación se ha definido desde diversas perspectivas. Pintrich y Shunk (2006) la consideran como un 
Contraste de Estudiantes Universitarios Presenciales y en Línea en un Curso Autogestivo: el Papel de la Autoeficacia y la Motivación

conjunto de fuerzas internas o de rasgos personales que se observan en respuestas conductuales diferenciales a determinados estímulos o escenarios de creencias y afectos. En esta misma perspectiva se define que la motivación tiene cuatro factores. El primero es el valor de la tarea, entre más interesado esté el estudiante, más motivado; el segundo es la orientación de las metas, es decir, los propósitos del estudiante se encaminan al logro; el tercer factor se refiere a las creencias de autoeficacia para realizar las tareas de un curso; el último factor es el grado de control que cada estudiante percibe tener sobre su aprendizaje. Como parte importante de la motivación se destacan las metas, de tal forma que la motivación de los estudiantes puede mejorar si enfocan sus esfuerzos en alcanzar las metas académicas definidas, de tal forma que el desempeño relacionado con las metas puede estar permeado por motivaciones intrínsecas como la superación académica personal o extrínsecas como el logro o la competencia (Richardson, Abraham \& Bond, 2012). De estos dos tipos de factores de la motivación los intrínsecos son los que se relacionan con la autoeficacia, de tal forma que los individuos que se perciben más capaces de alcanzar las metas deseadas presentan mayor motivación intrínseca, de igual forma serán estudiantes más exitosos (Dunn, 2014).

Autoeficacia, motivación y autorregulación en la educación a distancia

Algunos investigadores mencionan que en la educación en línea los estudiantes deben poseer una serie de habilidades para asegurar el éxito en su formación académica, una de estas habilidades es la autorregulación. De acuerdo con Berridi y Martínez (2017), la autorregulación es un mediador potencial y se vuelve un factor clave en ambientes virtuales de aprendizaje y está asociado al éxito en los cursos a distancia.

Dentro del aprendizaje autorregulado se distingue una característica particular que se relaciona con el desempeño de los estudiantes a distancia, la metacognición. Se trata de aquellas habilidades referentes a la conciencia, conocimiento y control de la cognición, propias del sujeto. En educación a distancia se enfatiza la necesidad de que los estudiantes logren autodirigir su aprendizaje, monito- reen su progreso para proponer sus propias metas de aprendizaje y así asegurar un mejor desempeño (Abrami et al, 2011).

Además de la autoeficacia, otro de los factores que se ha estudiado en relación al rendimiento o éxito en la educación a distancia es la autorregulación y las habilidades metacognitivas, en un estudio realizado por Martínez y Meza (2013) se encontraron diferencias entre las habilidades metacognitivas y de procesamiento de la información y el control de la autorregulación en donde los estudiantes del sistema a distancia poseen un nivel mayor de habilidades que los del sistema presencial.

Algunos investigadores como Pintrich (2003) han delineado principios que pueden ser aplicables en el aprendizaje en línea, dentro de estos se destacan: que los estudiantes motivados tienen mayor autoeficacia y creencias de competencia, las atribuciones adaptativas y los pensamientos de control sobre la tarea, así como el valor dado a las tareas y metas claras mantienen motivados a los estudiantes en una modalidad a distancia. Acorde con estos aspectos se ha buscado potenciar las oportunidades de la educación a distancia incluyendo elementos que apoyen la motivación, el sentido de autoeficacia y la autorregulación, incluyendo materiales y tareas que sean relevantes para los estudiantes, así como proporcionar realimentación enfocada en el desarrollo de competencias, experiencia y habilidades.

Autoeficacia, motivación y autorregulación y cursos autogestivos

Los cursos en línea abiertos, masivos y autogestivos han resultado una opción potencial para aquellas personas que no pueden acceder a un sistema escolarizado, o incluso son una forma de actualizarse o conocer de otros tópicos sin necesidad de matricularse en una universidad; sin embargo, la misma naturaleza de estos cursos permite que estudiantes con diferentes perfiles de motivación, intereses y expectativas, de tal manera que existen altas tasas de deserción en este tipo de cursos (Liyanagunawardena, Parslow \& Williams, 2014).

En este contexto, el estudiante necesita regular su propio aprendizaje, monitorear y ajustar su conducta y acciones al contexto de aprendizaje al 
cual se enfrenta. Por ello algunas investigaciones han apuntado a buscar respuesta sobre los factores cognitivos, afectivos y conductuales que impactan el aprendizaje en los cursos masivos y autogestivos (Hood, Littlejohn \& Milligan, 2015).

Investigaciones como la de Cheng \& Chau (2013), identificaron que existen cinco subprocesos que se relacionan con un mejor rendimiento, como son la elaboración, organización, pensamiento crítico, autorregulación metacognitiva y aprendizaje en pares. En esa misma línea Littlejohn et al (2016) realizaron un estudio con participantes de cursos abiertos masivos o Massive Online Open Courses (MOOC), sus hallazgos reportan que los participantes con altos puntajes de autorregulación tienden a discutir su aprendizaje en términos de la motivación y cómo ésta contribuye a su contexto profesional y de trabajo, en tanto que los que tienen bajos puntajes de autorregulación discuten su aprendizaje en términos más abstractos como la curiosidad y el deseo de pasar fronteras de aprendizaje.

Dado lo anterior la pregunta que guio la investigación fue, si existen diferencias en los constructos de autorregulación, motivación y autoeficacia entre estudiantes que provienen de un sistema presencial y los que tienen experiencia en cursos en línea.

\section{Materiales Y Métodos}

\section{Participantes}

Participaron en el estudio 80 estudiantes de la carrera de psicología de la Facultad de Estudios Superiores (FES) Iztacala, de la Universidad $\mathrm{Na}$ cional Autónoma de México, en dos grupos iguales, 40 de la modalidad presencial y 40 de la modalidad a distancia. De los 80,60 son mujeres y 20 son varones, con edades entre 18 y 56 años. El $23.7 \%$ estaban inscritos en los primeros tres semestres de la carrera, el $45.5 \%$ entre el cuarto y sexto semestre, y el 30.8\% entre el séptimo y noveno semestre. El muestreo fue no aleatorio y de tipo voluntario, ya que se incluyó a aquellos que respondieron a la invitación para tomar el curso.

\section{Instrumento}

La Escala sobre Autoeficacia y Autorregulación de Aquino (2015) está conformada por dos partes, la primera consta de 9 ítems en escala tipo Likert; seis de ellos evalúan expectativas de autoeficacia, los otros 3, miden expectativas de resultados. La segunda parte consta de 20 ítems, en escala tipo Likert, con 5 niveles de respuesta que van desde en total desacuerdo hasta totalmente de acuerdo. Esta parte mide cuatro factores principales de autorregulación académica: conciencia metacognitiva activa, conciencia control, esfuerzo diario en la realización de las tareas y procesamiento activo de la información. El instrumento ha reportado un alfa de .939 en la escala total, y las subescalas de .898 a .917 , en una muestra universitaria.

La Escala de Autopercepción de la Motivación Académica Personal desarrollada por Boza y Méndez (2013) está compuesta de 84 ítems, distribuidos en 6 dimensiones (metas vitales, actitudes ante el aprendizaje, motivos personales, condiciones del estudio, estrategias de aprendizaje e implicación en el estudio) con opciones de respuesta en escala tipo Likert del 1 al 7 en donde 1 es nada de acuerdo y 7 totalmente de acuerdo. Reporta una confiabilidad por alfa de Cronbach de .915 para la escala total y en las subescalas van de .676 a .855 . Se obtuvo validez de constructo a través de un análisis factorial con rotación varimax en una muestra de universitarios.

\section{Tipo y diseño}

Es un estudio de tipo descriptivo, con un diseño de investigación transversal debido a que se realizó la medición en un solo momento con la finalidad de describir y analizar las variables evaluadas en dos grupos de estudiantes (Hernández, Fernández y Baptista, 2015).

\section{Procedimiento}

Se implementó un curso autogestionable, en línea, sobre el proceso de construcción de instrumentos en psicología y se convocó a estudiantes de la carrera de psicología de la FES Iztacala de todos los semestres a participar en el curso. Se les invitó a responder una serie de cuestionarios en 
Contraste de Estudiantes Universitarios Presenciales y en Línea en un Curso Autogestivo: el Papel de la Autoeficacia y la Motivación

línea antes de comenzar el curso, indicándoles que la información sería anónima y confidencial, y que la información recopilada serviría para identificar las variables que influyen en la conclusión exitosa de los cursos; el tiempo promedio que tardaron en responder los cuestionarios fue de 20 minutos. Posteriormente se asignó a la población en dos grupos, de acuerdo a la modalidad de estudio en la carrera: presencial y en línea; ambos grupos tomaron el mismo curso. Finalmente, se realizó un seguimiento de los participantes y se identificaron los casos que lo concluyeron y aquellos que no para comparar las variables de interés que se habían medido y determinar si existen diferencias en estas a partir de quien finalizó o no el curso.

\section{Resultados}

Del grupo de participantes provenientes de la modalidad presencial 25 son mujeres y 15 son hombres, de entre 18 y 39 años, con una media de edad de 22 años, 39 solteros y sólo una persona casada; en este grupo 14 participantes terminaron el curso y el resto (26) desertó. En el grupo de estudiantes provenientes de la modalidad en línea 35 son mujeres y 5 varones, de entre 22 y 56 años, con una media de edad de 38 años, 13 solteros, 20 casados y 7 viviendo en unión libre. En este grupo terminaron el curso 12 participantes el resto (28) no lo concluyó.

Se compararon los puntajes de autoeficacia, autorregulación y motivación de los participantes de ambos grupos, encontrándose diferencias en el total de autoeficacia y regulación, así como en cuatro subescalas de este instrumento referentes a la autorregulación. No así en el instrumento de motivación ni en las subescalas de autoeficacia. Los resultados pueden verse en las tablas 1 y 2 .

Seguidamente, en los datos generales se preguntó sobre el programa educativo que cursan y fue el de Administración el de mayor porcentaje (70\%), seguido por el de Administración Turística (19\%) y Sistemas Computacionales (10\%).

La población mayormente encuestada fue situada en el puerto de Veracruz, con un $78.5 \%$ y Xalapa representó un $21.5 \%$.

\section{Tabla 1}

Comparación de las puntuaciones obtenidas en la escala de autoeficacia y regulación

\begin{tabular}{|c|c|c|c|c|c|c|}
\hline \multirow[t]{2}{*}{ Variables } & \multicolumn{2}{|c|}{ Presencial } & \multicolumn{2}{|c|}{ En línea } & \multirow{2}{*}{$\begin{array}{l}\mathrm{t} \text { de } \\
\text { Student }\end{array}$} & \multirow[t]{2}{*}{ Sig. } \\
\hline & Media & DE & Media & $\mathrm{DE}$ & & \\
\hline $\begin{array}{l}\text { Total Autoeficacia y } \\
\text { Autorregulación }\end{array}$ & 25.33 & 3.01 & 27.12 & 3.04 & -2.627 & .010 \\
\hline $\begin{array}{l}\text { Factor } 1 \text { autoefica- } \\
\text { cia expectativas de } \\
\text { autoeficacia }\end{array}$ & 25.85 & 3.08 & 26.47 & 3.10 & -.903 & .369 \\
\hline $\begin{array}{l}\text { Factor } 2 \text { autoefica- } \\
\text { cia expectativas de } \\
\text { resultados }\end{array}$ & 13.51 & 1.57 & 13.85 & 1.56 & -.957 & .342 \\
\hline $\begin{array}{l}\text { Factor } 3 \text { autorregu- } \\
\text { lación Conciencia } \\
\text { metacognitiva } \\
\text { activa }\end{array}$ & 23.70 & 3.61 & 25.60 & 3.60 & -2.352 & .021 \\
\hline $\begin{array}{l}\text { Factor } 4 \text { autorregu- } \\
\text { lación Conciencia } \\
\text { control y verifica- } \\
\text { ción }\end{array}$ & 29.70 & 3.53 & 31.90 & 2.76 & -3.099 & .003 \\
\hline $\begin{array}{l}\text { Factor } 5 \text { autorregu- } \\
\text { lación Esfuerzo dia- } \\
\text { rio en la realización } \\
\text { de las tareas }\end{array}$ & 15.17 & 2.50 & 17.30 & 2.19 & -4.037 & .000 \\
\hline $\begin{array}{l}\text { Factor } 6 \text { autorre- } \\
\text { gulación Procesa- } \\
\text { miento activo de la } \\
\text { información. }\end{array}$ & 11.62 & 1.99 & 12.62 & 1.89 & -2.301 & .024 \\
\hline
\end{tabular}

Fuente:: Elaboración propia (2017).

Tabla 2

Comparación de las puntuaciones obtenidas en la escala de motivación de dos grupos de estudiantes

\begin{tabular}{|c|c|c|c|c|c|c|}
\hline \multirow[t]{2}{*}{ Variables } & \multicolumn{2}{|c|}{ Presencial } & \multicolumn{2}{|c|}{ En línea } & \multirow{2}{*}{$\begin{array}{l}\mathrm{t} \text { de } \\
\text { Student }\end{array}$} & \multirow[t]{2}{*}{ Sig. } \\
\hline & Media & DE & Media & DE & & \\
\hline Total Motivación & 27.70 & 3.19 & 27.70 & 2.94 & .000 & 1.00 \\
\hline $\begin{array}{l}\text { Factor } 1 \text { Motivación } \\
\text { MetasVitales }\end{array}$ & 114.80 & 16.42 & 115.27 & 17.30 & -.126 & .900 \\
\hline $\begin{array}{l}\text { Factor } 2 \text { Motivación } \\
\text { Actitudes ante el } \\
\text { aprendizaje }\end{array}$ & 75.82 & 9.75 & 71.80 & 10.03 & 1.819 & .073 \\
\hline $\begin{array}{l}\text { Factor } 3 \text { Motivación } \\
\text { Motivos personales }\end{array}$ & 118.47 & 15.32 & 114.40 & 13.04 & 1.281 & .204 \\
\hline $\begin{array}{l}\text { Factor } 4 \text { Motivación } \\
\text { Condiciones e Impli- } \\
\text { cación en el estudio }\end{array}$ & 66.07 & 10.71 & 69.32 & 8.65 & -1.492 & .140 \\
\hline $\begin{array}{l}\text { Factor } 5 \text { Motivación } \\
\text { Estrategias de } \\
\text { aprendizaje }\end{array}$ & 58.25 & 9.57 & 60.47 & 8.23 & -1.114 & .269 \\
\hline
\end{tabular}

Fuente:: Elaboración propia (2017). 
El grupo de estudiantes provenientes de la modalidad en línea presenta medias más altas en las subescalas de autorregulación que tienen que ver con tener mayor conciencia metacognitiva activa, más percepción de control y verificación, se perciben más efectivos para realizar esfuerzos cotidianos en la realización de tareas y tienen un mejor procesamiento activo de la información, en comparación con los estudiantes que provienen de una modalidad presencial. Al mismo tiempo se encuentra que los puntajes de las escalas de autoeficacia son bajos en el caso de la expectativa de resultados y moderados en la expectativa de desempeño en el curso. En el caso de la motivación no se encuentran diferencias estadísticamente significativas, lo cual indica que ambos grupos tuvieron la misma motivación por estudiar el curso.

Una vez que el curso terminó, se averiguó cuantos participantes provenientes de cada modalidad terminaron con la finalidad de comparar los datos obtenidos al inicio de la investigación e identificar si existían diferencias entre ambos grupos. De los 80 participantes sólo 26 terminaron, 14 presenciales y 12 de la modalidad a distancia. Se compararon las medias de la autoeficacia y motivación de los estudiantes que, si terminaron respecto de los que no lo hicieron, con la finalidad de verificar si existen diferencias en las variables evaluadas. En los resultados expuestos en las tablas 3 y 4 se observa que no existen diferencias significativas; de tal manera que no existe alguna característica de autorregulación, autoeficacia o motivación que distingan a los que concluyen con éxito el curso.

\section{Tabla 3}

Comparación de las puntuaciones obtenidas en la Escala de Autoeficacia y regulación

\begin{tabular}{|c|c|c|c|c|c|c|}
\hline \multirow[t]{2}{*}{ Variables } & \multicolumn{2}{|c|}{ Finalizó } & \multicolumn{2}{|c|}{ No finalizó } & \multirow{2}{*}{$\begin{array}{l}\text { t de } \\
\text { Student }\end{array}$} & \multirow[t]{2}{*}{ Sig. } \\
\hline & Media & $\mathrm{DE}$ & Media & $\mathrm{DE}$ & & \\
\hline $\begin{array}{l}\text { Total Autoefica- } \\
\text { cia y Autorregu- } \\
\text { lación }\end{array}$ & 26.20 & 3.48 & 26.25 & 3.00 & -.077 & .938 \\
\hline $\begin{array}{l}\text { Factor } 1 \\
\text { autoeficacia } \\
\text { expectativas de } \\
\text { autoeficacia }\end{array}$ & 25.69 & 3.12 & 26.38 & 3.08 & -.943 & .631 \\
\hline $\begin{array}{l}\text { Factor } 2 \\
\text { autoeficacia } \\
\text { expectativas de } \\
\text { resultados }\end{array}$ & 13.56 & 1.55 & 13.74 & 1.58 & -.475 & .636 \\
\hline
\end{tabular}

\begin{tabular}{lllllll}
\hline $\begin{array}{l}\text { Factor 3 } \\
\text { autorregulación } \\
\text { Conciencia } \\
\text { metacognitiva } \\
\text { activa }\end{array}$ & 24.30 & 4.04 & 24.81 & 3.57 & -.569 & .571 \\
\hline $\begin{array}{l}\text { Factor } 4 \text { auto- } \\
\text { rregulación Con- } \\
\text { ciencia control y }\end{array}$ & 30.34 & 4.26 & 31.01 & 2.81 & -.841 & .403 \\
verificación & & & & & & \\
\hline $\begin{array}{l}\text { Factor } 5 \\
\text { autorregulación }\end{array}$ & 16.23 & 2.95 & 16.24 & 2.39 & -.016 & .987 \\
$\begin{array}{l}\text { Esfuerzo diario } \\
\text { en la realización } \\
\text { de las tareas }\end{array}$ & & & & & & \\
\hline $\begin{array}{l}\text { Factor } 6 \text { au- } \\
\text { torregulación }\end{array}$ & 12.23 & 2.28 & 12.07 & 1.86 & .327 & .745 \\
$\begin{array}{l}\text { Procesamiento } \\
\text { activo de la } \\
\text { información }\end{array}$ & & & & & & \\
\hline
\end{tabular}

Fuente:: Elaboración propia (2017).

\section{Tabla 4}

Comparación de las puntuaciones obtenidas en la Escala de Motivación por finalización del curso

\begin{tabular}{|c|c|c|c|c|c|c|}
\hline \multirow[t]{2}{*}{ Variables } & \multicolumn{2}{|c|}{ Finalizó } & \multicolumn{2}{|c|}{ No finalizó } & \multirow{2}{*}{$\begin{array}{l}\mathrm{t} \text { de } \\
\text { Student }\end{array}$} & \multirow[t]{2}{*}{ Sig. } \\
\hline & Media & $\mathrm{DE}$ & Media & $\mathrm{DE}$ & & \\
\hline Total Motivación & 27.46 & 3.32 & 27.81 & 2.94 & -.482 & .631 \\
\hline $\begin{array}{l}\text { Factor } 1 \text { Motiva- } \\
\text { ción MetasVi- } \\
\text { tales }\end{array}$ & 110.34 & 16.28 & 117.29 & 16.67 & -1.759 & .082 \\
\hline $\begin{array}{l}\text { Factor } 2 \\
\text { Motivación } \\
\text { Actitudes ante el } \\
\text { aprendizaje }\end{array}$ & 71.84 & 8.69 & 74.75 & 10.56 & -1.219 & .226 \\
\hline $\begin{array}{l}\text { Factor } 3 \text { Moti- } \\
\text { vación Motivos } \\
\text { personales }\end{array}$ & 113.92 & 16.22 & 117.64 & 13.24 & -1.904 & .277 \\
\hline $\begin{array}{l}\text { Factor } 4 \\
\text { Motivación } \\
\text { Condiciones e } \\
\text { Implicación en el } \\
\text { estudio }\end{array}$ & 68.57 & 9.75 & 67.27 & 9.90 & .522 & .583 \\
\hline $\begin{array}{l}\text { Factor } 5 \text { Motiva- } \\
\text { ción Estrategias } \\
\text { de aprendizaje }\end{array}$ & 59.53 & 7.80 & 59.27 & 9.51 & .121 & .904 \\
\hline
\end{tabular}


ciencia de control de las acciones de aprendizaje, el esfuerzo diario y el procesamiento activo de la información, las medias indican que se cuenta de forma moderada con dichas características. Finalmente, en el caso de la motivación aún cuando las medias son mayores en la subescala metas vitales para quien no finaliza, la prueba estadística refiere que no son estadísticamente significativos los resultados.

\section{Discusión y Conclusiones}

En concordancia al objetivo planteado se compararon dos grupos de estudiantes provenientes de dos modalidades de aprendizaje, a distancia y presencial, bajo el argumento de que al estudiar en un curso en línea autogestivo, los estudiantes de cada modalidad pueden diferir en la autorregulación, autoeficacia y la motivación que son los factores fundamentales para finalizar con éxito un curso académico en línea. Los resultados indican que la modalidad de la cual provienen da mejores indicadores de diferencias que si terminan o no el curso.

Los análisis estadísticos evidencian que existen diferencias, que justo los estudiantes que provienen del sistema a distancia obtienen mayores puntajes en escalas de autorregulación que es una de las características requeridas en dicha modalidad; es así que los estudiantes tienen mayor conciencia metacognitiva, identifican qué y cómo deben estudiar, asimismo controlan sus estrategias de estudio y verifican si éstas les permiten obtener los resultados esperados, posteriormente se esfuerzan por cumplir los trabajos y tareas de clase diariamente, que en el caso de los cursos autogestivos esto tiene que ver con ser constantes en la realización de las actividades y evaluaciones en cada uno de los temas del curso. Estos resultados son acordes a lo que Wang, Shannon \& Ross (2013) explicaron a través de un modelo de ecuaciones estructurales, con lo cual afirman que los estudiantes con experiencias previas de cursos en línea tienden a presentar más estrategias de aprendizaje efectivo y autorregulación.
Por otra parte, los indicadores de autoeficacia no resultaron con diferencias significativas, de tal manera que en ambos grupos de estudiantes la autoeficacia en las expectativas de aprendizaje están por encima de la media teórica, no así en las expectativas sobre los resultados donde los resultados en ambos grupos está por debajo de ella, lo cual indica que tuvieron expectativas moderadas sobre su desempeño en este curso, pero bajas en cuanto a obtener buenos resultados; esto puede estar relacionado con la temática del curso, ya que algunos de ellos perciben el tema de construcción de instrumentos como un tópico difícil, según referencias verbales por comprobar.

En el caso de la motivación no se identificaron diferencias significativas, de tal forma que ambos grupos de estudiantes se percibieron interesados en el tema del curso, porque concuerda con sus metas académicas, y sus motivos personales; sin embargo, esta motivación no fue determinante para finalizar el curso, es así que la motivación no es un factor diferencial entre estos dos grupos de estudiantes; al respecto, Broadbent \& Poon (2015) mencionan que la motivación debe estudiarse más a fondo, ya que puede no ser un diferenciador o predictor, sino un mediador entre la autoeficacia y el éxito académico.

Al realizar el seguimiento de los participantes del curso que terminaron exitosamente no se identificaron diferencias, lo cual indica que poseer autorregulación, autoeficacia y motivación no distinguen a los estudiantes perseverantes que finalizan, esto no coincide con algunos estudios en los que se afirma que la autorregulación es un factor fundamental para el éxito académico. Cabe resaltar que los estudiantes que provienen del sistema a distancia, tienen más experiencia con el uso de sistemas autogestivos de aprendizaje y por lo tanto han desarrollado más sus habilidades de autorregulación; por ende, tienen más oportunidades de tener éxito en este tipo de cursos donde se tiene la posibilidad de gestionar su propio aprendizaje, avance y tiempo.

Para seguir la línea de investigación será necesario realizar estudios correlacionales, con los que se pueda identificar si las estrategias de autorregula- 
ción son capaces de predecir el éxito en los cursos en línea autogestivos, verificar también el rol mediador de la motivación y de la autoeficacia.

\section{Agradecimiento}

Trabajo realizado con el apoyo del Programa UNAM DGAPA-PAPIME PE300917 Diseño de un curso en línea" Construcción de instrumentos en psicología II".

\section{REFERENCIAS BIBLIOGRÁFICAS}

Abrami, P., Bernard, R., Bures, E., Borokhovski, E. \& Tamim, R. (2011). Interaction in distance education and online learning: Using evidence and theory to improve practice. Journal of Computing in Higher Education, 23(2-3), 82103. Recuperado de: https://doi.org/10.1007/s12528-0119043-x

Aquino, M. (2015). Relación entre autoeficacia, autorregulación y rendimiento académico de los estudiantes de primer ingreso, de la licenciatura en nutrición del campus central de la Universidad Rafael Landívar en el curso de estrategias de razonamiento (CFI) (Tesis de Maestría). Universidad Rafael Landívar, Guatemala.

Azevedo, R. (2014). Issues in dealing with sequential and temporal characteristics of self-and socially-regulated learning. Metacognition and Learning, 9(2), 217-228. Recuperado de: https://doi.org/10.1007/s1 1409-014-9123-1

Bandura, A. (1993). Perceived self-efficacy in cognitive development and functioning. Educational psychologist, 28(2), 117-148. Recuperado de:

https://doi.org/10.1207/s15326985ep2802_3

Berridi, R. y Martínez, G. (2017). Estrategias de autorregulación en contextos virtuales de aprendizaje. Perfiles educativos, 39(156), 89-102.

Boza, C. y Méndez, G. (2013). Aprendizaje motivado en alumnos universitarios: validación y resultados generales de una escala. Revista de Investigación Educativa, 31 (2), 331-347. Recuperado de: https://doi.org/10.6018/ rie.31.2.163581

Broadbent, J. \& Poon, W. (2015). Self-regulated learning strategies \& academic achievement in online higher education learning environments: A systematic review. The Internet and Higher Education, 27, 1-13. Recuperado de: https://doi.org/10.1016/j.iheduc.2015.04.007

Cheng, G. \& Chau, J. (2013). Exploring the relationship between students' self-regulated learning ability and their ePortfolio achievement. The Internet and Higher Educa- tion, 17, 9-15. Recuperado de: https://doi.org/10.1016/j. iheduc.2012.09.005

Chiecher, A., Paoloni, P. y Ficco, C. (2015). Ingreso a la Universidad en modalidad a distancia. El papel de aspectos motivacionales y cognitivos en la configuración de logros académicos. Revista de Educación a Distancia (43).

Dunn, K. (2014). Why wait? The influence of academic self-regulation, intrinsic motivation, and statistics anxiety on procrastination in online statistics. Innovative Higher Education, 39(1), 33-44. Recuperado de: https://doi.org/10.1007/s10755-013-9256-1

Garello, M. y Rinaudo, M. (2012). Características de las tareas académicas que favorecen aprendizaje autorregulado y cognición distribuida en estudiantes universitarios. REDU. Revista de Docencia Universitaria, 10(3), 415-440.

Hernández, S., Fernández, C. y Baptista, L. (2015). Metodología de la Investigación. (Sexta Edición). México: Mc Graw-Hill.

Hood, N., Littlejohn, A. \& Milligan, C. (2015). Context Counts: How learners' contexts influence learning in a MOOC. Computers \& Education, 91, 83-91. Recuperado de: https://doi.org/10.1016/j.compedu.2015.10.019

Komarraju, M. \& Nadler, D. (2013). Self-efficacy and academic achievement: Why do implicit beliefs, goals, and effort regulation matter? Learning and Individual Differences, 25, 67-72. Recuperado de: https://doi.org/10.1016/j. lindif.2013.01.005

Lee, W., Lee, M. \& Bong, M. (2014). Testing interest and self-efficacy as predictors of academic self-regulation and achievement. Contemporary Educational Psychology (39). Recuperado de: https://doi.org/10.1016/j.cedpsych.2014.02.002

Lee, Y., Choi, J. \& Kim, T. (2013). Discriminating factors between completers of and dropouts from online learning courses. British Journal of Educational Technology, 44(2), 328-337. Recuperado de: https://doi.org/10.1111/j.14678535.2012.01306.x

Liyanagunawardena, T., Parslow, P., \& Williams, S. (2014). Dropout: MOOC participants' perspective. Documento presentado en European MOOC's Stakeholders Summit, 2014, Switzerland.

Littlejohn, A., Hood, N., Milligan, C. \& Mustain, P. (2016). Learning in MOOCs: Motivations and self-regulated learning in MOOCs. The Internet and Higher Education, 29, 40-48. Recuperado de: https://doi.org/10.1016/j. iheduc.2015.12.003

Martínez, P. y Meza, C. (2013). Estudio Comparativo: Estrategias de Aprendizaje, Habilidades de Autorregulación, Metacognitivas y Percepción de Autoeficacia de Alumnos de la Licenciatura en Psicología Presencial y SUAyED de la FES-Iztacala. Revista en Ciencias Sociales y Humanidades Apoyadas por Tecnologías, 2(1).

Mega, C., Ronconi, L. \& De Beni, R. (2014). What makes a good student? How emotions, self-regulated learning, and motivation contribute to academic achievement. Journal 
Contraste de Estudiantes Universitarios Presenciales y en Línea en un Curso Autogestivo: el Papel de la Autoeficacia y la Motivación

of Educational Psychology, 106 (1), 121. Recuperado de: https://doi.org/10.1037/a0033546

Pintrich, P. \& Schunk, D. (2006). Motivación en contextos educativos. Madrid: Pearson.

Pintrich, P. R. (2000). The role of goal orientation in self-regulated learning. Handbook of self-regulation, 451, 451-502. Recuperado de: https://doi.org/10.1016/B978-012109890-2/50043-3

Pintrich, P. R. (2003). A motivational science perspective on the role of student motivation in learning and teaching contexts. Journal of educational Psychology, 95(4), 667. Recuperado de: https://doi.org/10.1037/0022-0663.95.4.667

Pintrich, P. R. (2004). A conceptual framework for assessing motivation and self-regulated learning in college students. Educational psychology review, 16(4), 385-407. Recuperado de: https://doi.org/10.1007/s10648-004-0006-x

Richardson, M., Abraham, C. \& Bond, R. (2012). Psychological correlates of university students' academic performance: a systematic review and meta-analysis. Psychological bulletin, 138(2), 353. Recuperado de:https://doi. org/10.1037/a0026838

Wang, C., Shannon, D. \& Ross, M. (2013). Students' characteristics, self-regulated learning, technology self-efficacy, and course outcomes in online learning. Distance Education, 34(3), 302-323. Recuperado de: https://doi.org/10.10 80/01587919.2013.835779

Zimmerman, B. \& Schunk, D. (2011). Self-regulated learning and performance: An introduction and an overview. In B. J. Zimmerman \& D. H. Schunk (Eds.), Handbook of self-regulation of learning and performance (pp. 1-12). New York, NY: Routledge. 


\title{
Sistema Inteligente de Tutoría para entrenamiento procedimental apoyado en un diálogo adaptado al contexto
}

\section{Intelligent Tutoring System for procedural training supported in a dialogue adapted to the context}

\author{
Jose Paladines Morán ${ }^{1}$ \\ Universidad Estatal del Sur de Manabí, Ecuador \\ Jaime Ramírez Rodríguez ${ }^{2}$ \\ Universidad Politécnica de Madrid, España
}

Recibido: 01-10-2017

Aceptado: 11-12-2017

\section{Cita recomendada}

Paladines, J. y Ramírez, J. (2017) Sistema inteligente de tutoría para entrenamiento procedimental apoyado en un diálogo adaptado al contexto. Hamut'ay, 4 (2), 17-29.

Recuperado de: http://dx.doi.org/10.21503/hamu.v4i2.1469

\section{RESUMEN}

El objetivo de este documento es presentar una propuesta de un Sistema Inteligente de Tutoría para entrenamiento procedimental en un entorno virtual 2D/3D, capaz de mantener un diálogo en lenguaje natural basado en el contexto. De esta manera, cada alumno será capacitado por medio de un diálogo en lenguaje natural que tome en cuenta sus características específicas, su progreso en el desarrollo de la tarea y el entorno donde se realiza la tarea. Por lo tanto, la retroalimentación de tutoría será el resultado de un diálogo adaptado al contexto. Para dar soporte al diálogo, se utilizará un gestor de diálogo, construido sobre alguna de las plataformas conocidas para la creación de gestores de diálogo actualmente disponibles.

Palabras Clave: Sistema Inteligente de Tutoría, Procesamiento de Lenguaje Natural, Diálogo adaptado al Contexto.

\section{Abstract}

In order to provide support environments for education, the aim of this paper is to present a proposal for an Intelligent Tutoring System for procedural training in a 2D / 3D virtual environment, capable of maintaining a dialogue in natural language based on the context. In this way, each student will be trained through a dialogue in natural language that takes into account the students' specific characteristics, their progress in the development of the task and the environment where the task is performed. Therefore, the tutoring feedback will be the result of a dialogue adapted to the context. To support the dialogue, a dialogue manager will be used, built on one of the currently available

\footnotetext{
1 Ingeniero en Sistemas, Facultad de Ciencias Técnicas de la Universidad Estatal del Sur de Manabí, Ecuador. Estudiante de Doctorado en el programa de Software, Sistemas y Computación. E-mail: jose.paladines@unesum.edu.ec

2 Doctor en Informática, Profesor contratado en la Escuela Técnica Superior de Ingenieros de la Universidad Politécnica de Madrid.

E-mail: jramirez@fi.upm.es
} 
well-known platforms for the creation of dialogue managers.

Keywords: Intelligent tutoring system, Natural Language Process, Dialogue adapted to context.

\section{INTRODUCCIÓN}

Hoy en día, los entornos de aprendizaje están cambiando significativamente gracias a la incorporación de diversas tecnologías que están promoviendo un proceso de aprendizaje más personalizado. Así, tenemos por un lado, a los entornos virtuales $2 \mathrm{D} / 3 \mathrm{D}$ que aportan una mejor experiencia al momento de explorar el entorno educativo, ya que facilitan el desarrollo de tareas que mejoran la transferencia de conocimientos y habilidades a situaciones reales mediante la contextualización del aprendizaje (Dalgarmo \& Lee, 2010); y por otro lado se encuentran los Sistemas Inteligentes de Tutoría (SITs), que son sistemas basados en la aplicación de técnicas de la Inteligencia Artificial que emulan a un profesor humano en ciertas tareas docentes, sobre todo, en aquellas relacionadas con la supervisión de los ejercicios prácticos de los alumnos (Murray, 1999).

Aunque el modelado de los SITs representa, en general, una tarea compleja, se han desarrollado algunos SITs para diferentes propósitos con interfaces conversacionales (Graesser et al 2001); uno de ellos es Autotutor (A. Graesser \& et al., 2005), un SIT diseñado para la enseñanza de computación y física newtoniana que dispone de un sistema de diálogo de iniciativa mixta a través de preguntas que invitan a largas explicaciones y razonamientos. Sin embargo, después de estudiar el estado del arte en la materia, podemos afirmar que existen muy pocos agentes conversacionales que se integran con los SITs para el entrenamiento de procedimientos, entre ellos sobresalen Jacob (Evers \& Nijholt, 2000) y Paco (Rickel, Lesh, Rich, Sidner, \& Gertner, 2001) que mostraremos en los trabajos relacionados, y que a pesar de dar tutoría procedimental, están concebidos para que el estudiante interactúe con el sistema a través de un avatar en un entorno virtual 2D/3D y dialogue con el sistema mediante el uso del lenguaje natural.
Dado que el lenguaje natural es un aspecto fundamental del comportamiento humano, los sistemas de lenguaje natural deben tener en consideración tanto el conocimiento acerca de la estructura del lenguaje (las palabras, el significado de las palabras, las reglas gramaticales, etc.), como el conocimiento del entorno donde se desarrolla el diálogo (Hung, Gonzalez, \& DeMara, 2009). Para facilitar esta tarea, se deben utilizar técnicas de Procesamiento del Lenguaje Natural (PLN), que hoy en día ya están proporcionando a los programas de computadora la capacidad de entender el habla humana.

Basado en lo expuesto, este documento tiene como objetivo presentar una propuesta de un SIT para el entrenamiento procedimental en un entorno virtual $2 \mathrm{D} / 3 \mathrm{D}$, capaz de mantener un diálogo en lenguaje natural basado en el contexto. De esta forma, cada alumno será entrenado en el entorno virtual por medio de un diálogo en lenguaje natural tomando en cuenta sus características específicas, su progreso en el desarrollo de la tarea y el ambiente donde realiza la tarea. Por lo tanto, la retroalimentación de tutoría incluirá un diálogo contextualizado o adaptado al contexto.

Para dar soporte al diálogo, utilizaremos un gestor de diálogo que será construido sobre alguna de las plataformas conocidas y actualmente disponibles para la creación de gestores de diálogo. Cabe indicar que estas plataformas han alcanzado un notable grado de madurez, entre otros motivos, por las facilidades que ofrecen para interpretar y procesar el lenguaje natural en diferentes dominios de aplicación; a tal punto que han transformado la forma en que interactuamos con la tecnología informática.

Este trabajo representa un primer paso en el proceso de diseño de un sistema con las características mencionadas anteriormente. El resto de este artículo está estructurado de la siguiente manera: 
la sección 2 presenta los trabajos más relacionados con los objetivos de este artículo; la sección 3 se centra en algunas plataformas bien conocidas que facilitan la construcción de gestores de diálogo; la sección 4 describe varias características deseadas del sistema propuesto y presenta la arquitectura del SIT propuesto; la sección 5 detalla tres ejemplos de aplicación de la arquitectura propuesta; y finalmente, la sección 6 presenta las conclusiones del trabajo y menciona algunas líneas de trabajo futuro.

\section{Trabajos relacionados}

En esta sección, nos centraremos en presentar los SITs con PLN construidos para ambientes virtuales en 2D/3D. Dentro de este grupo, distinguiremos entre SITs orientados a la enseñanza de conceptos y al entrenamiento de tareas (procedimientos). Sin embargo, antes de presentar este grupo de SITs, consideramos necesario mencionar algunos SITs para entrenamiento de procedimientos que, a pesar de no contar con PLN, son sistemas notables que pueden supervisar el comportamiento del estudiante y proporcionar una valiosa retroalimentación de tutoría. Estos sistemas son:

Steve (Rickel \& Johnson, 1999), es un agente animado diseńado para entrenar al personal de la marina para operar y mantener maquinaria compleja en un entorno 3D; incorpora características novedosas, aunque en un estado elemental, que le permite mantener una activa interacción con el alumno y detectar su actitud frente a la tutoría (atento, distraído, falto de motivación); cuenta con módulos que le proporcionan características y habilidades que son independientes del dominio, lo cual no excluye la posibilidad de capacitar a Steve para trabajar en un dominio específico.

Lahystotrain (Los Arcos et al., 2000), es un sistema desarrollado para entrenar a cirujanos en operaciones de laparoscopia e histeroscopía compuesto por una simulación de Realidad Virtual y un ATS (Advanced Training System). La formación se adquiere a través de dos fases, en la primera el estudiante adquiere conocimientos teóricos relacionados con las patologías a tratar y en la segunda se ponen a prueba dentro del simulador las habilidades prácticas adquiridas. Durante la prueba de conoci- mientos el SIT puede proporcionar dos tipos de explicaciones, proactivas y reactivas: las proactivas están orientadas a aspectos relacionadas con el procedimiento y las reactivas a la corrección de errores.

SafeChild (Gu, Sosnovsky, \& Ullrich, 2015), es un sistema diseńado para enseñar a los niños a desenvolverse con seguridad como peatones en situaciones con tráfico. Este sistema proporciona a los nińos un entrenamiento guiado y asistido en una amplia gama de escenarios de entrenamiento, y consta de tres componentes principales: un entorno de una ciudad en realidad virtual como área para el entrenamiento, una interfaz flexible para interactuar con el entorno y un SIT que monitorea el comportamiento del alumno detectando errores individuales y deficiencias en sus habilidades cognitivas de alto nivel.

Todos estos sistemas proporcionan una retroalimentación de tutoría que comprende: dar consejos cuando el estudiante comete un error o pide ayuda. En este tipo de sistemas, sin embargo, los mensajes de tutoría se limitan a explicaciones prefabricadas asociadas con errores o pistas. Además, estos sistemas no pueden entender y contestar preguntas abiertas del estudiante, ni evaluar los conocimientos del estudiante a partir de sus comentarios durante la práctica.

En cuanto a los SITs con PLN, en primer lugar, mencionaremos algunos sistemas cuya retroalimentación de tutoría está dirigida a la enseñanza de conceptos. Entre ellos tenemos:

CircSim (Glass, 2001), considerado como uno de los primeros SITs dotado de una cierta capacidad de diálogo en lenguaje natural, es un sistema que enseńa el mecanismo baroreceptor reflejo de la presión arterial a estudiantes de primer año de medicina. El diálogo está bajo el control del tutor inteligente, de forma que el sistema hace preguntas y el estudiante contesta con texto libre imitando el estilo socrático de tutoría. Las aportaciones del estudiante son sometidas a un análisis sintáctico apoyado en un extenso catálogo de conceptos erróneos, respuestas erróneas y otros insumos inesperados que presentan oportunidades de tutoría. No obstante, las preguntas sólo admiten respuestas cortas de una o dos palabras, por lo que su rango de respuesta es limitado y no induce a un lenguaje que contenga mayores explicaciones. 
Why2-Atlas (VanLehn et al, 2002), facilita la enseñanza de la física cualitativa haciendo que los estudiantes escriban largas explicaciones (ensayos) sobre fenómenos mecánicos simples. Utiliza el análisis sintáctico profundo y el razonamiento abductivo para convertir el ensayo del estudiante en una prueba lógica y descubrir sus conceptos erróneos. Está compuesto por varios módulos, entre los cuales sobresale el entendedor de nivel de sentencias (ENS) que utiliza un preprocesador léxico, un analizador, un módulo de reparación (todos ellos conforman un paquete denominado CARMEL) y un analizador estadístico.

Autotutor (Graesser et al 2005), es un sistema desarrollado para la enseńanza de la computación y la física newtoniana. Mantiene un diálogo basado en turnos con un método de PLN bastante elaborado que permite diálogos con iniciativa mixta para facilitar la iniciación de nuevos temas de discusión. Las conversaciones se realizan de manera escrita, pero posee un sistema de síntesis de voz y una representación gráfica de un tutor con ciertas expresiones faciales y gestos. Este sistema utiliza Análisis Semántico Latente (ASL) para comparar las explicaciones de los estudiantes con un conjunto de expectativas (respuestas ideales) e ideas erróneas (respuestas incorrectas).

Tanto Why2-Atlas como Autotutor ayudan al estudiante a construir explicaciones correctas a través del diálogo, pero difieren en las técnicas de PLN empleadas para interpretar las expresiones de los estudiantes.

Beetle II (Dzikovska et al 2014), es un sistema desarrollado para enseñar la construcción de un circuito electrónico. Permite entradas en lenguaje natural sin restricciones y la aplicación de diferentes estrategias de diálogo para realizar una retroalimentación adaptativa dinámica. Implementa un sistema de diálogo orientado a tareas que es más dependiente del dominio que el de Autotutor. Beetle implementa una estrategia pedagógica "Predecir-Verificar-Evaluar" para invitar al estudiante a pensar profundamente acerca de los fenómenos que observa y a explicar sus predicciones/errores en una simulación. Para guiar al estudiante, Beetle II aplica tácticas de tutoría que pueden usarse en diferentes contextos de resolución de problemas. Ade- más, Beetle utiliza una ontología para representar el conocimiento del dominio.

A continuación, vamos a mencionar los únicos SITs que se han encontrado en la literatura que cuentan con PLN para el entrenamiento de procedimientos, estos son Jacob y Paco.

Jacob (Evers \& Nijholt, 2000), es un agente pedagógico que enseña a resolver el problema de las Torres de Hanoi en un entorno virtual 3D. Este sistema integra conocimientos de diferentes disciplinas, tales como: SITs, realidad virtual, tecnología de agentes y PLN. El modelo de tarea y el modelo de instrucción forman parte de la mente de Jacob y actúan como controladores que observan el mundo abstracto y tratan de alcanzar los objetivos específicos de instrucción manipulando el cuerpo de Jacob. El modelo de instrucción encapsula el conocimiento de la tarea y las capacidades de comprensión del lenguaje natural permitiendo que la interacción con el usuario se de a través de acciones relativas a las tareas, en las que el alumno introduce por teclado los enunciados que luego son analizados e interpretados utilizando una representación apropiada del conocimiento del entorno virtual. Seguidamente, el sistema responde a través de declaraciones o realizando acciones que han sido definidas a través de plantillas.

Paco (Rickel, Lesh, Rich, Sidner, \& Gertner, 2002), es un agente pedagógico que implementa su estrategia de tutoría por medio de un sistema de diálogo colaborativo basado en Collagen. En este sistema, el diálogo se va generando por medio de reglas de actos de discurso, las cuales, a su vez, se apoyan en el modelo de tareas, el modelo del estudiante y la interacción con el usuario. La formación procedimental está basada en una simulación que implementa el manejo de los motores de turbina de gas que impulsan los barcos. En este contexto, Paco elige repetidamente un escenario, es decir, una tarea a realizar a partir de un estado de simulación particular, para que los estudiantes apliquen con flexibilidad procedimientos bien definidos en una variedad de situaciones de un entorno de trabajo real.

Tanto Jacob como Paco proporcionan ayuda cuando se solicita retroalimentación positiva, aunque en el caso de Jacob es ocasional. En general, Jacob 
y Paco tienen muchas limitaciones con respecto al diálogo en lenguaje natural. Sin embargo, a pesar de no poder entender las preguntas abiertas de los estudiantes, proporcionan respuestas basadas en un cierto nivel de comprensión de lo que requiere el estudiante en cada momento.

\section{Plataformas para crear un gestor de diálogo}

El PLN surge con la finalidad de hacer posible la comprensión y el procesamiento de información expresada en lenguaje natural, facilitando el desarrollo de determinadas tareas como el análisis de opiniones, la traducción automática, los sistemas de diálogo interactivos, reconocimiento de patrones, clasificación de entidades, entre otras (Dudhabaware \& Madankar, 2014).

Gracias a los servicios en la nube, existen plataformas con frameworks especializados para implementar sistemas de diálogo. Los sistemas de diálogo proporcionan a las personas una vía de interacción con una aplicación informática a través de diálogos escritos (e incluso orales), similares a los que entablan entre sí los seres humanos sobre un asunto concreto (Mallios \& Bourbakis, 2016).

Estas plataformas están alcanzando un alto grado de madurez en el tratamiento de las estructuras de diálogo, lo cual ha provocado una significativa proliferación de su uso en diferentes dominios y ha elevado la complejidad de los sistemas desarrollados.

Para lograr su cometido, las plataformas utilizan el poder del aprendizaje automático para resolver el difícil problema de extraer el significado de las entradas del usuario en lenguaje natural. De esta manera, cualquier aplicación cliente que converse con usuarios puede pasar la entrada del usuario a un gestor de diálogo construido con una de estas plataformas y recibir los resultados derivados de una comprensión del lenguaje natural. Esto es posible sin necesidad de que el programador de la aplicación cliente conozca los algoritmos de aprendizaje automático que se están empleando.

Entre las plataformas más populares se encuentran Api.ai de Google, Wit.ai de Facebook Messenger, Watson de IBM, LUIS de Microsoft, entre otras. Cada una de estas plataformas tienen APIs para desarrolladores disponibles en diversos sistemas operativos, dispositivos y lenguajes de programación. Para estructurar el flujo de conversación o diálogo, estas plataformas utilizan algunos elementos comunes que, en su conjunto, facilitan el PLN, entre ellos están: el enunciado, las intenciones y las entidades (Singh, 2017).

El enunciado es la entrada del usuario que la aplicación necesita interpretar, que en algunas ocasiones no están bien formuladas.

Las intenciones son como verbos en una oración, representan las acciones que el usuario desea realizar, es decir el propósito expresado en la entrada del usuario.

Las entidades serían como los sustantivos de una oración, representan una instancia de una clase de objeto que es relevante para la intención de un usuario.

Algo sobresaliente de estas plataformas es que permiten que el diálogo pueda ser ajustado a las diferentes situaciones de un determinado escenario por medio de una estructura denominada contexto, que se utiliza de forma interna y externa para pasar información entre una aplicación cliente y el gestor de diálogo.

Una aplicación desarrollada en cualquiera de estas plataformas, toma un enunciado del usuario y extrae intenciones y entidades que corresponden a actividades relativas a la lógica de la aplicación cliente. De este modo, esta aplicación puede tomar la acción más apropiada basándose en las intenciones del usuario y así generar un diálogo efectivo.

Las plataformas mencionadas, a pesar de estar orientadas a un fin similar, tienen características diferenciadas. Por ello, la elección de la plataforma idónea dependerá de la aplicación que se vaya a construir, teniendo en cuenta básicamente el modelado del flujo de la conversación que es en sí lo que va a definir el comportamiento de la aplicación.

Api.ai actualmente llamada Dialogflow, a través de los intentos, crea un enlace entre lo que dice un usuario y qué acción debe tomar el sistema; además brinda servicios de integración con otras 
plataformas (Google, 2015). Los contextos son útiles para diferenciar peticiones que podrían tener un significado diferente en relación a las peticiones anteriores. Los intentos y contextos permiten crear máquinas de estado que modelan grandes y complejos flujos de conversación. Asimismo, dispone de una sección de entrenamiento en versión beta.

Wit.ai dispone de entidades predefinidas y considera a las intenciones del usuario como historias (Facebook, 2015). Cada historia representa un ejemplo de una posible conversación. Una historia puede ser vista como un gráfico de las intenciones a las que se pueden agregar ramas que se activan en condiciones tales como la existencia o no de valores de variables específicas. A pesar de ello, las historias están en versión beta y en ocasiones es difícil seguir en ellas el flujo de la conversación.

Watson dispone de muchos servicios cognitivos que favorecen el desarrollo de determinadas tareas. Entre esos sistemas cognitivos cabe destacar el Servicio Conversation que permite la implementación de un sistema de diálogo que es controlado por un espacio de trabajo en el que se definen las intenciones, las entidades y las variables de contexto (IBM, 2016). Los usuarios interactúan con su aplicación a través de su interfaz de usuario proporcionando enunciados. Para cada enunciado proporcionado, la aplicación se conecta al espacio de trabajo y el servicio de conversación interpreta el enunciado del usuario, proporciona una respuesta y dirige el flujo de conversación.

Para LUIS los enunciados, los intentos y las entidades son los conceptos claves para modelar el diálogo. LUIS es incapaz de reconocer palabras raras, por lo tanto a parte de las entidades puede utilizar una lista de frases para generalizar e identificar nuevos elementos de una categoría (Microsoft, 2016). Además, se pueden agregar funciones al modelo para proporcionar sugerencias sobre cómo reconocer las entradas que se desean etiquetar o clasificar. Estas funciones ayudan a reconocer tanto los intentos como las entidades a través de términos relacionados o patrones para reconocer dichos términos.

Cabe señalar que, la mayoría de las plataformas disponen de entidades predefinidas que dan una mayor robustez a la aplicación. Sin embargo, tanto Watson como LUIS proponen un marco de desarrollo un poco más complejo y más potente que las otras plataformas, ya que disponen de servicios que aprenden de forma rápida y por tanto minimizan el esfuerzo requerido para crear los sistemas de diálogo (IBM, 2016; Microsoft, 2016).

En general, independientemente de la plataforma que utilicemos, sostenemos que para poner en marcha el gestor de diálogo es necesario entrenar su espacio de trabajo, es decir: las intenciones necesitan que se les suministren muchos ejemplos de enunciados de usuario; y las entidades requieren que se les refieran todos sus posibles valores junto a los sinónimos que probablemente los usuarios utilizarán.

Características de un Sistema Inteligente de Tutoría para entrenamiento procedimental en un entorno virtual 2D/3D con Procesamiento de Lenguaje Natural

Como podemos ver en la sección de trabajos relacionados, hay una notable escasez de SITs para entrenamiento procedimental en un entorno virtual 2D/3D que cuenten con PLN. Este hecho ha motivado el trabajo que vamos a presentar en este artículo, que consiste en una arquitectura para un SIT dirigido al entrenamiento procedimental que estará equipada con un gestor de diálogo, que será implementado por medio de una de las plataformas explicadas en la sección anterior. Antes de presentar esta arquitectura, vamos a explicar de qué manera se va a utilizar el contexto en la gestión del diálogo con el alumno.

Con el fin de que el estudiante reciba una retroalimentación de tutoría apropiada, es necesario contar no sólo con la frase del estudiante, sino con una noción del contexto en el cual se dice dicha frase. Por lo tanto, el gestor de diálogo asociado al SIT deberá disponer de la suficiente información como para poder proporcionar un diálogo contextualizado. Para proporcionar este tipo de diálogo, el contexto que manejará el gestor deberá contener información relativa a:

- Los conocimientos del estudiante,

- El entorno virtual (con información estática y dinámica), y 
- El progreso actual del alumno en la actividad a realizar.

Basándose en esta información, el SIT podrá suministrar una tutoría personalizada a través de un diálogo contextual adaptado a: lo que el estudiante sabe y no sabe; la ubicación de su avatar en el entorno virtual en el momento del diálogo; la fase de la actividad en que se encuentra el estudiante, etc.

Algunos ejemplos de la retroalimentación de tutoría personalizada que proporcionará un diálogo contextualizado son los siguientes:

- Responder a preguntas sobre la ubicación de un objeto en el entorno virtual o cómo llegar a dicho objeto, incluso cuando este objeto está lejos del avatar del estudiante.

- Responder a las preguntas sobre la próxima acción que se debe realizar.

- Recomendar actividades de aprendizaje para cubrir las lagunas de conocimientos demostradas por el estudiante.

- Proporcionar pistas proactivamente para guiar al estudiante con la ejecución de una tarea, si se observa que el estudiante necesita ayuda, aunque no la esté pidiendo.

- Fomentar un diálogo afectivo para mitigar la inactividad de los estudiantes o sus momentos de desánimo durante la práctica.

\section{Arquitectura Propuesta}

Para una mejor comprensión de la arquitectura propuesta, en la Figura 1 se muestra dicha arquitectura, la cual, como vamos a justificar a continuación, brindará una tutoría personalizada teniendo como eje central el entorno virtual donde se realiza el entrenamiento.

La arquitectura está integrada por cuatro componentes principales: el entorno de entrenamiento procedimental, el sistema de Comprensión de Lenguaje Natural (CLN), el SIT y el gestor de diálogo. Como se va a explicar a continuación, cada uno de ellos cumple distintas funciones con la finalidad de sustentar la tutoría en lenguaje natural.

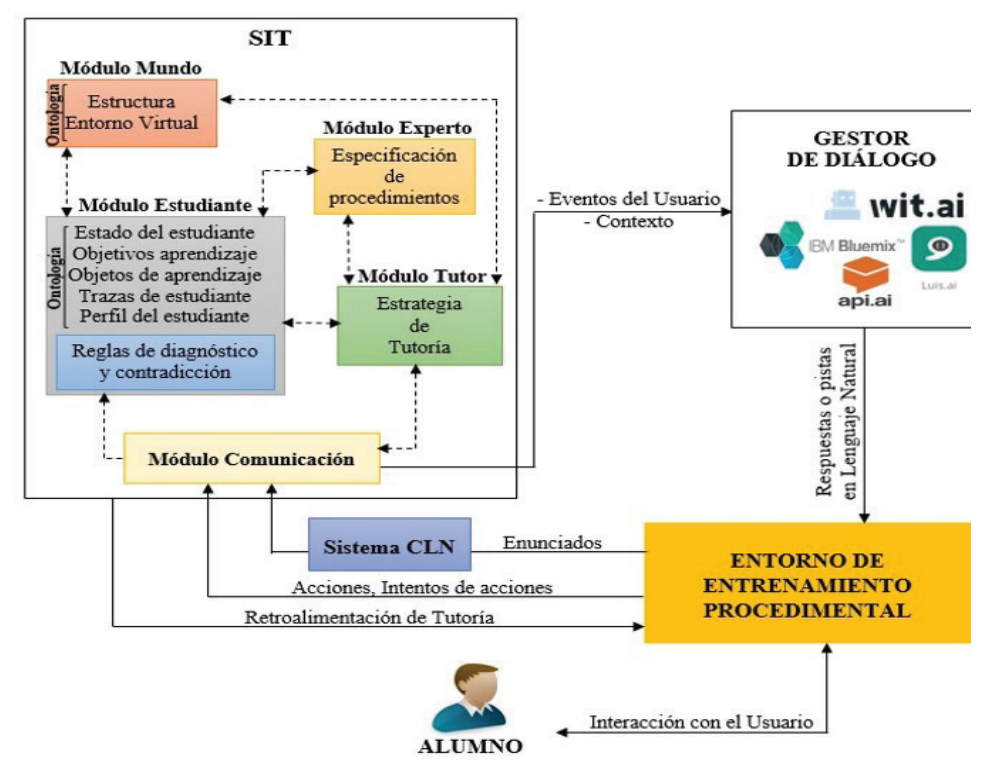

Figura 1. Arquitectura de un SIT con PLN para entrenamiento procedimental

El entorno de entrenamiento procedimental, es el escenario que simula al mundo real donde se llevan a cabo las actividades de entrenamiento. Este escenario puede ser diseñado con elementos 3D para dar más realismo a las tareas que el estudiante debe realizar a lo largo de la práctica.

El sistema de comprensión del lenguaje natural, se encargará de recibir las frases del usuario, las interpretará y extraerá de ellas las entidades y relaciones que las componen. Luego preprocesará el enunciado del usuario, de manera que luego los módulos del SIT puedan trabajar con la semántica del enunciado. Este sistema, se podría implementar utilizando, el servicio de "Natural Language Understanding” de Watson (IBM, 2015).

El sistema inteligente de tutoría, integrará los módulos correspondientes a un SIT clásico, es decir, el módulo del estudiante, el módulo de tutoría, el módulo experto y el módulo de comunicación. Adicionalmente, se agregará al SIT un módulo del mundo, para representar las características del entorno virtual de formación, a fin de posibilitar un efectivo proceso de tutoría, y contendrá información sobre los aspectos constituyentes del entorno relacionados con los avatares y los objetos 2D/3D del entorno virtual. Además, este módulo representará la estructura física de los escenarios y su contenido para que el sistema pueda responder a una pregunta sobre la situación de un objeto o 
cómo ir de un lugar a otro.

Cabe señalar que, la información expuesta, no solo será necesaria para la tutoría, sino también para validar las acciones realizadas por el estudiante. Otros dos módulos que tendrán un papel clave en nuestra propuesta serán el módulo del estudiante y el módulo experto:

El módulo del estudiante contendrá información relacionada con las acciones del estudiante; sus movimientos a través del entorno virtual; el tiempo que necesitó para realizar una acción o un grupo de acciones; las preguntas que hizo; las sugerencias que recibió por parte del tutor, etc. A partir de esta información el mismo módulo inferirá, con un cierto nivel de fiabilidad, los conocimientos del alumno, lo cual, a su vez, resultará útil para decidir la mejor estrategia de tutoría. Para lograr este fin adoptaremos el modelo del estudiante propuesto en (Clemente, Ramírez, \& de Antonio, 2011).

El módulo experto especificará el conocimiento que debe ser enseñado al estudiante. Como estamos abordando el entrenamiento procedimental, el modelo contendrá una descripción del procedimiento a ser aprendido.

Dentro del SIT, el contexto del diálogo se definirá por medio de una ontología y se rellenará con información proveniente del modelo del estudiante (estado de los conocimientos, progreso de la actividad, trayectoria del estudiante en el entorno virtual), el modelo experto (el plan correcto, la siguiente acción correcta) y el modelo del mundo (estructura del mundo virtual, posición del avatar del estudiante, descripciones de los objetos). Luego, antes de pasar el contexto al gestor de diálogo, la representación ontológica del contexto se traducirá a otra representación comprensible para el gestor de diálogo.

El gestor de diálogo contendrá la definición de la estructura del diálogo, las intenciones y las entidades específicamente destinadas al entorno de formación, así como el sistema de ejecución de la plataforma elegida. Este componente será responsable de la comunicación con el usuario teniendo en cuenta la información contextual proporcionada por los modelos que integran el SIT.
El usuario puede interactuar con el entorno de formación procedimental generando eventos tales como intentos de acciones, preguntas, etc., que serán proporcionados al SIT a lo largo de la práctica.

El siguiente pseudocódigo describe cómo el gestor de diálogo puede ser integrado en el proceso de tutoría aplicado por el SIT en un entorno de entrenamiento procedimental.

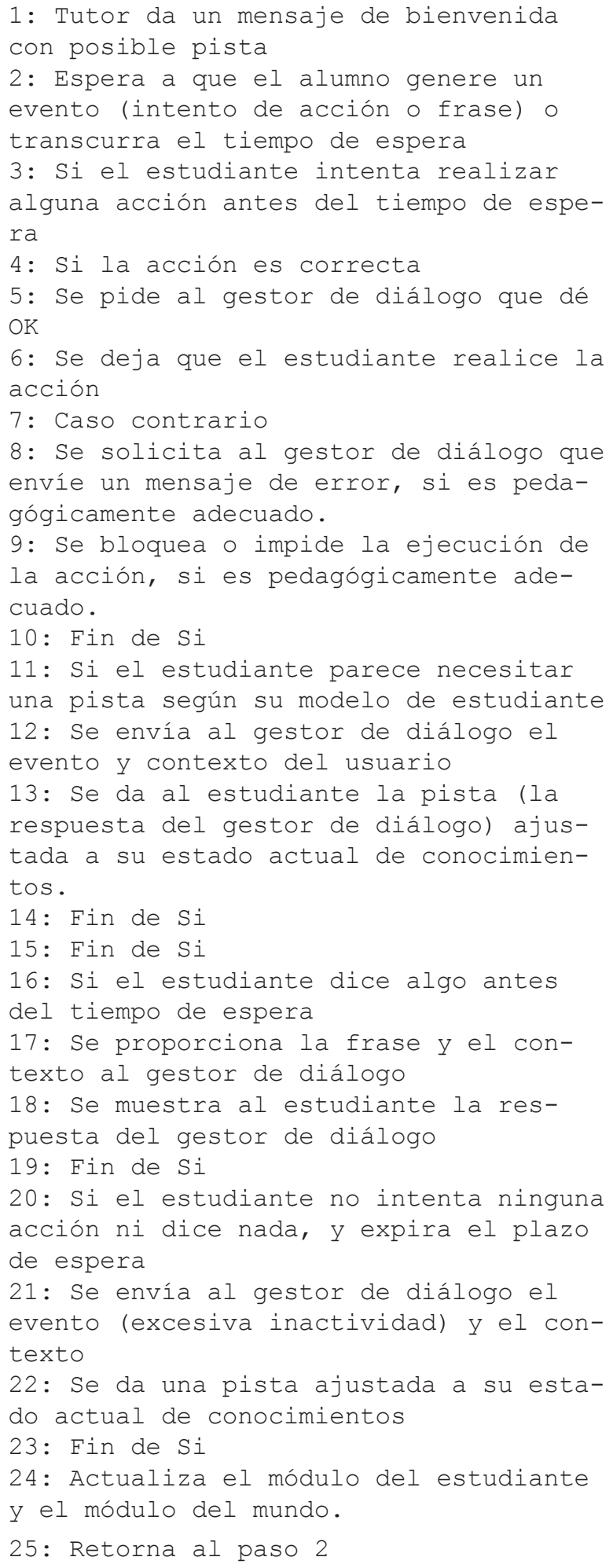


Ejemplos de Aplicación de la Arquitectura Propuesta

Para una mejor comprensión del proceso de tutoría explicado en el apartado anterior y de cómo intervienen en este proceso los módulos para la generación del diálogo en lenguaje natural, presentaremos tres ejemplos basados en una práctica "Preparación del Medio de Cultivo" que se realiza en un Laboratorio Virtual de Biotecnología ${ }^{3}$. Este laboratorio fue desarrollado sobre la plataforma de mundos virtuales OpenSimulator, como parte de una tesis de máster (Riofrío-Luzcando, Ramírez, y Berrocal-Lobo, 2012). Para realizar la práctica, el alumno controla un avatar y cuenta con la ayuda de un tutor automático, que le va dando indicaciones sobre las acciones a realizar en cada momento y le muestra mensajes de error, cuando se equivoca. Estas indicaciones y mensajes de error consisten en mensajes previamente configurados y asociados a cada una de las acciones que se deben realizar en la práctica.

Este Laboratorio Virtual de Biotecnología cuenta con cinco salas: hall, sala principal, sala de autoclaves, sala de fitotrón, sala de cabinas de flujo de laminar. La mayor parte de las tareas se realizan en la sala principal donde se encuentran la mayoría de los químicos y el instrumental tal como se observa en la Figura 2.

La versión actual del tutor automático no implementa la arquitectura propuesta en el apartado anterior. No obstante, los ejemplos que se van a explicar a continuación describen el comportamiento del SIT como si éste realmente estuviera dotado de la arquitectura propuesta e implementara el proceso de tutoría ya mencionado.

Para una mejor definición de los ejemplos que veremos a continuación se ha utilizado como base la Figura 3 de la arquitectura propuesta, de tal forma que se han dibujado círculos enumerados sobre ella para especificar la secuencia de pasos que ejecutan los módulos del SIT en cada escenario.

En este ejemplo presentamos un caso relacionado con la línea 3 del pseudocódigo, es decir, cuando el alumno intenta realizar una acción y ésta es correcta.

3. En http://youtu.be/mAFREZ5_iak se puede encontrar un vídeo de este laboratorio virtual

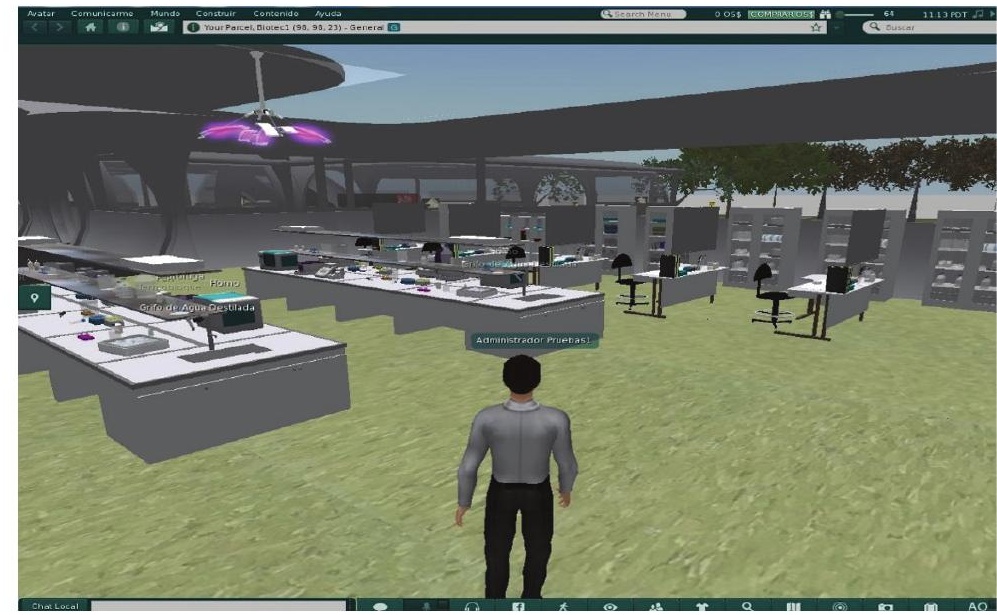

Figura 2. Sala principal del Laboratorio Virtual de Biotecnología

Ejemplo No. 1: El alumno intenta coger sacarosa para agregarlo a la mezcla y la acción es correcta de acuerdo al plan. La secuencia es la siguiente:

1. El alumno intenta coger un elemento químico: "sacarosa".

2. El entorno de entrenamiento procedimental retransmite el intento de acción (evento) al módulo comunicación.

3. El módulo comunicación envía el evento al módulo estudiante.

- El módulo estudiante registra en su ontología que el estudiante intenta realizar una acción.

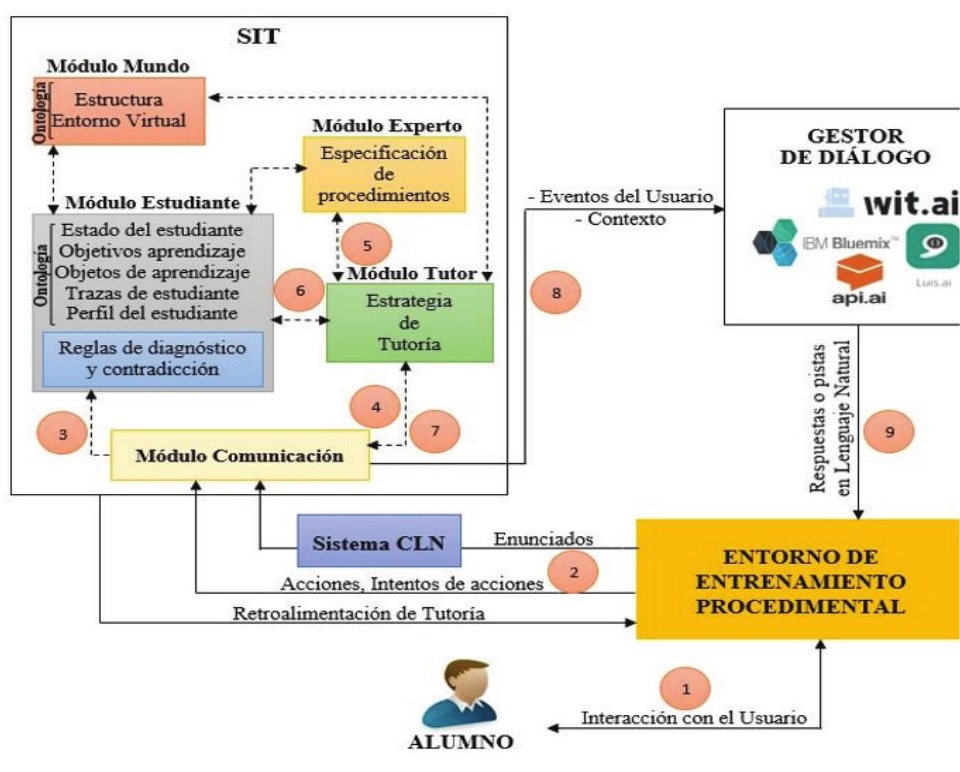

Figura 3. El alumno intenta agregar un químico a la mezcla y la acción es correcta 
- El objetivo de aprendizaje que se evaluará es: "El alumno debe incorporar sacarosa a la mezcla".

4. El módulo comunicación envía el evento al módulo tutor.

5. El módulo tutor le consulta al módulo experto si el evento es correcto y éste devuelve:

"Correcta, OK".

6. El módulo tutor le dice al módulo estudiante: "La acción coger sacarosa es correcta"

- El módulo estudiante infiere mediante una regla de diagnóstico que el estudiante ha adquirido dicho objetivo de aprendizaje o refuerza su creencia en dicha adquisición, ya que acaba de obtener una nueva evidencia de ello.

7. El módulo tutor le dice al módulo comunicación "La acción coger sacarosa es correcta".

8. El módulo comunicación le indica al gestor de diálogo que la acción es correcta.

9. El gestor de diálogo envía al entorno de entrenamiento procedimental el mensaje "Acción Correcta”.

En el siguiente ejemplo mostraremos un caso relativo a la línea 20 del pseudocódigo, es decir, cuando el alumno ha permanecido inactivo demasiado tiempo.

Ejemplo No. 2: El alumno tiene en la mano un vaso lleno con agua destilada, pero no sabe a dónde llevarlo y se queda parado. De acuerdo al plan, la siguiente acción correcta es llevar ese vaso a un agitador y soltarlo allí. Esta es la secuencia

1. El alumno permanece inactivo durante un tiempo lo suficientemente grande como para que el SIT infiera que no sabe qué hacer a continuación.

2. El entorno de entrenamiento procedimental retransmite la inactividad del alumno al módulo comunicación.

3. El módulo comunicación notifica la excesiva inactividad del alumno al módulo estudiante.

- El módulo estudiante registra en su ontología la excesiva inactividad del alumno.

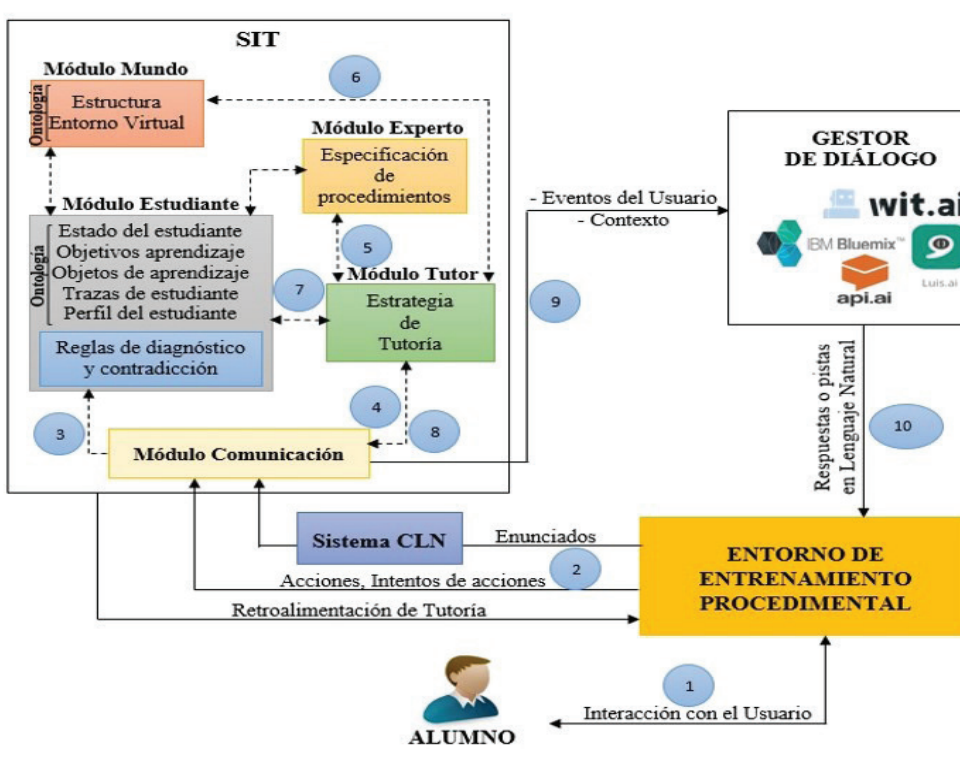

Figura 4. El alumno desconoce la siguiente acción que debe realizar

- El módulo estudiante a través de las reglas de diagnóstico infiere que el alumno no conoce la siguiente acción.

- El objetivo de aprendizaje que se evaluará es: "El alumno debe llevar el vaso lleno de agua destilada al agitador".

- Por tanto, el estado de conocimientos del estudiante contendrá: "El alumno no ha adquirido ese objetivo con un cierto grado de certeza”.

4. El módulo comunicación notifica la excesiva inactividad del alumno al módulo tutor.

5. El módulo tutor le consulta al módulo experto cuál es la siguiente acción y éste devuelve:

"Llevar el vaso de agua destilada al agitador"

6. El módulo tutor una vez que ha averiguado cuál es la siguiente acción, le pregunta al módulo mundo ¿Dónde está el agitador?, ¿Dónde está el alumno? y éste devuelve:

"El agitador está en la sala principal"

"El estudiante está en la sala de autoclave"

7. El módulo tutor le pregunta al módulo estudiante: ¿Cuál fue la última acción que realizó el alumno? ¿Cuál fue el rendimiento global del estudiante hasta el momento en la práctica? El módulo estudiante le dirá al tutor:

"El alumno llenó un vaso con agua destilada" 
"El rendimiento fue flojo (ha cometido muchos errores)"

8. El módulo tutor le envía al módulo comunicación la información recabada del módulo mundo y módulo estudiante con la que se elaborará la información del contexto. Además, le indica que el alumno va a necesitar una pista concreta, dado su rendimiento hasta el momento en la práctica.

9. El módulo comunicación envía al gestor de diálogo el evento "excesiva inactividad del alumno" y el contexto que contiene la siguiente información:

SIG_ACCION_CORRECTA: "Llevar el vaso de agua destilada al agitador"

"El agitador está en la sala principal"

"El estudiante está en la sala de autoclave"

"El alumno llenó un vaso con agua destilada"

\section{Nivel de Pista: Concreto}

10. El gestor de diálogo envía al entorno de entrenamiento procedimental la pista de acuerdo con el nivel que decidió el módulo tutor.

Concreto: "Debes salir de la sala de autoclave y llevar el vaso al agitador que está en la sala principal"

General: "Debes llevar el vaso al agitador que está en la sala principal”

En el siguiente ejemplo presentamos un caso que guarda relación con la línea 16 del pseudocódigo, es decir, cuando el alumno dice algo antes del tiempo de espera.

Ejemplo No. 3: El alumno pregunta por un nuevo químico que necesita para la mezcla. La secuencia es como sigue:

1. El alumno pregunta ¿Dónde está el agar?

2. El Entorno de entrenamiento procedimental retransmite la pregunta al Sistema CLN.

3. El Sistema CLN interpreta la pregunta y la descompone en entidades y relaciones y las envía al módulo de comunicación del SIT

4. El módulo comunicación envía la pregunta descompuesta en entidades y relaciones al módulo estudiante.

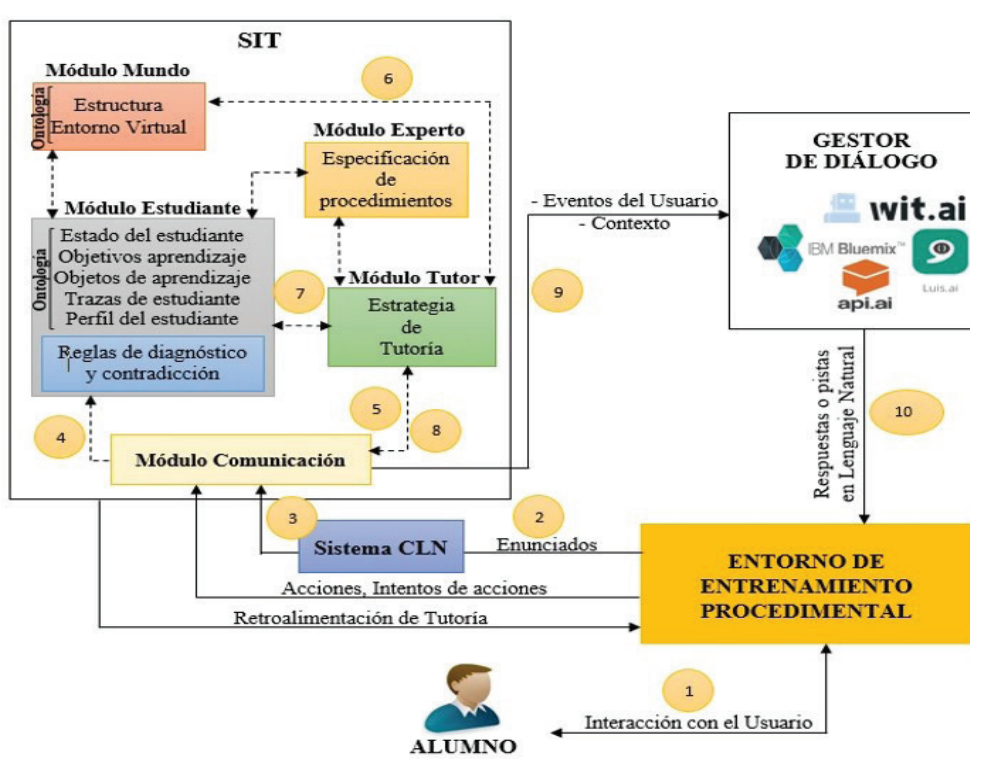

Figura 5. El alumno dice algo antes del tiempo de espera

- El módulo estudiante a través de las reglas de diagnóstico deduce que el alumno no sabe dónde está el agar y actualiza el estado del estudiante.

- El objetivo de aprendizaje que se evaluará es: "El alumno sabe dónde está el agar".

- Por tanto, el estado de conocimientos del estudiante contendrá: "El alumno no ha adquirido ese objetivo con un cierto grado de certeza”.

5. El módulo comunicación envía la pregunta al módulo tutor ¿¿Dónde está el agar?.

6. El módulo tutor una vez que le llega la pregunta del alumno, le pregunta al módulo mundo ¿Dónde está el agar? ¿Dónde está el estudiante? y éste devuelve:

- El agar está dentro de la vitrina” y "La vitrina está en la sala principal"

- "El estudiante está en la sala principal"

7. El módulo tutor le pregunta al módulo estudiante: ¿Sabe el alumno dónde está la vitrina? ¿Cuál fue el rendimiento global del estudiante hasta el momento en la práctica?

Como el alumno ya ha tomado anteriormente otro químico de la vitrina y esto quedó registrado en la ontología del estudiante, el módulo estudiante le contestará al módulo tutor: 
"Sí, el alumno ya sabe dónde está la vitrina”.

"El rendimiento fue bueno (cometió pocos errores)"

8. El módulo tutor envía al módulo comunicación la información recabada del módulo mundo y módulo estudiante con la que se elaborará la información del contexto.

9. El módulo comunicación envía al gestor de diálogo la pregunta del alumno ¿Dónde está el agar? y el contexto con la siguiente información:

\section{"El estudiante está en la sala principal" "El agar está en la vitrina" \\ "La vitrina está en el la sala principal" "El estudiante sabe dónde está la vitrina" Nivel de Pista: General}

10. El gestor de diálogo envía al entorno de entrenamiento procedimental la pista de acuerdo al nivel que decidió el módulo tutor.

General: "El agar está en el mismo sitio que el otro químico que añadiste antes"

Concreto: "El agar está en la vitrina de la sala principal"

\section{Discusión y Conclusiones}

Hemos presentado una propuesta de un SIT para el entrenamiento procedimental con PLN en el que se muestran algunas de sus características y la arquitectura del sistema que abarcaría el SIT junto al gestor de diálogo. Para dar soporte al diálogo hemos propuesto utilizar un gestor de diálogo que se podría construir sobre la plataforma de Watson - IBM y su Servicio Conversation. El motivo de esta elección es que esta plataforma es la más robusta al momento de integrar las variables de contexto con los componentes de la estructura del diálogo, así como por la posibilidad de utilizar el Servicio de Natural Language Understanding que proporcionará el sistema de comprensión en lenguaje natural.

Para detallar la solución propuesta, se ha presentado un pseudocódigo que describe cómo se integraría el gestor de diálogo en el proceso de tutoría del SIT, y ejemplos para tres casos diferentes, en los que se muestra la interacción entre los módulos de la arquitectura.

Este artículo describe los primeros resultados a los que se ha llegado en una tesis doctoral todavía en curso. Además de lo que hemos presentado, en el futuro planeamos refinar la arquitectura presentada: profundizando en el concepto de "contexto", y diseñando una estructura de diálogo que aproveche la información de este contexto para proporcionar mensajes en lenguaje natural adaptados a cada estudiante y a su situación en el entorno virtual.

\section{Agradecimiento}

Agradece el apoyo económico brindado por parte de la Universidad Estatal del Sur de Manabí - Ecuador.

\section{REFERENCIAS BIBLIOGRÁFICAS}

Clemente, J., Ramírez, J., \& de Antonio, A. (2011). A proposal for student modeling based on ontologies and diagnosis rules. Expert Systems with Applications, 38(7), 8066-8078. Recuperado de: https://doi.org/10.1016/j. eswa.2010.12.146

Dalgarmo, B., \& Lee, M. J. W. (2010). What are the learning affordances of 3-D virtual environments? British Journal of Educational Technology, 41, 10-32. Recuperado de: https://doi.org/10.1111/j.1467-8535.2009.01038.x

Dudhabaware, R., \& Madankar, M. (2014). Review on Natural Language Processing Tasks for Text Documents. In IEEE International Conference on Computational Intelligence and Computing Research (pp. 1-5). Coimbatore. Recuperado de: https://doi.org/10.1109/ICCIC.2014.7238427

Dzikovska, M., Steinhauser, N., Farrow, E., Moore, J., \& Campbell, G. (2014). BEETLE II: Deep Natural Language Understanding and Automatic Feedback Generation for Intelligent Tutoring in Basic Electricity and Electronics. International Journal of Artificial Intelligence in Education, 24(3), 284-332. Recuperado de: https://doi.org/10.1007/ s40593-014-0017-9

Evers, M., \& Nijholt, A. (2000). Jacob - An Animated Instruction Agent in Virtual Reality. In T. Tan, Y. Shi, \& W. Gao (Eds.), Advances in Multimodal Interfaces --- ICMI 
2000: Third International Conference Beijing, China, October 14--16, 2000 Proceedings (pp. 526-533). Springer Berlin Heidelberg.

Facebook, M. (2015). Wit.ai. Recuperado de: https://wit. ai/docs/recipes

Glass, M. (2001). Processing Language Input in the CIRCSIM-Tutor Intelligent Tutoring System. In J. D. M. et Al (Ed.), Artificial Intelligence in Education (pp. 210-221). San Antonio: IOS Press.

Google. (2015). Dialogflow. Recuperado de: https://dialogflow.com/docs/intents

Graesser, A. C., Chipman, P., Haynes, B., \& Olney, A. (2005). AutoTutor: An intelligent tutoring system with mixed-initiative dialogue. In IEEE Transactions in Education (pp. 612-618).

Graesser, A. C., VanLehn, K., Rosé, C. P., Jordan, P. W., \& Harter, D. (2001). Intelligent Tutoring Systems with Conversational Dialogue. AI Mag., 22(4), 39-51. Recuperado de: http://dl.acm.org/citation.cfm?id=567363.567366

Gu, Y., Sosnovsky, S., \& Ullrich, C. (2015). SafeChild: An Intelligent Virtual Reality Environment for Training Pedestrian Safety Skills. In G. Conole, T. Klobu?ar, C. Rensing, J. Konert, \& É. Lavoué (Eds.), Design for Teaching and Learning in a Networked World: 10th European Conference on Technology Enhanced Learning, EC-TEL 2015, Toledo, Spain, September 15-18, 2015, Proceedings (pp. 141-154). Cham: Springer International Publishing. Recuperado de: https://doi.org/10.1007/978-3-319-24258-3_11

Hung, V., Gonzalez, A., \& DeMara, R. (2009). Towards a Context-Based Dialog Management Layer for Expert Systems. In International Conference on Information, Process, and Knowledge Management (pp. 60-65). IEEE. Recuperado de: https://doi.org/10.1109/eKNOW.2009.10

IBM. (2015). Natural Language Understanding. Recuperado de: https://www.ibm.com/watson/services/natural-language-understanding/

IBM. (2016). Watson conversation. Recuperado de: https://console.bluemix.net/docs/services/conversation/getting-started.html\#gettingstarted

Los Arcos, J., Muller, W., Fuente, O., Orúe, L., Arroyo, E., Leaznibarrutia, I., \& Santander, J. (2000). LAHYSTOTRAIN: Integration of Virtual Environments and ITS for Surgery Training. In G. Gauthier, C. Frasson, K. VanLehn (Eds.): ITS 2000, LNCS 1839 (pp. 43-52). Springer-Verlag. Recuperado de: https://doi.org/10.1007/3-540-451080_8

Mallios, S., \& Bourbakis, N. (2016). A survey on human machine dialogue systems. In 7 th International Conference on Information, Intelligence, Systems \& Applications (IISA) (pp. 1-7). Recuperado de: https://doi.org/10.1109/ IISA.2016.7785371

Microsoft. (2016). Learn about Language Understanding Intelligent Service (LUIS). Recuperado de: https://docs. microsoft.com/en-us/azure/cognitive-services/LUIS/Home
Murray, T. (1999). Authoring Intelligent Tutoring Systems: An Analysis of the State of the Art. Internacional Journal of Artificial Intelligence in Education (IJAIED), 10, 98-129.

Rickel, J., \& Johnson, W. L. (1999). Animated agents for procedural training in virtual reality: Perception, cognition, and motor control. Applied Artificial Intelligence, 13, 343382.

Rickel, J., Lesh, N., Rich, C., Sidner, C., \& Gertner, A. (2002). Collaborative Discourse Theory as a Foundation for Tutorial Dialogue. In Proceedings of Sixth International Conference on Intelligent Tutoring System (pp. 524-551). Springer-Verlang. Recuperado de: https://doi. org/10.1007/3-540-47987-2_56

Riofrío-Luzcando, D., Ramírez, J., y Berrocal-Lobo, M. (2012). Diseño e Implementación de un Laboratorio Virtual de Biotecnología. Tesis de Máster, ETS de Ingenieros Informáticos Universidad Politécnica de Madrid, Madrid, España.

Singh, B. (2017). Chat Bots - Designing Intents and Entities for your NLP Models. Recuperado de: https://blogs. msdn.microsoft.com/brijrajsingh/2017/01/29/chat-bots??designing-intents-and-entities-for-your-nlp-models/

VanLehn, K., Jordan, P. W., Rosé, C. P., Bhembe, D., Böttner, M., Gaydos, A., ... Srivastava, R. (2002). The Architecture of Why2-Atlas: A Coach for Qualitative Physics Essay Writing. In S. A. Cerri, G. Gouardères, \& F. Paraguaçu (Eds.), Intelligent Tutoring Systems: 6th International Conference, ITS 2002 Biarritz, France and San Sebastian, Spain, June 2--7, 2002 Proceedings (pp. 158-167). Springer Berlin Heidelberg. 


\section{Capital Intelectual, Gestión del Conocimiento en la Interacción Gobierno y Gestión de las Tecnologías de la Información desde Perspectiva COBIT 5}

\section{Intellectual capital, knowledge management in the interaction government and management of information technologies from COBIT 5 perspective}

Percy Edwin De la Cruz Vélez de Villa ${ }^{1}$

Universidad Nacional Mayor de San Marcos, Perú

Recibido: 10-06-2017

Aceptado: 07-12 -2017

\section{Cita Recomendada}

De la Cruz, P. (2017) Capital Intelectual, Gestión del Conocimiento en la Interacción Gobierno y Gestión de las Tecnologías de la Información desde Perspectiva COBIT 5. Hamut'ay, 4 (2), 30-44. Recuperado de: http://dx.doi.org/10.21503/hamu.v4i2.1470

\section{RESUMEN}

Este artículo hace una reflexión sobre el Capital Intelectual y la Gestión del Conocimiento desde una propuesta de perspectiva COBIT 5 (Control Objectives for Information and Related Technology), exponiendo la importancia para alcanzar objetivos estratégicos y obtener un nivel de calidad idóneo, a través de la eficiencia, eficacia y efectividad en todo el ámbito de procesos y procedimientos orientados al Desarrollo Organizacional, por lo que el objetivo es presentar estos conceptos a través de la investigación documental analizada en base de datos, Google académico, catálogos on-line y repositorios. La propuesta de perspectiva COBIT 5, se describe en su Principio 4 "Habilitar un enfoque holístico". En la explicación se detalla cada habilitador y su interacción con el Capital Intelectual y Gestión del Conocimiento, en la que se observa la viabilidad para lograr los objetivos y metas institucionales asegurando y cerrando la brecha entre Gestión de Tecnologías de la Información y los objetivos del negocio. Se concluye del análisis que la participación de estos dos conceptos en todos los procesos es muy activa e importante, por lo que se propone su definición explícita en los modelos de Gobierno.

Palabras Clave: Gobierno de la Tecnología de Información, Gestión de la Tecnología de Información, Capital Intelectual, Gestión del Conocimiento, ISO/IEC 38500: 2015, COBIT 5.

\section{Abstract}

This article provides a reflection on Intellectual Capital and Knowledge Management out of a COBIT 5 framework proposal (Control Objectives for Information and Related Technology), stating the importance to achieve strategic objectives and to obtain an ideal quality level, through efficiency, efficacy and effectiveness in the whole area of processes and procedures oriented to the Orga-

1 Magister en Computación e Informática, especialista en Tecnologías de la Información, profesor principal de la Universidad Nacional Mayor de San Marcos. Email: Pdelacruzv@unmsm.edu.pe 
nizational Development; thus, the objective is to present these concepts through a documentary investigation analyzed in data bases, Google Scholar, on-line catalogs and repositories. The COBIT 5 framework proposal is described in its Principle 4 "Enabling a holistic approach". In the explanation, each enabler and its interaction with the Intellectual Capital and Knowledge Management is detailed, in which the viability to achieve the institutional objectives and goals is observed, ensuring and closing the gap between Information Technology Management and business objectives. From the analysis, it is concluded that the participation of these two concepts in all the processes is very active and important, so its explicit definition is proposed in the Governance models.

Keywords: Information Technology Governance, Information Technology Management, Intellectual Capital, Knowledge Management, ISO/IEC 38500: 2015, COBIT 5.

\section{INTRODUCCIÓN}

En la sociedad actual el conocimiento asociado al capital humano como activo intangible es un factor clave de éxito para hacer a las organizaciones más competitivas, la gestión de ese conocimiento esta basado en la evolución de la Gestión de la Información hacía la generación de Valor; este es el punto motivacional para la propuesta entendiendo que el objetivo de cualquier institución se enmarca en la supervivencia, rentabilidad y crecimiento.

Según Steward (1998) la Gestión del Conocimiento (GC) es el conjunto de procesos que hacen que el Capital Intelectual (CI) de la empresa crezca. El CI está ganando importancia día a día como un enfoque para la medición de los intangibles, especialmente en el contexto de crecimiento de la economía basada en el conocimiento, sobre el cual Akpinar \& Akdemir (1999) precisan que la riqueza económica en la actualidad se basa en el conocimiento y ya no en el proceso de producción.

Respecto a la tecnología, el objetivo principal del Gobierno de la Tecnología de Información (GTI) es conseguir la alineación entre la estrategia del negocio y la estrategia de las Tecnologías de la Información (TI), cerrar esta brecha es fundamental para que la Gestión de las Tecnologías de la Información cumpla su función primordial de generación de valor para los grupos de interés, minimizando los riesgos y optimizando los recursos. Rodríguez, Aguilar y Raudales (2017) manifiestan que, a fin de ordenar, es plausible controlar la GC mediante implementación en la empresa de certificaciones, haciendo uso de estándares como COBIT 5 (2012) o estándares de la Organización Internacional de Normalización (por sus siglas en inglés-ISO). En la versión 5, el COBIT diferencia con más detalle el Gobierno de la Gestión de la TI. Siguiendo este marco de referencia, las empresas aseguran el logro de sus objetivos; sin embargo, en el COBIT 5 y en la normatividad actual de GTI no está explícitamente definida la participación de CI y la GC. Se propone que sólo entendiendo y considerando desde su concepción en el marco, así como en la norma ISO/IEC 38500: 2015 centrada en el gobierno y derivada en la gestión de TI, se consolida esta, para que la ejecución sea exitosa.

El objetivo es presentar un estudio preliminar de reflexión sobre el concepto y la relación del CI, GC en el Gobierno y la Gestión de la TI, bajo la perspectiva del COBIT 5 mediante sus siete habilitadores. Para lo cual se ha considerado como objetivos específicos los siguientes:

1. Definir conceptos como: GC, CI, GTI, Gestión de la TI, se aborda el COBIT 5 tangencialmente para focalizar el principio 4 y los 7 habilitadores, detallando como en su accionar están involucrados las personas, la GC y el CI.

2. Tomar como base el COBIT 5, ya que provee a las empresas un marco de trabajo integral que ayuda a alcanzar sus objetivos para el gobierno y la gestión de TI.

3. Determinar cómo influye la GC en el desarrollo organizacional, lo cual se muestra en la tabla 1 . 
4. Analizar y sintetizar la revisión bibliográfica relacionada a la GC vinculada al CI, asimismo identificar qué aporte o método utilizan, lo cual se describe en la tabla 2.

5. Analizar los siete habilitadores del COBIT 5 y se identifica su relación con GC, CI con Capital Humano $(\mathrm{CH})$, Capital Estructural (CE) y Capital Relacional (CR), como se detalla en la tabla 3.

6. Identificar, ubicar y mostrar como la GC, CI están en cada tarea, actividad y proceso, lo cual se presenta en las conclusiones.

\section{Método}

Este trabajo es una investigación de revisión documental, en la cual se explora la literatura referente al CI, GC, los marcos de gobierno de TI como: la ISO / IEC 38500: 2015 (Calder-Moir, 2013). Así también el COBIT 5 relacionando al Gobierno y Gestión de la TI.

El método utilizado fue:

a. Ubicar el tema de análisis (taxonomía) en: Association for Computing Machinery (ACM)

Applied computing

Enterprise computing

IT governance

Institute of Electrical and Electronics Engineers (IEEE)

M.7.0 Governance

M.7.0.c Norms and regulations

M.7.0.d Policies

\section{M.9.0 Architecture}

M.9.1 Bridging business and IT

M.9.1.1. IT architectures

M.9.1.2. IT governance

b. La selección del material bibliográfico y documental se apoyó en Google Académico para COBIT 5 y otros fundamentos teóricos. Para la GC, CI, así como para el GTI, en repositorios, bibliotecas digitales y bases de datos como: Scielo, ACM, PROQUEST, ELSE-

\section{VIER, ScienceDirect.}

c. Criterios de inclusión. Se consideraron publicaciones de artículos, libros y otro material de lectura de los últimos seis años en el área de la temática mencionada líneas anteriores; asimismo, en la búsqueda de la información se utilizaron palabras claves como capital intelectual, gestión del conocimiento, gestión de tecnologías de la información, COBIT 5, Knowledge management, government, Intellectual capital and management of information technologies.

d. De toda la literatura presentada, son nueve artículos los que sirvieron de base para el trabajo y construcción de las tablas correspondientes, los cuales fueron complementados con libros digitales, físicos y artículos de revistas indexadas como se detalla en las referencias bibliográficas, los cuales fundamentaron el marco teórico del estudio.

En la tabla 1, se observa la importancia que tiene la GC en las organizaciones, en la tabla 2 se identifican los artículos seleccionados y su relación con el CI y/o GC; asimismo se describe el método y aporte. En la tabla 3, con base al COBIT 5, se relaciona los habilitadores (7) con la GC y el CI; en este análisis por cada habilitador se precisa cómo o dónde está la participación de los conceptos: $\mathrm{CI}$ y GC.

La intención es mostrar que los conceptos CI y GC están presentes y cumplen un rol importantísimo y, los marcos de referencia de Gobierno y Gestión de la TI, no manifiestan explícitamente sus aportes.

Por otro lado, de los nueve artículos como base del estudio el $88 \%$ cumplen estrictamente los criterios de inclusión. Debemos precisar que el artículo de Vidovic (2010) no ha sido sometido a revisión o aprobación formal; pero lo han citado ya artículos que están en PROQUEST así cómo tesis de maestría entre otros, motivo por el cual se considera válido como fuente de referencia en este estudio. 


\section{Capital intelectual (CI)}

También se conoce como el nuevo activo invisible y la definición más ampliamente utilizado de CI es "el conocimiento que da valor a una organización" o como lo refiere Villegas, Hernández y Salazar (2015 p. 184) el conocimiento es una fuente primordial que propicia la creación y generación de ventaja competitiva y riqueza en las organizaciones. A partir de esta definición se concluye que la GC genera CI. Por lo tanto, la supervivencia y el éxito competitivo de las empresas dependerán mucho de la gestión estratégica de su $\mathrm{CI}$ en comparación con los recursos financieros. En la economía basada en el conocimiento, para ser una nación desarrollada y para mantener el estado desarrollado, el tener un capital humano de alta calidad es una prioridad. Además, para aumentar la competitividad de una organización, la mano de obra debe ser más eficiente, adaptable y competente. Por este motivo muchas organizaciones, e inclusive países, han entendido de la urgencia de su aplicación y es un punto de la agenda principal en el marco del Noveno Plan de Malasia y el nuevo modelo económico de 2010.

El CI es tan importante como la inversión de capital para las empresas. Por lo tanto, los gobiernos de los países deberían equilibrar estas inversiones, más aún los países en vías de desarrollo (Chen, Cheng \& Hwang, 2005). De acuerdo con Bontis \& Richardson (2000), hay tres elementos principales del CI que son: el Capital Humano $(\mathrm{CH})$, Capital Estructural (CE) y el Capital Cliente también llamado Capital Relacional (CR), y es a través de esta combinación que se crea valor para la organización, el análisis correspondiente al CI es para determinar su riqueza intelectual.

Las empresas que poseen todos los componentes del Capital Intelectual, están en mejores condiciones para competir en el negocio (Amrizah \& Rashidah, 2013).

Según Wiig (1997) el conocimiento y el CI son conceptos relacionados, pero, en su gestión, sus objetivos y alcances son diferentes; ambos son los activos más importantes de una organización. La gestión del CI se concentra básicamente en renovar y maximizar el valor de los activos intelectuales de la organización, la GC se concentra en faci- litar y gestionar las actividades relacionadas con el conocimiento (creación, captura, transformación y uso); su función consiste en planear, implementar, operar y monitorear todas las actividades y programas relacionados con el conocimiento que se requiere para una gestión eficaz del CI (Wiig, 1997).

El Capital Humano $(\mathrm{CH})$ como elemento del capital intelectual, según Fitz - Enz (2009) menciona que este es una combinación de tres factores: a) el carácter o la naturaleza que se lleva al trabajo; por ejemplo, inteligencia, energía, actitud positiva, fiabilidad y compromiso, b) las capacidades de la persona para aprender, tales como la inteligencia, la imaginación, la creatividad y c) la motivación del talento para compartir información o conocimiento, el espíritu de equipo y la orientación de meta.

Como otro de los elementos del capital intelectual el Capital Estructural (CE), que es la infraestructura que apoya a los empleados para crear un rendimiento óptimo, incluyendo la capacidad de la organización para llegar al mercado, hardware, software, bases de datos, estructura organizativa, patentes, marca registrada y toda capacidad de las organizaciones para apoyar la productividad de los empleados (Bontis, et al., 2000). El concepto de la existencia de CE habilita la creación de CI y de enlace-procesamiento de los recursos humanos. Según Gogana et al., (2014), son 15 conceptos clave los que definen el CE, creados por las personas en su trabajo cotidiano en la organización (véase figura 1). Estas palabras deben capitalizarse por medio de la GC. Permitiendo y asegurando el desarrollo de las organizaciones.

El tercer elemento del capital intelectual es el Capital Relacional (CR), también llamado Capital Social (CS) que es el resultado de la inteligencia competitiva y social consubstanciada por el valor de las relaciones y acciones de la empresa compartidas con los agentes externos o sociales (IADE-CIC., 2003). Según Bontis (1999), es el conocimiento individual de los canales de mercado, clientes y proveedores, bien como el conocimiento del impacto de las asociaciones gubernamentales o industriales. Ejemplo de ello está en las relaciones con los empleados; el CI no sólo in- 


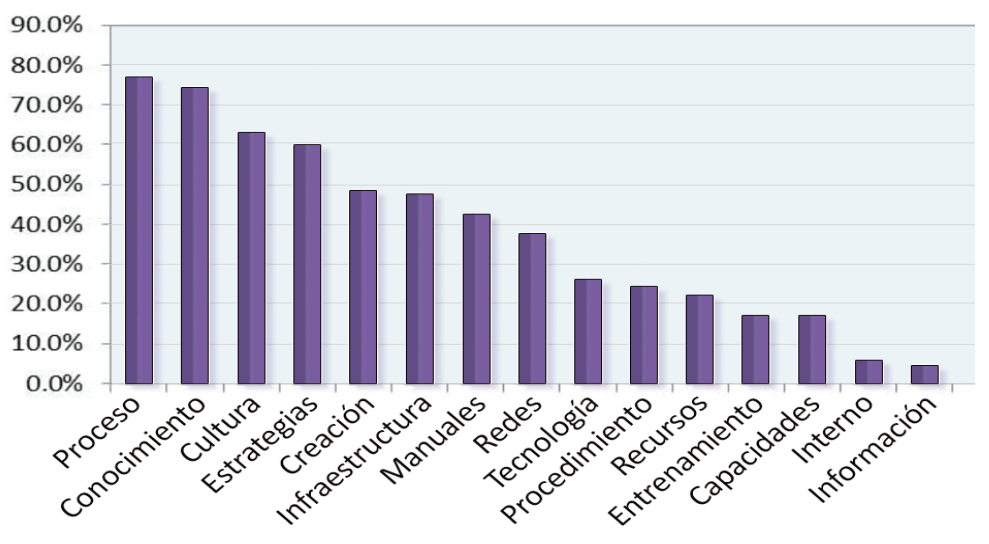

Figura 1. Quince palabras claves para definir CE Fuente: (Gogana et al., 2014)

cluye los contenidos de la mente o la mente de los empleados, sino que también incluye la estructura intangible y compleja entre ellos para realizar actividades y funciones organizacionales.

Según Trimurni \& Erlinac (2015) el Capital Social afecta significativamente la gobernanza a través del desarrollo del capital social, que es la capacidad de organizarse, construir una red de cooperación y participar en la sociedad. Una herramienta muy importante para la gestión empresarial es el cuadro de mando. Este instrumento, introducido por Kaplan y Norton (1992) hace que la tarea de evaluar el CI sea menos subjetiva.

\section{Gestión del conocimiento (GC)}

La GC es un nuevo y controvertido término que tiene muchas y diferentes definiciones. Fue introducido por primera vez en la Conferencia de Gestión de Europa en 1986. El Centro de Productividad y Calidad estadounidense define la GC como las estrategias y procesos de identificación, captura y aprovechamiento de los conocimientos (Atefeh et al, 1999, p. 172). Por otro lado, Knapp (1998) lo define como el arte de transformar la información y los activos intelectuales en un valor duradero para las organizaciones de clientes y su gente. Según Marulanda, Giraldo y López (2013) definen la GC como el proceso sistemático de buscar, organizar, filtrar y presentar información con el objetivo de hacerlo comprensible para las personas en un área específica de interés y a partir del mismo determinar qué se evalúa. Otros auto- res lo definen como un proceso que comprende crear, aplicar y transferir conocimientos en la organización, con el fin de conseguir ventaja competitiva de acuerdo a sus objetivos (Wiig, 1997; Alavi \& Leidner, 2001).

Darroch (2003) lo define como el proceso de crear, compartir, distribuir y utilizar el conocimiento en la organización. Otros investigadores han identificado diferentes procesos de GC: i) La creación, transferencia y aplicación (Spender, 1996), ii) Captura, transferencia y aplicación (De Long, 1997), iii) Identificación, captura, desarrollo, distribución, difusión, aplicación y almacenamiento (Probst et al, 2000).

Todos estos procesos, según la investigación realizada por Tarí \& García (2009), dan lugar a las dimensiones del conocimiento: a) Creación (Aprendizaje Organizativo), b). Almacenamiento y transferencia (Conocimiento Organizativo) y c) Aplicación y uso (Organización del Aprendizaje). De este modo, capturar, almacenar, compartir y distribuir conocimiento permiten innovar (Baptista et al., 2006).

Según Vidovic (2010) las ventajas de la GC sobre el Desempeño Organizativo, se ve en la tabla 1.

\section{Tabla 1}

Resultados de la gestión del conocimiento

\begin{tabular}{ll}
\hline $\begin{array}{l}\text { Grupo de } \\
\text { resultado }\end{array}$ & Resultados \\
\hline Rendimiento de & - Mejor toma de decisiones \\
los empleados & - Nuevas o mejores formas de trabajar \\
& - Comunicación mejorada \\
& - Habilidades mejoradas de los empleados \\
& - Mayor colaboración \\
\hline Desempeño de & - Aumento de las ganancias \\
la Organización & - Reducción de costos \\
& - Aumento del empoderamiento de empleados \\
& - Mayor retención/atracción de los empleados \\
& - Royor Productividad \\
\hline Rendimiento & - Aumento de las acciones \\
del Mercado & - Mamento del tamaño del mercado \\
& - Calidad mejorada de producto o servicio \\
& - Creación de más valor para el cliente \\
& - Entrada a diferentes tipos de mercado \\
\hline
\end{tabular}

Elaboración propia.

Fuente: Anantatmula \& Kanungo, (2006, p.29) 
Asimismo, es relevante sustentar la importancia que tiene la GC para las organizaciones, según Tarí \& García (2013) la GC influye en los resultados operativos, financieros y de innovación en las organizaciones; según Arteche (2011), manifiesta que la GC tiene algunos retos que debe cumplir. Por ejemplo: cómo la organización puede transformarse en una organización inteligente; también refiere que su factor de éxito está en función de determinar cuál es el modelo adecuado. En esta adecuación es ideal apoyarse en un sistema de gestión de conocimiento (SGC) que permita unificar la estrategia de GC y la estrategia de proceso de la organización empresarial con el fin de alcanzar los objetivos organizacionales. Considerando que los SGC son:

Una clase de sistemas de información aplicados para gestionar conocimiento organizativo y desarrollados para soportar y mejorar procesos de creación, almacenamiento, recuperación, transferencia y aplicación del conocimiento" (Alavi \& Leidner, 2001, p. 107).

Por su parte Anantatmula \& Kanungo (2006) insisten en la importancia de la medición de la gestión del conocimiento y citan tres razones para medir el éxito de un sistema de gestión del conocimiento: 1) proporcionar una base para la valoración, 2) estimular enfoque de la administración en lo que es importante y 3) para justificar las inversiones.

Gobernanza y Gestión de la tecnologías de la información

Para dejar claros los términos que hacen referencia a Gobernanza, gobierno corporativo y gobierno de las TI, se describen a continuación algunas definiciones que especifican estos aspectos.

La Gobernanza Corporativa, según el Comité de Organizaciones Patrocinadoras de la Comisión de Normas (COSO, 2013) y la Organización para la Cooperación y el Desarrollo Económico (OCDE, 2004) hacen mención que es; la provisión de la estructura que permite determinar los objetivos de la organización y supervisar el rendimiento, a fin de asegurar que los objetivos sean cumplidos; según la ISO/IEC 38500: 2015, el Gobierno
Corporativo se centra en seis principios: responsabilidad, estrategia, adquisición, rendimiento, conformidad y comportamiento humano, y tres funciones que son evaluar, dirigir y monitorizar.

Gobernanza de las TIC ISO 38500 - COBIT / Val IT, manifiestan que es la especificación del marco de derecho a la toma de decisiones y a la alta responsabilidad para favorecer un comportamiento deseable en el uso de las TIC.

El gobierno corporativo, para Haji, \& Ghazali, (2013), es un sistema o una forma en que las empresas se controlan para ser esta responsable de sus grupos de interés, relacionando además con el CI con los atributos del gobierno corporativo.

Respecto al Gobierno de la TI para que este desempeñe un gobierno idóneo se basa en los principios de gobierno corporativo para la gestión y el uso de las TI para alcanzar los objetivos empresariales. Para TIC-CRUE (2016) es un sistema que permite dirigir y controlar la utilización de las TI actuales y futuras; a través de la dirección y evaluación de planes de uso de estas y a su vez sirven de soporte a la organización. Además, pretenden atender las demandas externas (de los clientes) en un horizonte temporal futuro (Peterson, 2003). Para Toomey (2009) el foco del Gobierno de la TI lleva directamente al modelo más básico de los negocios: Planifica, Construye y Ejecuta (véase área izquierda de la figura 2).
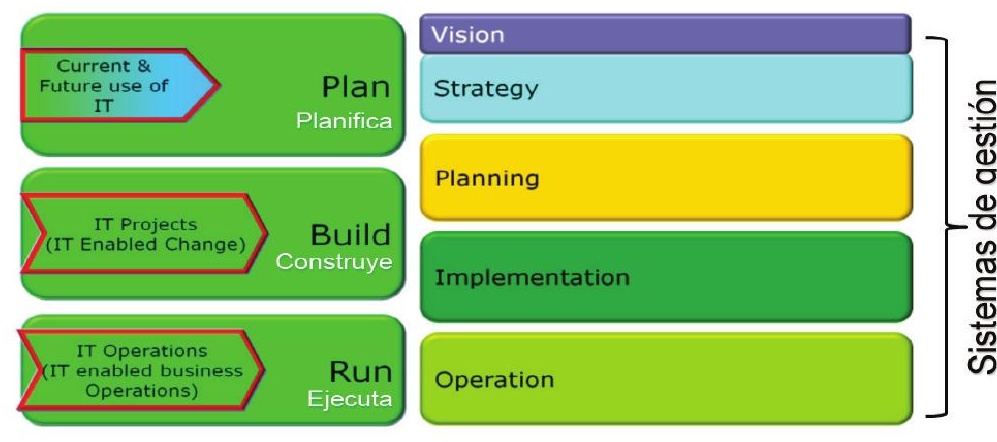

Figura 2. Principales sistemas de la gestión TI.

Fuente (Toomey, 2009). 


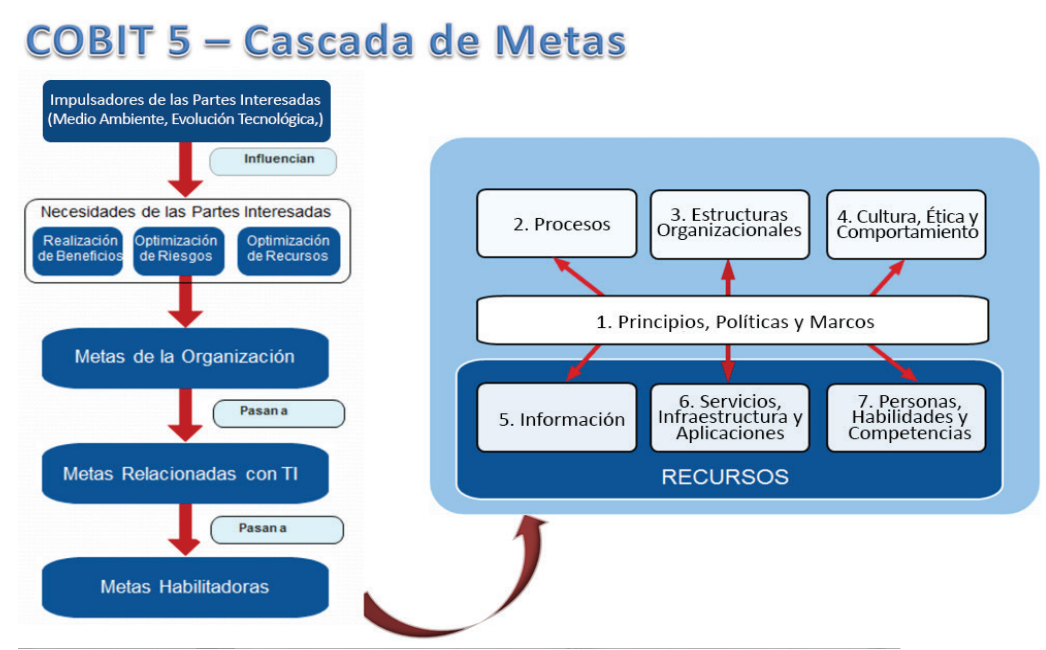

Figura 4. Cascada de metas desde Gobierno de TI hacia la gestión de TI. Fuente: (ISACA, 2014, Pág. 7)

Tabla 2

Revisión de la literatura de artículos

\begin{tabular}{|c|c|c|c|}
\hline Referencia & Nombre del artículo & Relación & Método/Aporte \\
\hline $\begin{array}{l}\text { Abd Rahman } \\
\text { et.al., } 2015\end{array}$ & $\begin{array}{l}\text { El nivel de conocimiento del Gobierno } \\
\text { Corporativo en los órganos federales } \\
\text { estatutarios en Malasia - } 2015\end{array}$ & $\begin{array}{l}\text { Importancia de la GC en el } \\
\text { consejo de administración }\end{array}$ & $\begin{array}{l}\text { Examina el nivel de conocimiento de la adminis- } \\
\text { tración sobre el concepto, principios y prácticas de } \\
\text { gobierno corporativo (encuestas). }\end{array}$ \\
\hline $\begin{array}{l}\text { Jameelah, } \\
\text { et.al.,2015 }\end{array}$ & $\begin{array}{l}\text { El efecto del capital intelectual sobre el } \\
\text { rendimiento de las organizaciones }\end{array}$ & $\begin{array}{l}\text { Efecto del } \mathrm{Cl} \text { en el rendi- } \\
\text { miento }\end{array}$ & $\begin{array}{l}\text { Usa } 6 \text { elementos del } \mathrm{Cl} \text { y analiza su aporte al rendi- } \\
\text { miento (otros estudios lo reagrupar y queda } 3 \text { ) }\end{array}$ \\
\hline $\begin{array}{l}\text { Sadalia \& } \\
\text { Nurbaity, } 2015\end{array}$ & $\begin{array}{l}\text { Análisis discriminante del capital inte- } \\
\text { lectual - Universidad de Medan }\end{array}$ & $\begin{array}{l}\text { El Gobierno Corporativo } \\
\text { tiene una gran influencia } \\
\text { sobre el } \mathrm{Cl}\end{array}$ & $\begin{array}{l}\text { Usa método análisis discriminante apoyado con } \\
\text { SPSS }\end{array}$ \\
\hline $\begin{array}{l}\text { Todericiu \& } \\
\text { Serban, } 2015\end{array}$ & $\begin{array}{l}\text { Capital Intelectual y su relación con las } \\
\text { Universidades }\end{array}$ & $\begin{array}{l}\text { Relación } \mathrm{Cl} \text { en las Univer- } \\
\text { sidades }\end{array}$ & $\begin{array}{l}\text { Trata de investigar el papel del } \mathrm{Cl} \text { en las organiza- } \\
\text { ciones de hoy en día modernos y, en particular, su } \\
\text { relevancia para las instituciones educativas. }\end{array}$ \\
\hline $\begin{array}{l}\text { Gogana, et.al., } \\
2014\end{array}$ & $\begin{array}{l}\text { Capital Estructural - un modelo de } \\
\text { medición propuesto }\end{array}$ & Capital Estructural & $\begin{array}{l}\text { Identifica los elementos de la CE que ayudan a } \\
\text { asegurar el éxito de la organización. }\end{array}$ \\
\hline $\begin{array}{l}\text { Mahfoudh \& } \\
\text { Izah., } 2012\end{array}$ & $\begin{array}{l}\text { Características de rendimiento del } \\
\text { capital intelectual y de la Junta de } \\
\text { Bancos del CCG }\end{array}$ & $\begin{array}{l}\mathrm{Cl} \text { y el rendimiento, mide } \\
\text { el rendimiento del } \mathrm{Cl} \text { a } \\
\text { través de método del valor } \\
\text { añadido del coeficiente } \\
\text { intelectual (VAIC) desarro- } \\
\text { llado por Pulic (1998) }\end{array}$ & $\begin{array}{l}\text { Examina la relación entre las características de la } \\
\text { mesa de directores (diversidad nivel de estudios, la } \\
\text { diversidad nacionalidad, tabla de enclavamiento, ta- } \\
\text { maño del mesa directiva y el número de consejeros } \\
\text { independientes) y el rendimiento }\end{array}$ \\
\hline Vidovic, 2010 & $\begin{array}{l}\text { Enlace entre la calidad de la GC y } \\
\text { el rendimiento financiero: Caso de } \\
\text { Croacia }\end{array}$ & $\begin{array}{l}\text { Elección de la GC y } \\
\text { rendimiento }\end{array}$ & $\begin{array}{l}\text { Usa ROS y ROA como medidas de rendimiento } \\
\text { organizacional }\end{array}$ \\
\hline $\begin{array}{l}\text { Sayyed, et. al., } \\
2011\end{array}$ & $\begin{array}{l}\text { Examinando el impacto de los facili- } \\
\text { tadores de la GC sobre los procesos } \\
\text { de GC }\end{array}$ & $\begin{array}{l}\text { Impacto de los facilitadores } \\
\text { de GC sobre los procesos } \\
\text { básicos }\end{array}$ & Encuentra una relación directa \\
\hline $\begin{array}{l}\text { Beinborn, et.al., } \\
2009\end{array}$ & $\begin{array}{l}\text { Propuesta de un modelo teórico para } \\
\text { Gobernanza de TI y alineamiento del } \\
\text { negocio con } \mathrm{TI}\end{array}$ & $\begin{array}{l}\text { Al explicar el alineamiento } \\
\text { se soporta sobre el } \mathrm{Cl}: \mathrm{CH} \text {, } \\
\mathrm{CR}, \mathrm{CS}\end{array}$ & $\begin{array}{l}\text { Elaborar un modelo que será explicado y empírica- } \\
\text { mente evaluado sobre el alineamiento }\end{array}$ \\
\hline
\end{tabular}

Elaboración propia. 
En la tabla 3 se relacionan los siete habilitadores y se asocian a la CI y a la GC. Se observa que todos los habilitadores están relacionados con la GC (columna 3) y sólo algunos están asociados al CI (columnas 4, 5 y 6), según el análisis realizado.

Tabla 4

Habilitadores y su relación con la GC y CI

\begin{tabular}{|c|c|c|c|c|c|}
\hline \multirow[b]{2}{*}{ Catalizador } & \multirow{2}{*}{$\begin{array}{l}\text { Interacción entre Gobier- } \\
\text { no y Gestión de la TI en } \\
\text { COBIT } 5\end{array}$} & \multirow[b]{2}{*}{$\mathrm{GC}$} & \multicolumn{3}{|l|}{$\mathrm{Cl}$} \\
\hline & & & $\mathrm{CH}$ & CE & $\mathrm{CR}$ \\
\hline $\begin{array}{l}\text { Principios, } \\
\text { Políticas y } \\
\text { Marcos }\end{array}$ & $\begin{array}{l}\text { Son los vínculos mediante } \\
\text { el cual las decisiones del } \\
\text { Gobierno (establecen orien- } \\
\text { taciones) son ejecutadas en } \\
\text { la gestión. }\end{array}$ & $\sqrt{ }$ & & $\sqrt{ }$ & + \\
\hline Procesos & $\begin{array}{l}\text { En los procesos catalizado- } \\
\text { res se distingue procesos } \\
\text { de Gobierno y de Gestión, } \\
\text { incluyes prácticas y activi- } \\
\text { dades para c/u, inclusive a } \\
\text { la matriz RACl. }\end{array}$ & $\sqrt{ }$ & & $\sqrt{ }$ & + \\
\hline $\begin{array}{l}\text { Estructuras } \\
\text { organizativas }\end{array}$ & $\begin{array}{l}\text { En cada empresa se } \\
\text { definen varias estructuras } \\
\text { de organizativas en función } \\
\text { de su composición y ámbito } \\
\text { de decisiones. }\end{array}$ & $\sqrt{ }$ & & $\sqrt{ }$ & + \\
\hline
\end{tabular}

\begin{tabular}{|c|c|c|c|c|c|}
\hline $\begin{array}{l}\text { Cultura Ética } \\
\text { y Comporta- } \\
\text { mientos }\end{array}$ & $\begin{array}{l}\text { El comportamiento es } \\
\text { un catalizador del buen } \\
\text { Gobierno y de Gestión, se } \\
\text { establece en el más alto } \\
\text { nivel. }\end{array}$ & $\sqrt{ }$ & $\sqrt{ }$ & $\sqrt{ }$ & + \\
\hline Información & $\begin{array}{l}\text { El modelo de procesos } \\
\text { describe las I/O de los dis- } \\
\text { tintos procesos, basados en } \\
\text { prácticas de otros procesos, } \\
\text { incluyendo la información } \\
\text { intercambiada entre los } \\
\text { procesos de Gobierno y de } \\
\text { Gestión. }\end{array}$ & $\sqrt{ }$ & $\sqrt{ }$ & $\sqrt{ }$ & + \\
\hline $\begin{array}{l}\text { Servicios, } \\
\text { Infraestructura } \\
\text { y Aplicaciones }\end{array}$ & $\begin{array}{l}\text { Se requieren servicios so- } \\
\text { portados por las aplicacio- } \\
\text { nes e infraestructura, para } \\
\text { proporcionar información } \\
\text { adecuada al órgano de } \\
\text { Gobierno, para Dirigir, } \\
\text { Evaluar y Monitorear. }\end{array}$ & $\sqrt{ }$ & & $\sqrt{ }$ & + \\
\hline $\begin{array}{l}\text { Personas, } \\
\text { habilidades y } \\
\text { Competencias }\end{array}$ & $\begin{array}{l}\text { Las actividades de Gobier- } \\
\text { no y de Gestión requieren } \\
\text { un conjunto de habilida- } \\
\text { des distintas. Estas son } \\
\text { requeridas para completar } \\
\text { exitosamente todas las } \\
\text { actividades y para tomar las } \\
\text { decisiones correctas, así } \\
\text { como para llevar a cabo las } \\
\text { acciones correctivas. }\end{array}$ & $\sqrt{ }$ & $\sqrt{ }$ & & + \\
\hline
\end{tabular}

Elaboración propia.
Según COBIT 5-marco (2013) en todo momento las organizaciones y sus ejecutivos están haciendo esfuerzos para:

- Crear y mantener información de calidad para apoyar las decisiones del negocio.

- Generar valor comercial a sus inversiones habilitadas por la TI; vale decir lograr metas estratégicas y mejoras al negocio mediante el uso eficaz e innovador de la TI.

- Lograr una excelencia operativa mediante la aplicación eficiente y fiable de la tecnología.

- Mantener y controlar el riesgo relacionado con TI a niveles aceptables.

- Optimizar el costo y los servicios de TI, entre otros.

Estas preocupaciones necesitan ser puestas en contexto y diferenciar los roles que competen. Para lograr valor para las partes interesadas se requiere un buen gobierno y una buena administración de los activos de TI y de la información.

COBIT 5 proporciona este marco integral que ayuda a las organizaciones a lograr sus metas y entregar valor mediante un gobierno y una administración efectiva de la TI, como se puede observar en la figura 5.

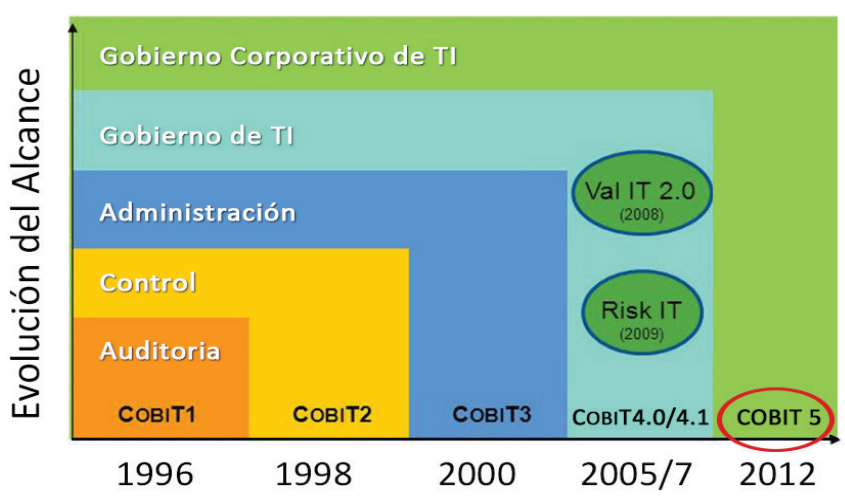

Figura 5. Marco empresarial de ISACA.

Fuente: (CiGRAS, 2014).

COBIT 5 une los cinco principios que permiten a la organización construir un marco efectivo de Gobierno y Administración basado en una serie holística de siete habilitadores, que optimizan la inversión en tecnología e información, así como su uso en beneficio de las partes interesadas. Los 
principios y habilitadores de COBIT 5 son genéricos y útiles para las organizaciones de cualquier tamaño bien sean comerciales, sin fines de lucro o en el sector público. Al basarse en cinco principios y siete habilitadores, COBIT 5 utiliza prácticas de gobierno y gestión para describir las acciones que son ejemplo de mejores prácticas de su aplicación.

Los cinco principios de COBIT 5:

1. Satisfacer las necesidades de las partes interesadas.

2. Cubrir la compañía de forma integral.

3. Aplicar un solo marco integrado.

4. Habilitar un enfoque holístico.

5. Separar el gobierno de la administración.

Los siete habilitadores se esquematizan en la figura 6 , así como su relación.

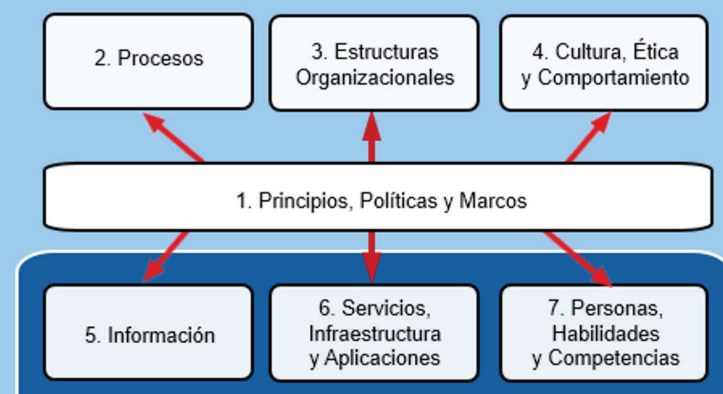

RECURSOS

Figura 6. COBIT 5 Habilitadores de empresa. Fuente: (COBIT 5, 2012, Pág. 27)

\section{HABILITADORES Y SU ANÁLISIS RELACIO-}

NADO A LA GC Y CI

De acuerdo a la propuesta se detalla a continuación cada uno de los siete habilitadores en uso de COBIT 5.

\section{Principios, Políticas y Marcos (1)}

"Son los vehículos para traducir el comportamiento deseado en guías prácticas para la gestión día a día" (COBIT 5, 2012). Estos son determinados por el órgano de dirección más alto, se sus- tenta en la parte normativa (definida en su plan estratégico y las buenas prácticas según manuales de referencia), las políticas y la cultura organizacional que corresponden al CE y la ejecución es realizada por las personas $(\mathrm{CH})$; pero esa interacción humana se denomina $\mathrm{CR}$, que se da según las mejores prácticas usando las herramientas pertinentes, etc. (CE).

\section{Procesos (2)}

"Describen un conjunto organizado de prácticas y actividades para alcanzar ciertos objetivos y producir un conjunto de resultados que soporten las metas generales relacionadas con la TI" (COBIT 5, 2012).

Entendiéndose que hay procesos a nivel de gobierno, así como a nivel de gestión cada uno con sus entradas y salidas propias. Se sustentan en los manuales respectivos de cada institución donde se consignan la descripción de los procesos automatizados o no. Esta documentación corresponde al CE y es resultado de la generación de conocimiento y registro en su fase de combinación propiamente dicha (Nonaka \& Takeuchi, 1995).

\section{Estructuras Organizacionales (3)}

"Son las entidades de toma de decisiones clave en una organización” (COBIT 5, 2012). Corresponde a una adecuación dinámica de las organizaciones a efectos de lograr sus objetivos estratégicos, estas estructuras deben estar definidas en el Manual de Organización y Funciones (MOF) donde se describen puestos, dependencias jerárquicas etc., corresponde al CE.

El modelo propuesto por Tallon, et al. (2013) asocia al GTI usando artefactos de Gobierno de la Información; el enfoque dominante de la literatura de GTI ha sido cómo las empresas gobiernan los artefactos físicos de las TI (hardware, software y redes). El objetivo del modelo es ampliar la teoría del GTI mediante el descubrimiento de las estructuras y prácticas utilizadas para gobernar artefactos de información. Se incorpora y se observaron cómo las prácticas de Gobierno de la Información pueden desbloquear el valor de los crecientes datos dentro de las organizaciones. Se 
precisa que los activos de información están dentro del CE.

\section{Cultura, Ética y Comportamiento (4)}

"De los individuos y de la empresa, son muy a menudo subestimados como factor de éxito en las actividades de gobierno y gestión" (COBIT 5, 2012).

Se puede hablar de ética organizacional, determinada por los valores que la empresa ha definido y ética individual relaciona a cada individuo $(\mathrm{CH})$. Incluso, se podría hablar de ética de equipo. La cultura y la ética conllevan a un comportamiento deseado de las personas el cual debe tener como horizonte los objetivos institucionales. La cultura se sustenta en el CE y la ética y el comportamiento están asociados al $\mathrm{CH}$.

\section{La Información (5)}

"Impregna toda la organización e incluye toda la información producida y utilizada por la empresa. La información es necesaria para mantener la organización funcionando y bien gobernada, pero a nivel operativo, la información es muy a menudo el producto clave de la empresa en sí misma” (COBIT 5, 2012). Y esta se encuentra presente en todo el ambiente de cualquier organización; por otro lado, la información es la fuente donde se genera el conocimiento al ser incorporado al individuo (internalización o socialización del proceso de generación de conocimiento). La información está registrada en diferentes medios, por ende, corresponde a CE; también el conocimiento está registrado en la mente de las personas; pero cuando se expresa es información, motivo por el cual corresponde al $\mathrm{CH}$ y en el caso que se haya registrado en algún sistema basado en conocimiento estaría en el contexto del CE. También la información es el insumo que facilita la interacción entre agentes permitiendo obtener el CR.

\section{Servicios, Infraestructura y Aplicaciones (6)}

"Incluyen la infraestructura, la tecnología y las aplicaciones que proporcionan a la empresa servicios y tecnología de procesamiento de la información" (COBIT 5, 2012).
La información integrada y almacenada en algún soporte tecnológico (infraestructura) relacionada con alguna aplicación para lograr algún objetivo institucional se traduce hacia ese entorno como un servicio permitiendo interactuar, comunicarse etc., para lograr el objetivo previsto.

En aras de mejorar la confianza de los clientes hay un experimento de Huang et al. (2011) usando las TI aplicando COBIT; en este trabajo los autores desarrollan y prueban un nuevo factor en su modelo, la confianza en el comercio electrónico (e-comercio): La banca por Internet. El control interno de la banca por Internet es muy consistente con los altos niveles de los factores de confianza como la seguridad, la privacidad y otros temas de riesgo. Sin embargo, este tipo de asociación aún no ha sido ampliamente reconocido como un modelo de confianza desde el punto de vista del consumidor de comercio electrónico. Este estudio trata de crear nuevos factores en la GTI de COBIT donde los autores consideran el sello de confianza virtual como Sello de confianza del Gobierno de la TI de COBIT, se propone ampliar los vínculos de la empresa con un nuevo servicio (e-comercio) y lo importante es darle la confianza y seguridad, el cual pasa por crear una cultura en ambas entidades, manifestándose el $\mathrm{CR}$, mientras que la infraestructura, cultura y servicio corresponden al CE.

\section{Personas, Habilidades y Competencias (7).}

"Están relacionadas con las personas y son necesarias para poder completar de manera satisfactoria todas las actividades, para la correcta toma de decisiones y de acciones correctivas" (COBIT 5, 2012).

Este habilitador corresponde al $\mathrm{CH}$, el conocimiento reside en las personas que tienen las habilidades, capacidades y competencias para realizar el cambio que requiere la institución y eso se manifiesta mediante el comportamiento pragmático en la ejecución de las directivas y realización de las buenas prácticas con ética para poder realizar ese cambio organizacional que le permita ser cada vez más competitivo y sostenible a la organización.

Un factor determinante es la cultura organizacio- 
nal, según Robbin (2004) la cultura es un conjunto de valores, creencias, normas, procedimientos y significados compartidos por los miembros de la organización.

De la revisión de la literatura se observa que para la evaluación de la GTI en las organizaciones ya se está considerando a la GC como el motor para ese cambio esperado, se puede confirmar en el enfoque de Bin-Abbas, H. \& Bakry, S. (2014) que esta es una arista del pentágono del método STOPE (Strategy, Technology, Organization, People and Environment); para la integración de los diferentes dominios están usando la Gestión del Conocimiento (personas con $64.9 \%$ y estas son parte integral del capital humano $(\mathrm{CH})$ ).

Este método permite la integración de diferentes dominios donde los autores Bin-Abbas \& Bakry (2014) lo integran con los principios de la GC como un valor añadido y las fases de Six Sigma como un proceso de mejora cíclica. Asimismo, sostiene que el problema con el uso y aplicación de las recomendaciones de GTI disponibles, referencias de evaluación etc., son diversas y en algunos casos largas y complicadas. También considera que estas recomendaciones no proporcionan la suficiente atención a los principios de GC. Por tanto, surge la necesidad de unificar y simplificar la evaluación de gobernabilidad, lográndose mejorar dichas evaluaciones teniendo en cuenta los principios de GC. El enfoque STOPE, que desarrollan para superar estos inconvenientes lo agrupan en cinco dominios en los que se ha prestado especial atención al factor humano en la gestión de TI a través de dos consideraciones principales:

1. GC se asocia directamente con la conducta humana; y

2. La consideración de un dominio independiente para las personas entre los cinco dominios principales del ámbito de GTI considerado (figura 7).

Con esta simplicidad y definida las competencias, las personas pueden fácilmente desarrollar las habilidades para el logro de los objetivos institucionales, siguiendo las guías y marcos establecidos.

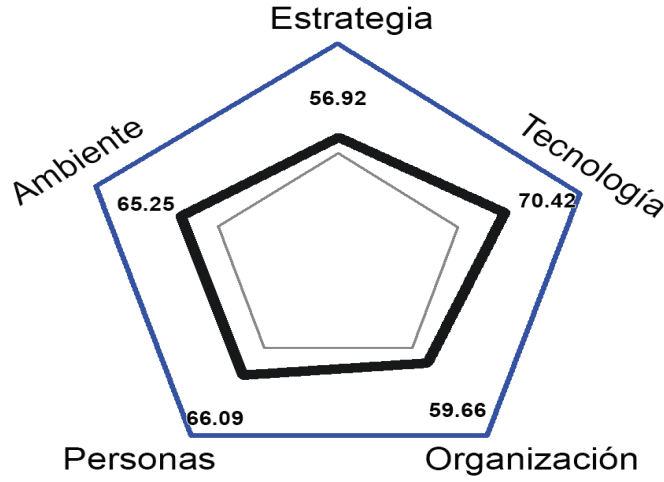

Figura 7. Porcentaje de Rendimiento del Gobierno de la TI aplicando STOPE

Fuente: (Bin-Abbas, H. \& Bakry, S., 2014).

\section{Conclusiones}

El capital intelectual es tan importante como la inversión de capital para las empresas.

La Gestión del CI debe ser parte del cuerpo de conocimiento y uso del Gobierno Corporativo y consecuentemente en la Gestión de la TI. Se sugiere tener cuidado en los conceptos de gobierno corporativo, gobernanza de TI, GTI a fin de tener una visión clara y precisa en cuanto a sus alcances y aportes.

El gobierno de la organización se refiere al marco de responsabilidad global que coordina todas las actividades de gestión respecto a todos los stakeholders (partes interesadas), mientras que el gobierno corporativo corresponde principalmente a la junta o consejo de gobierno, el equipo de gestión ejecutiva y los accionistas. El gobierno de las TI, por su parte, se centra en el uso de la tecnología para satisfacer los objetivos de la organización fijados por la dirección. Por ello, el gobierno corporativo incluye aspectos del gobierno de las TI, ya que, sin una gestión eficaz de las TI los encargados de las responsabilidades corporativas no podrían desempeñarse de forma efectiva (Fink et ál., 2006).

Los resultados del SGC se producen y se observan en el largo plazo, este escenario podría ser la razón por la cual los gerentes desconocen el funcionamiento de la GC en sus organizaciones, consecuentemente no hay el apoyo ni el compromiso respectivo o en todo caso es tardío. 
Capital Intelectual, Gestión del Conocimiento en la Interacción Gobierno y Gestión de la Tecnologías de la Información desde Perspectiva COBIT 5

Se recomienda que el responsable del área de TI/ SI sea parte integrante del comité de gobierno de TI para asegurar un alineamiento más efectivo.

De la interacción entre el Gobierno y la Gestión de la TI, partiendo de ISO/IEC 38500: 2015 y el COBIT 5 (en función del cuarto principio y siete habilitadores) se identificó la fuerte relación de la GC y CI y cómo estos son agentes naturales del cambio.

El buen uso de la GC por parte de una organización la hace más competitiva, el uso de la GC en la organización soportado por la tecnología la convierte en una organización inteligente. Esta organización inteligente tiene como objetivo su desarrollo y sostenibilidad y quién asegura estos logros son los marcos y las buenas prácticas determinadas por COBIT 5, entre otras.

Uno de los problemas de los marcos de gobierno sea ISO/IEC 38500: 2015 o el COBIT 5, inclusive Calder-Moir (2013) afirma que no precisan la gestión de los activos intangibles como así tampoco las bondades que puede ofrecer la GC para facilitar su ejecución de sus directivas.

Se Considera que se deben realizar más investigaciones y profundizar el tema a fin que se entienda y se revaloricen las potencialidades y aportes del CI y la GC.

Como trabajos futuros se recomienda hacer una revisión más exhaustiva en cuanto a la participación como agentes de cambio de la GC y CI en cualquier modelo o marco de Gestión de TI.

\section{REFERENCIAS BIBLIOGRÁFICAS}

Abd Rahman, H., Mustaffa, M., Zubaidah, Z. \& Roslani, E. (2015). The Level of Knowledge of Corporate Governance in Federal Statutory Bodies in Malaysia, 7th International conference on financial criminology 2015 13-14 April 2015, Wadham College, Oxford, United Kingdom.

Akpinar, A. T. \& Akdemir, A. (1999). Intellectual capital, in third European Conference, 332-340. Recuperado de: http://joanes.opf.slu.cz/vvr/akce/turecko/pdf/Akpinar.pdf

Alavi, M. \& Leidner, D. (2001). Review. Knowledge management and knowledge management systems: conceptual foundations and research issues, MIS Quarterly, 25(1), 107136. Recuperado de: https://doi.org/10.2307/3250961

Amrizah, K. \& Rashidah, A. (2013). Intellectual Capital Profiles: Empirical Evidence of Malaysian Companies Kamaluddin \& Rahman. International Review of Business Research Papers, 9(6), 83-101. Recuperado de: http://irbrp. $\mathrm{com} /$ static/documents/November/2013/6

Anantatmula, V. \& Kanungo, S. (2006). Structuring the underlying relations among the knowledge management outcomes. Journal of Knowledge Management, 10(4), 25-42. Recuperado de: https://doi. org/10.1108/13673270610679345

Arteche, R. (2011). Retos y alternativas de la gestión del conocimiento (GC) como propuesta para la colaboración en organizaciones inteligentes. Educar, 47(1), 121-138.

Atefeh, S., McCamble, L., Moorchead, C. \& Gitters, S. (1999). Knowledge management: the new challenge for the 21 century. Journal of Knowledge Management, 3(3), 172-179. Recuperado de: https://doi. org/10.1108/13673279910288572

Baptista, M., Annansingh, F., Eaglestone, B. \& Wakefield, R. (2006). Knowledge management issues in knowledge-intensive SMEs. Journal of Documentation, 62 (1), 101-119. Recuperado de: https://doi. org/10.1108/00220410610642075

Barney, J. B. (1991). Firm Resource and Sustained Competitive Advantage. Journal of management, 17(1), 99-120. Recuperado de: https://doi.org/10.1177/014920639101700108

Beimborn, D., Franke, J., \& Weitzel, T. (2009). Proposing a theoretical model for IT governance an IT business alignment. 42nd Hawaii International Conference on System Sciences, Big Island, HI, USA.

Bin-Abbas, H. \& Bakry, S. (2014). Assessment of IT governance in organizations: A simple integrated approach. Computers in Human Behavior 32, 261-267. Recuperado de: https://doi.org/10.1016/j.chb.2013.12.019

Bontis, N. (1999). Managing Organizational Knowledge by Diagnosing Intellectual Capital: Framing andadvancing the state of the field. International Journal of Technology Management, 18 (5,6,7,8), 433-463. Recuperado de: https://doi. org/10.1504/IJTM.1999.002780

Bontis, N., Keow,W. \& Richardson, S. (2000). Intellectual capital and business performance in Malaysian industries. Journal of Intellectual Capital, 1 (1), 85 - 100. Recuperado de: https://doi.org/10.1108/14691930010324188

Calder-Moir, (2013). It Governance Framework. The IT Governance \& ISO38500. Recuperado de: http://www. itgovernance.co.uk/download/Calder-Moir-v2.pdf

Chen, M., Cheng, S. \& Hwang, Y. (2005). An empirical investigation of the relationship between intellectual capital and firms' market value and financial performance. Journal of Intellectual Capital, 6(2), 159-176. Recuperado de: https://doi.org/10.1108/14691930510592771

Chen, Y., Wang, Y., Nevo, S., Jin, J. F., Wang, L., \& Chow, 
W. S. (2014). IT capability and organizational performance: the roles of business process agility and environmental factors. European Journal of Information Systems, 23, 326342. Recuperado de: https://doi.org/10.1057/ejis.2013.4

COBIT 5, (2012). Framework "COBIT" 5: Enabling Processes” ISACA. Rolling Meadows, USA.

CiGRAS (2014) Como aporta COBIT 5 y gobernanza de TI a la gobernanza empresarial. V Congreso Internacional sobre Gobierno, Riesgos, Auditoria y Seguridad de la Información. ISACA. Capitulo Montevideo. Recuperado de: https://m.isaca.org/chapters8/Montevideo/cigras/Documents/CIGRAS2014-COBIT\%20y\%20Gobernanza\%20 de\%20TI.pdf

COBIT 5-marco, (2013). Un Marco de Negocio para el Gobierno y la Gestión de las TI de la Empresa. ISACA-Framework. Recuperado de: https://articulosit.files.wordpress. com/2013/07/cobit5-framework-spanish.pdf

COSO (2013). Committee of Sponsoring Organizations of the Treadway Commission. Control Interno - Marco Integrado. Resumen Ejecutivo. Traducido al español. Instituto de Auditores Internos de España. Recuperado de: http:// doc.contraloria.gob.pe/Control-Interno/Normativa_Asociada/coso_2013-resumen-ejecutivo.pdf

Darroch, J. (2003). Developing a measure of knowledge management behaviors and practices. Journal of knowledge management, 7(5), 41-54. Recuperado de: https://doi. org/10.1108/13673270310505377

De Long, D. (1997). Building the knowledge-based organization: How culture drives knowledge behaviors. Center for Bussines Innovation, Ernst \& Young: LLP.

Fink, D., Huegle, T. y Dortschy, M. A (2006). Model of Information Security Governance for E-Business. Idea Group Publishing. Recuperado de: https://doi.org/10.4018/978-159140-911-3.ch001

Fitz-Enz, J. (2009). The ROI of Human Capital, American Management Association. N. Y., USA.

Gogana, L., Durana. D. \& Draghici, A. (2014). Structural capital - A proposed measurement model, 2nd Global Conference on Business economics, management and tourist, 30-31 October, 2014, Prague, Czech Republic.

Haji, A. \& Ghazali, N. (2013). A longitudinal examination of intellectual capital disclosures and corporate governance attributes in Malaysia. Asian Review of Accounting, 21 (1), 27 - 52. Recuperado de: https://doi. org/10.1108/13217341311316931

Huang, S.-M., Shen, W.-C., Yen, D. \& Chou, L.-Y. (2011). IT governance: Objectives and assurances in internet banking. Advances in Accounting, incorporating Advances in International Accounting 27, 406-414. Recuperado de: https://doi.org/10.1016/j.adiac.2011.08.001

IADE-CIC (2003). Modelo Intellectus: medición y gestión del capital intelectual. Documentos Intelectos, Madrid.

ISACA (2014). COBIT 5. Niveles de Capacidad. Desafío de Formalización de procesos costo y beneficios. Cigras,
Capítulo Montevideo. Crowe Horwath. Recuperado de: http://www.isaca.org/chapters8/Montevideo/cigras/Documents/Cigras_2014_COBIT\%205\%20-\%20Niveles\%20 de\%20Capacidad.pdf

Jameelah. M., Osmanb. I., Musa., S (2015). Effect of Intellectual Capital on Organizational Performance, 2nd Global Conference on Business and Social Science-2015, GCBSS-2015, 17-18 September 2015, Bali, Indonesia.

Kaplan R. \& Norton P., (1992). The Balanced Scorecard -Measures that Drive Performance, Harvard Business Review. PMid:10119714

Knapp, E.M. (1998). Knowledge Management. Business and Economic Review, 44(4), 3-7. Recuperado de: https:// goo.gl/zCW6hp

Mahfoudh. A. \& Izah., N. (2012). "Intellectual Capital Performance and Board Characteristics of GCC Banks". Procedia Economics and Finance, 2, 219-226. Recuperado de: https://doi.org/10.1016/S2212-5671(12)00082-2

Marco-Empresarial (2012). Un marco empresarial completo. Recuperado de: www.isaca.org/cobit

Marulanda, C. E., Giraldo, J. A., y López, M. (2013). Evaluación de la gestión del conocimiento en las organizaciones de la red de tecnologías de información y comunicaciones del eje cafetero en Colombia, Inf. tecnol., 24 (4), 23-24. Recuperado de: https://doi.org/10.4067/S071807642013000400012

Nonaka, I. \& Takeuchi, H. (1995). The knowledge-creating company: How Japanese companies create the dynamics of innovation. New York: Oxford University Press.

OCDE, (2004). Principios de Gobierno Corporativo de la OCDE (Organización para la cooperación y el desarrollo económico). (Traduccción). Recuperado de: Palao, M. (2010). Reflexión sobre el Estado del Arte del Buen Gobierno TIC. Bogotá: ISACA. Recuperado de: https://doi. org/10.1787/9788485482726-es

Peterson, R. (2003). Integration Strategies and Tactics for Information Technology Governance. Strategies for Information Technology Governance. Hershey, PA: Idea Group Publishing.

Pham, T. (2005). An empirical study of knowledge transfer within Vietnam's information technology companies. Recuperado de: https://pdfs.semanticscholar.org/e08d/da9cb0559133a04f7339c1dc7cab43a903d4.pdf

Probst, G., Raub, S. \& Romhardt, K. (2000). Managing Knowledge: Building Blocks for Success, New York: John Wiley \& Sons.

Robbin, S. P. (2004). Organizational behavior (11th ed). Upper Saddle River, NJ: Prentice-Hall.

Rodríguez, J., Aguilar, M. y Raudales, N. (2017). Una mirada breve al software para la Gestión del Conocimiento. RIDTEC, 13(1).

Sadalia, I. y Nurbaity, A. (2015). Discriminant Analysis of Intellectual Capital Model of State University in Medan, 2nd Global Conference on Business and Social Science-2015, 
Capital Intelectual, Gestión del Conocimiento en la Interacción Gobierno y Gestión de la Tecnologías de la Información desde Perspectiva COBIT 5

GCBSS-2015, 17-18 September 2015, Bali, Indonesia

Sayyed, M. A., Sayyed. M. Z. \& Sayyed. M. R, (2011). Examining the Impact of KM Enablers on Knowledge Management Processes. Procedia Computer Science, 3, 1211-1223. Recuperado de: https://doi.org/10.1016/j. procs.2010.12.196

Spender, J. C. (1996). Organizational Knowledge, learning and memory: three concepts in search of a theory. Journal of organizational change management 9(1), 63- 78. Recuperado de: https://doi.org/10.1108/09534819610156813

Steward, T. A. (1998). La nueva riqueza de las organizaciones: el capital intelectual, Chile: Granica.

Tallon, P., Ramírez, R. \& Short, J. (2013). The Information Artifact in IT Governance: Toward a Theory of Information Governance. Journal of Management Information Systems 30(3), 41-177. Recuperado de: https://doi.org/10.2753/MIS0742-1222300306

Tarí, J. y García, M. (2009). Dimensiones en la gestión del conocimiento y de la gestión de la calidad: Una revisión de la literatura. Investigaciones Europeas de Dirección y Economía de la Empresa, 15 (3), 135-148. Recuperado de: https://doi.org/10.1016/S1135-2523(12)60105-1

Tarí, J. y García, M. (2013). ¿Puede la gestión del conocimiento influir en los resultados empresariales? Cuadernos de Gestión, 13 (1) 151-176. Universidad del País Vasco/Euskal Herriko Unibertsitatea Vizcaya, España

Teece, D. J., (2000). Strategies for managing knowledge assets: the role of firmstructure and industrial context. Long Range Plann., 33, 35-54. Recuperado de:

https://doi.org/10.1016/S0024-6301(99)00117-X

TIC-CRUE (2016). Gobierno de las tecnologías de la información en universidades. Conferencia de rectores de las universidades españolas. Recuperado de: http://tic.crue.org/ wp-content/uploads/2016/04/FolletoGobiernoTI.pdf

Todericiu, R. \& Serban. A (2015). Intellectual Capital and its Relationship with Universities, 22nd International Economic Conference - IECS 2015. "Economic Prospects in the Context of Growing Global and Regional Interdependencies".

Toomey, M. (2009). A Framework for Governance and Management of IT. The infonomics Letter, mayo.

Trimurni. L. \& Erlinac, S. (2015). The Effect of Social Capital on Governance and Sustainable Livelihood of Coastal City Community Medan, 2nd Global Conference on Business and Social Science-2015, GCBSS-2015, 17-18 September 2015, Bali, Indonesia.

Vidovic, M. (2010). The link between the quality of knowledge management and financial performance - The case of Croatia.

Villegas, E., Hernández, M. y Salazar, B. (2015). La medición del capital intelectual y su impacto en el rendimiento financiero en empresas del sector industrial en México. Contaduría y Administración, 62, 184-206. Recuperado de: https://doi.org/10.1016/j.cya.2016.10.002
Wiig, K. M. (1997). Knowledge Management: An Introduction and Perspective. Journal of Knowledge Management, 1(1), 6-14. Recuperado de: https://doi. org/10.1108/13673279710800682 


\title{
Blog, Correo Electrónico y Foros Temáticos: Su Uso, Dominio y Actitud en Estudiantes de Educación Medio Superior de México
}

\author{
Blog, Email and Thematic Forums: Its Use, Mastery and Attitude in \\ Mexico's Higher Education Students \\ Joanna Koral Chávez López ${ }^{1}$ \\ Marcela Patricia del Toro Valencia ${ }^{2}$ \\ Olga López Pérez ${ }^{3}$ \\ Universidad Michoacana de San Nicolás de Hidalgo, México
}

Recibido: 10-09-2017 Aceptado: $17-12-2017$

\section{Cita Recomendada}

Chávez, J., Del Toro, M. y López, O. (2017) Blog, correo electrónico y foros temáticos: Su uso, dominio y actitud en estudiantes de educación medio superior de México. Hamut'ay, 4 (2), 45-54. Recuperado de: http://dx.doi.org/10.21503/hamu.v4i2.1471

\section{RESUMEN}

Los cambios ocasionados por la irrupción de la tecnología en el campo educativo desde el nivel básico hasta el nivel superior ha influenciado a que las instituciones que imparten enseñanza integren las tecnologías a este contexto como estrategias al proceso de aprendizaje y en mejoras de este, por lo que en este estudio el objetivo fue conocer cuál es la actitud, el uso y el dominio de las TIC en estudiantes, relacionado al uso de blogs, correo electrónico y foros temáticos, por lo que se utilizó un diseño no experimental, transversal con alcance descriptivo-correlacional, planteándose como hipótesis general que existe relación entre las variables actitud, uso y dominio hacia las TIC en estudiantes de nivel medio superior y tres hipótesis específicas derivadas de ésta. Para la recolección de datos se aplicó el Cuestionario sobre la Actitud, Uso y Dominio de las Tecnologías de Información y Comunicación adaptado al castellano, con una confiabilidad de $\alpha=.98$, a una muestra de 3790 estudiantes de nivel medio superior, con edades entre 14 a 20 ańos. El contraste de las hipótesis propuestas arrojó una correlación positiva entre el uso del blog, el correo electrónico, el foro temático y el dominio de estas herramientas, siendo los varones los que mejor usan las TIC, no encontrándose diferencias en la variable actitud hacia las TIC.

Palabras Clave: Actitud a las tecnologías, Sociedad de la Información, Educación y Tecnologías de Información y Comunicación.

\section{Abstract}

Emerging technologies have caused changes in the educational field, from elementary to higher level. They have influenced educational institutions, which have incorporated these technologies

1 Ingeniero en Sistemas Computacionales, Maestro en Educación; E-mail:joanna.koral.ch@gmail.com

2 Licenciada en Psicología; E-mail: didactica.marcelad@gmail.com

3 Licenciada en Psicología; E-mail: olga.lp.umsnh@gmail.com 
Blog, Correo Electrónico y Foros Temáticos: Su Uso, Dominio y Actitud en Estudiantes de Educación Medio Superior de México

into their setting as strategies for the learning process and its improvement. Then the objective of this study was to know what is the attitude, use and mastery of ICTs in students, in relation to the use of blogs, email and thematic forums. We used a non-experimental, cross-sectional design with a descriptive-correlational scope.

The general hypothesis states that there is a relationship among the variables: attitude, use and mastery of ICTs in students from higher level. Another three specific hypotheses were derived out of it. To collect data,we applied the Questionnaire on Attitude, Use and Mastery of Information and Communication Technologies, which was adapted to Spanish. We had a reliability of $\alpha=.98$, in a sample of 3790 students from higher level, aged $14-20$.

The contrast of the proposed hypotheses showed a positive correlation between the use of the blog, email, the thematic forum and the mastery of these tools, being the men the ones that best use the ICTs, finding no differences in the attitude variable towards the ICTs.

Keywords: Attitude towards technologies, Information Society, Education and Information and Communication Technologies.

\section{INTRODUCCIÓN}

Los cambios sociales reconocidos por la incorporación de las Tecnologías de la Información y la Comunicación (TIC) son un tema central en el marco de las preocupaciones educativas, las cuales han tenido que ser incluidas en el quehacer educativo. Desde esta perspectiva, la Universidad Nacional Autónoma de México (UNAM), norma en su Plan de Desarrollo Institucional 2015-2019 (Graue, 2017), que el mejoramiento del entorno educativo debe tener como programas estratégicos el acceso, uso, aplicación y desarrollo de las TIC, haciendo que estas impacten en todos los ámbitos académicos en la UNAM y que permita el desarrollar habilidades en TIC en la comunidad universitaria. Sumado a ello, lo estipulado en la Constitución Política de los Estados Unidos Mexicanos relacionado al Derecho de Acceso y Uso de las Tecnologías de la Información y la Comunicación (INEHRM, 2015) enfatiza que la integración de las TIC al país auxilia a mejorar la calidad de la educación, a adquirir y difundir información por estos medios digitales y el tener el acceso universal a la cultura y educación; esta situación se ratifica la UNESCO (2017) al afirmar que la integración de las TIC a la educación favorece el acceso, propicia igualdad de prácticas de instrucción y efectiviza la gestión administra- tiva y académica. Teniendo en cuenta estos referentes se realizó el presente estudio, teniendo como objetivo el conocer cuál es la actitud, el uso y el dominio de TIC en estudiantes, relacionado al uso de blogs, correo electrónico, foros temáticos y bibliotecas virtuales, si estos favorecen la incorporación de estrategias y la transformación de la práctica educativa, a partir del uso de las tecnologías como herramientas de adquisición de información y elaboración de conocimientos. Lo cual hace posible colocar las TIC como medios de apoyo para la construcción de conocimiento y no solo como medios de acceso a la información y/o comunicación, aspecto al que se dirige este trabajo, pero haciendo énfasis en el contexto mexicano, el nivel medio superior de educación formal, y el sistema de educación pública.

\section{La Educación y las Tecnologías de la Informa- ción y la Comunicación en México}

La educación ha estado cambiando a través de los años. Es por ello que las instituciones educativas han tenido que reformular sus planes de estudios, al mismo tiempo que se han visto en la necesidad de formar, actualizar y evaluar el quehacer docente. Así, las instituciones educativas han asumido la responsabilidad de implementar estrategias que permitan innovar las prácticas educativas. Ade- 
más de generar mecanismos de gestión sobre la adquisición de equipos tecnológicos y desarrollo de infraestructura, cada institución considera cómo implementar las TIC en la práctica de enseñanza y aprendizaje.

En este sentido, el gobierno federal mexicano elaboró el Programa Sectorial de Educación (PSE), del cual se derivarán programas regionales e institucionales que determinan las prioridades nacionales, al mismo tiempo que orientan las políticas públicas de los diversos sectores. El PSE, publicado en el Diario Oficial de la Federación (DOF, 2013) establece cinco metas y tres estrategias pensadas en el logro de la meta nacional, enfocadas a conseguir un México con Educación de Calidad, lo cual se resume en su capítulo I de diagnóstico, mencionando que:

Para participar en la sociedad del conocimiento es necesario el acceso a información actualizada y oportuna. Pero ello no es suficiente. Se requiere de una cultura de aprecio y uso del conocimiento que permita discernir y valorar, formar para la ciudadanía y la solidaridad. Esta cultura se gesta desde la educación básica, se profundiza en la educación media superior y debe ser alentada en los estudios superiores. Exige reforzar las capacidades de comprensión lectora, expresión escrita y verbal, razonamiento analítico y crítico, creatividad y, de manera destacada, la capacidad para aprender a aprender (DOF, 2013, p2).

En México se localizan propuestas que priorizan las TIC en cada uno de los niveles que componen el Sistema Educativo Mexicano y que se exponen en la tabla 1. Uno de los proyectos iniciales es el caso del proyecto "Computación Electrónica en la Educación Básica”, éste data de 1985 y se focalizó a la educación primaria y secundaria (SEP, 1987). Fue hasta el Programa Nacional de Educación 2001-2006, que se estableció la necesidad y demanda de reformar el plan de educación de la educación media superior, con la intención de formar sujetos capaces de incorporarse y aportar a la sociedad de la comunicación, al desarrollo social y económico del país, lo cual se considera posible a partir de introducir enfoques educativos centrados en el aprendizaje y el uso de las TIC (SEP, 2001).

\section{Tabla 1}

Sistema Educativo Mexicano (SEM)

\begin{tabular}{lll}
\hline Modalidades & \multicolumn{1}{c}{ Tipo Educativo } & \multicolumn{1}{c}{ Nivel } \\
\hline Escolarizado & Educación Básica & - Preescolar \\
& & - Primaria \\
& & - Secundaria \\
\cline { 2 - 3 } & Educación Media & - Profesional Técnico \\
& Superior & - Bachillerato General \\
& & - Bachillerato Técnico \\
\cline { 2 - 3 } & Educación Superior & - Técnico superior \\
& & - Licenciatura Normal \\
& & - Licenciatura Universi- \\
& & taria \\
& & Posgrado \\
\hline No escolarizada & Capacitación & \\
& Inicial, especial, para adultos, semiescolarizada \\
\hline
\end{tabular}

Fuente: Secretaría de Educación Pública (SEP, 2001)

El blog, el correo electrónico y los foros como TIC en la Educación

Hoy en día el proceso de comunicación virtual ha desplazado a la comunicación tradicional, porque lo que es de suma importancia hablar de las herramientas de comunicación virtual de las cuales se ha tenido que estudiar, aprender y emplear en diversos contextos y sobre todo en el uso como estrategia de aprendizaje en el aula.

Se reconoce que existen diversos usos de las TIC, tales como son: para comunicarse, para entretenimiento, para acceder a contenidos audiovisuales $\mathrm{u}$ otros materiales. En México, a pesar de que la tecnología no presenta un precio monetario de fácil adquisición, en los últimos años, especialmente en el 2016, se observó un incremento del 2.1\% en el uso de la tecnología con respecto al 2015. Así, el $65.1 \%$ de la población, utilizan teléfonos inteligentes y dentro de los cuales, el 81\% cuentan con una conexión móvil (ADI, 2017; Alonso, 2017).

La Organización para la Cooperación y el Desarrollo Económico (OCDE), resalta la necesidad de disminuir toda brecha digital (Alonso, 2017). Dicha demanda se sustenta en los planteamientos de la Unión Internacional de Telecomunicaciones (UIT) y en su análisis sobre la economía Latinoa- 
Blog, Correo Electrónico y Foros Temáticos: Su Uso, Dominio y Actitud en Estudiantes de Educación Medio Superior de México

mérica y el Caribe debido a que debería haber una estrecha relación con la tecnología, a pesar, que según Charles director de la incubadora Wayra, expresó que en México se registró un avance en la adopción y uso de las tecnologías de información; no obstante, resalta que existe una brecha digital sobre las formas de uso productivo y no productivo de las TIC (López, 2015), por lo que actualmente, uno de los retos del estudio de diversas disciplinas, corresponde al interés de estudiar la brecha digital. Brecha que radica en identificar cómo usar las TIC, no sólo en contextos de entretenimiento, sino en usarlas como herramientas o estrategias de apoyo en contextos educativos y profesionales. Díaz - Barriga (2013) resalta que las TIC son parte del sistema de pensamiento y de acceso a la información de los jóvenes y estos son más proclives a experimentar estos cambios constantes que se experimenta en estas tecnologías, por lo que hace énfasis en que los docentes no solo a nivel personal sino a nivel profesional debe emplear como recursos los medios informáticos que tiene a su alcance como los foros, blog, el correo electrónico, programas libres y la Web en general; asimismo Yanacón y Costaguta (2013, citado en Larreal, 2015) refieren que en el caso del blog, el foro y el correo electrónico, estos ambientes permiten a los estudiantes el participar de manera reflexiva ya que cuentan con el tiempo y espacio para hacerlo, por estar listos a ser utilizados; y de modo síncrono el chat y las videoconferencias, entre otros cuyas características permiten que las personas participan al mismo tiempo, sin importar el lugar donde se encuentren, sea de manera presencial o virtual.

En el caso del blog, herramienta de comunicación virtual usado con frecuencia en la educación, para Gálvez (2010, citado en Larreal, 2015), es una

página web en la que se puede integrar texto, imágenes, hipervínculos, vídeos y muchos otros objetos, permitiendo que los usuarios pueden hacer labor de autores o escritores, puesto que mediante esta herramienta se puede contener mensajes de una $o$ varias personas respecto a un tema específico y quienes lean el blog pueden participar mediante sus aportaciones o cuestionamientos, promoviendo la reflexión individual y colectiva (Larreal, p. 723).

Por su parte Noel (2015) resalta que los blogs son plataformas valiosas para el aprendizaje constructivista y se pueden adaptar para apoyar una amplia gama de conceptos educativos, al permitir que los estudiantes puedan mostrar fácilmente sus pensamientos y puntos de vista en línea; asimismo indica que los blog tienen un impacto positivo en el aprendizaje al apoyar las actividades educativas constructivistas de manera cognitiva y de interacción social, donde pueden tomar decisiones respecto al contenido, la comunicación y la privacidad, además les permiten construir su propio conocimiento creando de forma independiente un registro de su aprendizaje en el momento y espacio de lo que ellos dispongan. Para Cuenca (2015) el foro aporta a los estudiantes una relación constructivista a través de la vinculación que se da entre los conocimientos previos y los nuevos conocimientos que se van adquiriendo a través de la reflexión y de la participación en conjunto; esto debido a que el docente la aplica como estrategia de enseñanza antes, durante o después de brindar un contenido temático el cual tiene una valoración muy útil para el seguimiento de cursos en educación superior, resaltando en los resultados de su estudio que el 100\% de los estudiantes acepto que el foro es una estrategia didáctica, que a su vez les permite un autoaprendizaje en contenidos específicos.

Otra de las herramientas usada con mayor frecuencia, corresponde al correo electrónico, considerado un canal ágil de comunicación, por lo que los mensajes escritos deben tener una estructura de la lengua escrita, es decir, un inicio, desarrollo y fin, deben de carecer de coloquialismo y contener un tono neutro y formal de acuerdo a la relación entre el que lo envía y el que lo recibe (Escofet y Rodríguez, 2013). Debido a la sencillez, facilidad, seguridad y gratuidad del correo electrónico, este se ha incluido como otra estrategia para el proceso de enseñanza aprendizaje, como también lo describe en su estudio Blasco (2010) al utilizar éste como herramienta de enseñanza aprendizaje en la Universidad de Hong Kong, incluida como parte de las 9 sesiones de aprendizaje relacionado a Lengua y cultura, destacando los estudiantes lo positivo en mayor porcentaje al permitir realizar 
intercambio con estudiantes de otras latitudes, a través de este medio fortaleciendo la temática asignada por el docente. En esta misma línea Puerta y Sánchez (2010) refieren que el correo electrónico es un medio de comunicación asincrónico, personal y que a través de la transmisión de texto brinda la posibilidad de dar un mensaje especifico complementándolo con adjuntar archivos, además permite fortalecer la conexión entre escritura y pensamiento, hace que el estudiante analice más lo que quiere expresar, al dirigirse al otro desde un uso del lenguaje con reglas de cortesía inherentes al escenario educativo.

En el caso del Foro, es definido como un espacio compartido, virtual o físico, en el que se reúnen varias personas para intercambiar y reunir ideas y experiencias sobre uno o diversos temas. Así, para participar en un foro no es necesario tener muchos conocimientos teóricos ya que consiste en el intercambio de ideas o mensajes cuyo objetivo es que todos los participantes amplíen sus conocimientos del tema. Algunos son moderados bajo criterios propios, pero muchos otros son abiertos. Según Carrasco et al. (2017) el foro brinda la construcción de conocimientos colaborativo, así como favorece un aprendizaje consiente, autónomo e interactivo, permitiendo al estudiante elaborar nuevos saberes basados en sus interpretaciones, experiencias e interacciones con sus pares, en la propuesta de ideas conjuntas que generan conocimiento a través del debate y discusión.

Derivado de lo anterior, y en vías de obtener más información que apoye los procesos de enseñanza y aprendizaje, es que la hipótesis general es que existe relación entre las variables actitud, uso y dominio hacia las TIC en estudiantes de nivel medio superior.

\section{Materiales y Método}

\section{Tipo y Diseño}

El estudio buscó conocer el nivel de la actitud que los estudiantes del nivel medio superior tienen respecto a las TIC en el uso y dominio del blog, el correo electrónico, foros temáticos y bibliotecas virtuales; se desarrolló con un enfoque cuantitativo, con un diseño no experimental, transversal y con alcance descriptivo-correlacional. Los datos se recogieron con una escala de medición numérica, para analizarlos mediante estadística descriptiva e inferencial.

\section{Participantes}

La población con la que se realizó la investigación, estuvo conformada por 3790 estudiantes de nivel medio superior, fase propedéutica, siendo está la que los prepara para poder continuar estudios de nivel licenciatura en áreas específicas de conocimiento disciplinar, quienes estuvieron inscritos y distribuidos en cinco preparatorias adscritas a la Universidad Michoacana de San Nicolás de Hidalgo (UMSNH) de la ciudad de Morelia, Michoacán, México.

La muestra fue de tipo no probabilística, conformada por el total de estudiantes (3790) de nivel medio superior; el rango de edad fue de 14 a 20 años, en ambos géneros.

La distribución de la población con base en áreas de conocimiento, correspondió al 20.9\% (794) cursando el tronco común, en el cual se proporciona una formación integral básica, el 10.4\% (395) pertenecían a Ciencias Económico-Administrativas, en este sentido el 20.1\% (760) cursan Ciencias Histórico-Social, en el área de Ciencias de Químico-Biológicas fueron el 35.3\% (1337) y a la carrera de Ingeniería y Arquitectura, con el $13.3 \%$ (504) del total de los estudiantes.

\section{Instrumento}

Se utilizó el Cuestionario sobre la Actitud, Uso y Dominio de las Tecnologías de Información y comunicación de adaptación al castellano realizada por Orantes (2009), con un índice de consistencia interna $\alpha=.98$. El instrumento evalúa la Actitud, Uso y Dominio que poseen los estudiantes respecto a las herramientas básicas de las TIC en el proceso de enseñanza y aprendizaje. Está conformado por 44 reactivos con escala tipo Likert con cinco opciones de respuesta para cada 
Blog, Correo Electrónico y Foros Temáticos: Su Uso, Dominio y Actitud en Estudiantes de Educación Medio Superior de México

dimensión. El instrumento se ha utilizado para explorar las actitudes que pueden presentar los estudiantes hacia las TIC, el nivel de dominio sobre ellas y la frecuencia con la que las usan en su desarrollo académico. Está dividido en dos partes; la primera es una introducción a la encuesta en la que se le expone al participante las características del instrumento y recoge información sociodemográfica: sexo, edad, bachillerato, si tiene computadora en casa y si tienen servicio de internet en la misma; la segunda parte explica las instrucciones para responder los ítems tipo Likert, con cinco opciones de respuesta. Para el caso de las actitudes (percepción que tienen los estudiantes sobre el uso de las TIC), las opciones van desde: 1) Completamente en desacuerdo, al 5) Completamente de acuerdo; para el uso (uso las diferentes TIC para el enriquecimiento del aprendizaje y formación académica), desde: 1) Nunca la uso, hasta 5) Siempre la uso y, para el dominio (experiencia que tiene sobre el uso y funcionamiento de las TIC), del 1) No capacitado, hasta el 5) Altamente capacitado. La segunda parte está compuesta por los 44 ítems que evalúan las tres variables y que presento un alfa de cronbach de .916 y dichos ítems fueron distribuidos del 1 al 5 para las actitudes hacia las TIC, presentando en la muestra un alfa de Cronbach de .739, del 16 al 30 uso de las TIC con un alfa de Cronbach de .874 y del 31 al 44 el dominio de las TIC con un valor de .906 en alfa de Cronbach.

\section{Procedimiento}

El proceso de la investigación que da origen a los resultados presentados en este trabajo, se recuperó a partir de las siguientes etapas:

Primera Etapa: Búsqueda de información. Se localizó y recuperó información bibliográfica y antecedentes de las variables a medir, así como datos de encuestas que se realizan en México para conocer la situación del país respecto a las Tecnologías de Información y Comunicación. Dicha información se recopilo en bibliotecas virtuales, bases de datos, periódicos, Google académico y Web of Science, con el objetivo de tener un fundamento teórico de las variables a analizar y de una situación actual de las TIC.
Segunda Etapa: Elaboración de materiales. Posterior a la recopilación de información, se prepararon los cuestionarios a aplicar, así como los documentos de solicitud de participación que se entregaron a las escuelas para autorizar la colaboración en la investigación.

Tercera Etapa: Trabajo de Campo. Una vez que se autorizó la participación, se acudió a las escuelas para la recopilación de los datos. El procedimiento específico fue la presentación personal ante el profesor a cargo del grupo, presentación del oficio de autorización y la aplicación del cuestionario; a los estudiantes se les leyeron las instrucciones para contestar y se les solicitó responder. Esta fase duró tres meses.

Cuarta Etapa: Sistematización de los resultados. Se capacitó a las mismas personas que aplicaron el instrumento para la captura de los datos, se les envío un modelo de base de datos, en formato SPSS v21, en la que capturaron los datos compilados en los instrumentos que ellos mismos habían aplicado. Una vez capturados e integrados los datos se procesaron con el paquete SPSS.

\section{Resultados}

De los estudiantes que participaron el $47.8 \%$ (1812) de la población son hombres y el 52.2\% (1978) son mujeres, con una edad promedio de 16.9 ańos. El 79.7 \% cuentan con computadora en casa y el $20.3 \%$ no tiene computadora; del total de los estudiantes, el $80.1 \%$ disponen del servicio de Internet en casa y el $19.9 \%$ no cuentan con el servicio. Primeramente, se describen los resultados de la variable actitud, con la finalidad de tener una idea del comportamiento de esta variable. De los ítems que miden el uso y dominio solo se describirán los reactivos que evalúan respecto al blog, el correo electrónico y foros temáticos bibliotecas virtuales.

La figura 1 muestra los porcentajes para la variable actitud hacia las TIC, en la cual se puede observar la percepción que tienen los estudiantes de las preparatorias de la UMSNH sobre el uso de las TIC para su actividad académica. Se observa que el 38.8\% (1471) consideran tener una buena 


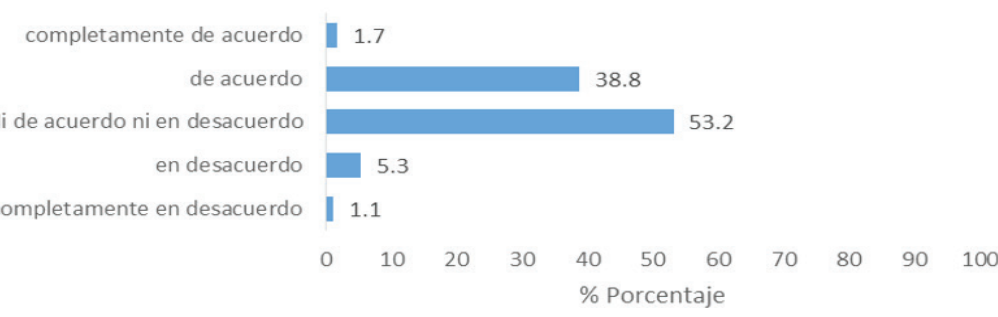

Figura 1 Actitud hacia las TIC.

Fuente: Elaboración propia.

actitud hacia las TIC para su formación académica, el 53.2\% (2016) muestran no estar ni de acuerdo ni en desacuerdo hacia las TIC, tal vez porque durante su formación no han podido trabajar o no han realizado actividades en las cuales interactúen con las TIC y, por otro lado, el 5.3\% (200) muestran estar en desacuerdo.

En la figura 2 se muestra los resultados para la pregunta: ¿Utilizo los foros temáticos para enriquecer mi aprendizaje? Como se puede observar, el 31\% (1174) de los estudiantes utilizan foros de manera normal; es decir, respecto a los temas que necesitan consultar, el 26.7\% (1012) lo usan muy poco y el $21 \%$ (795) lo utilizan regularmente. Es decir, que no todos los días o para todas sus actividades académicas lo consultan.

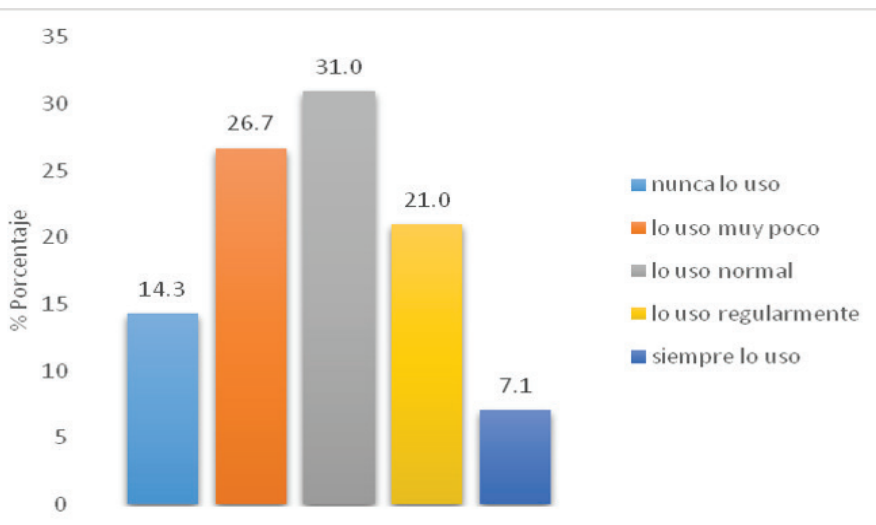

Figura 2. Uso de foros temáticos.

Fuente: Elaboración propia.

La figura 3 muestra los resultados para la pregunta: ¿Uso blogs para mi formación académica? El $25.1 \%$ (950) utiliza los blogs muy poco, el $28.7 \%$ (1086) lo utilizan normalmente para realizar sus actividades academicas y el $23.7 \%$ (900) lo utilizan regularmente todos los días.

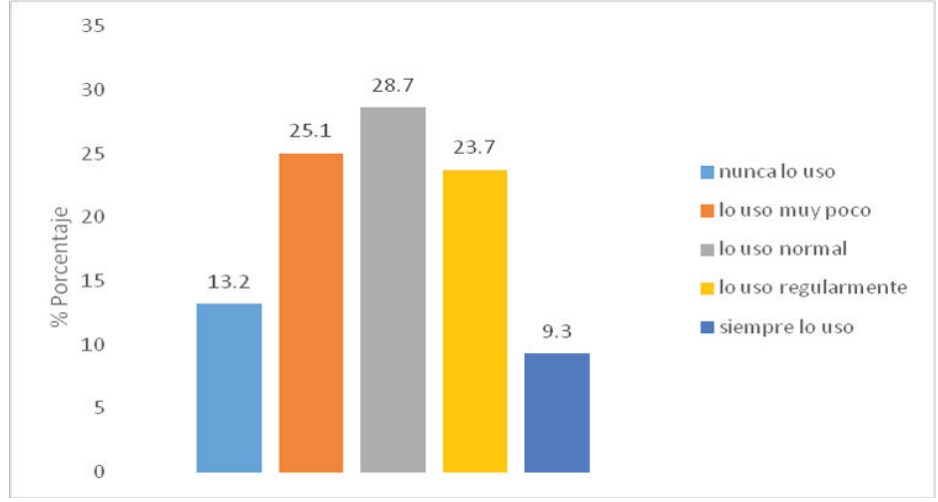

Figura 3 Uso de blogs.

Fuente: Elaboración propia.

En la figura 4 se muestran los resultados para la pregunta: ¿Uso el correo electrónico (e-mail) para fines académicos? Indican que según el 22\% (834) lo utilizan muy poco y el $27 \%$ (1022) lo usan normalmente y el $24.4 \%$ (923) lo emplean regularmente todos los días.

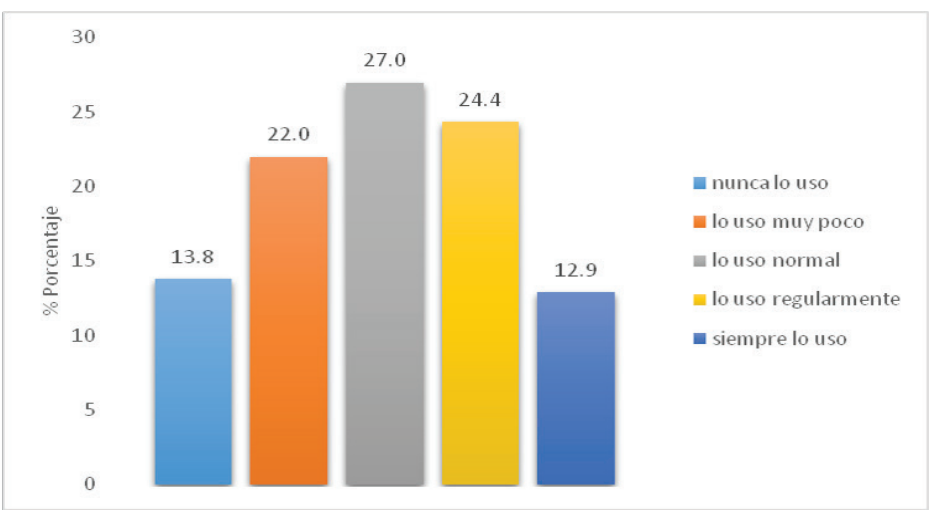

Figura 4 Uso de correo electrónico.

Fuente: Elaboración propia.

Para la pregunta ¿Tengo dominio en el manejo de los blogs?, el 30.4\% (1151) de los estudiantes refirieron estar poco capacitado en el dominio de blogs, lo que lleva a pensar que solo los consultan, pero no dominan su uso con la finalidad de aportar respecto a temas académicos; el 33.6\% (1275) opinaron sentirse capacitados en dichas herramientas y el 16.9\% (640) dijeron estar muy capacitados para utilizar los blogs, de acuerdo a la figura 5. 
Blog, Correo Electrónico y Foros Temáticos: Su Uso, Dominio y Actitud en Estudiantes de Educación Medio Superior de México

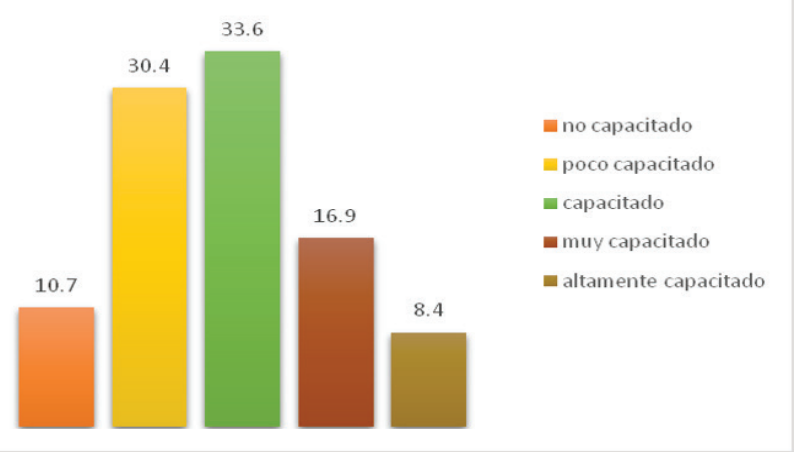

Figura 5 Dominio del blogs. Fuente: Elaboración propia.

Tomando en cuenta que la muestra no resulta de una distribución normal, el análisis inferencial para contrastar las hipótesis de investigación se realizó con la prueba de correlaciones de Spearman, bajo las siguientes hipótesis.

H1: Existe relación entre las variables actitud, uso y dominio hacia las TIC en estudiantes de nivel medio superior.

HO: No Existe relación entre las variables actitud, uso y dominio hacia las TIC en estudiantes de nivel medio superior.

Tabla 2

Correlaciones entre Actitud, Uso y Dominio

\begin{tabular}{lcc}
\cline { 2 - 3 } & Uso & Dominio \\
\hline Actitud & $.389^{\star *}$ & $.255^{*}$ \\
\hline Dominio & $.527^{\star *}$ & \\
\hline
\end{tabular}

Nota: ${ }^{*} \mathrm{p}<.01$

Fuente: Elaboración propia

En torno a la asociación entre las variables de estudio, tal y como se muestra en la tabla 2, existen correlaciones positivas entre Actitud hacia las TIC y Uso hacia las mismas; y esta a su vez se relaciona de manera positiva con Dominio la cual también presenta una correlación positiva con Actitud.

Para las siguientes hipótesis, los resultados se muestran en la tabla 3.

H1: Existe relación entre las variables uso y dominio del blog, correo electrónico y foros temáticos en estudiantes de nivel medio superior, que emplean como medios para desarrollar prácticas pedagógicas que favorezcan el aprendizaje.

HO: No Existe relación entre las variables uso y dominio del blog, correo electrónico y foros temáticos en estudiantes de nivel medio superior, que emplean como medios para desarrollar prácticas pedagógicas que favorezcan el aprendizaje.

\section{Tabla 3}

Correlaciones entre Uso y Dominio de blog, correo electrónico y foros temáticos.

\begin{tabular}{lllll}
\hline & Blog & $\begin{array}{c}\text { Correo } \\
\text { electrónico }\end{array}$ & $\begin{array}{c}\text { Foros } \\
\text { temáticos }\end{array}$ \\
\hline Uso & Blog & $.261^{* *}$ & & \\
\cline { 2 - 4 } & Correo electrónico & & $.167^{* *}$ & \\
\cline { 2 - 4 } & Foros temáticos & & $.319^{* *}$ \\
\hline
\end{tabular}

Nota: ${ }^{*} \mathrm{p}<.01$

Fuente: Elaboración propia

En torno a la asociación entre las variables de uso y dominio de blog, correo electrónico y foros temáticos, se puede ver en la tabla 3 que existen correlaciones positivas entre el uso del blog y el dominio del mismo, así mismo existe correlación positiva entre el uso de correo electrónico y su dominio; También se encontró asociación en la variable uso de los foros temáticos y el dominio de los mismos.

Para identificar la posible relación entre todas las variables se realizó un análisis comparativo con ANOVA. De manera particular, en relación al género, se identificaron diferencias en las variables uso y dominio. Como se puede observar en la tabla 4, los hombres tienen mejor uso de las TIC y también se muestra mayor dominio que las mujeres. No se encontraron diferencias respecto a la variable actitud hacia las TIC.

\section{Tabla 4}

Diferencias por género

\begin{tabular}{lcccccc}
\cline { 2 - 5 } & \multicolumn{2}{c}{ Mujeres } & \multicolumn{2}{c}{ Hombres } & & \\
\cline { 2 - 5 } & $\mathrm{N}$ & $\mathrm{M}$ & $\mathrm{N}$ & $\mathrm{M}$ & $\mathrm{F}$ & Sig. \\
\hline Actitud & 1978 & 48.77 & 1812 & 48.76 & .004 & .951 \\
\hline Uso & 1978 & 44.29 & 1812 & 44.97 & 4.79 & .029 \\
\hline Dominio & 1978 & 44.94 & 1812 & 47.10 & 37.34 & .000 \\
\hline
\end{tabular}

Fuente: Elaboración propia 


\section{Discusión y Resultados}

La construcción colaborativa de conocimientos en la integración de las TIC se ha hecho más urgente en el ámbito educativo, debido a que los estudiantes de estas generaciones tienen un acercamiento constante y se nutren de estos medios en su vida cotidiana, como se puede observar en este estudio, siendo el 38.8\% ( $n=1471)$ de los estudiantes refieren tener una buena actitud hacia las TIC para su formación académica, aspectos que coinciden con Díaz-Barriga, A. (2013) quien indica que las TIC en la educación es un proceso y diseño flexible centrados en el estudiante y que estos lo utilizan en su desempeño académico. Por su parte, Álvarez et al. (2016) enfatizan que las TIC como medios tecnológicos facilitan la comunicación y la información haciendo que los estudiantes las consideren un complemento en su proceso de enseñanza aprendizaje.

El acceso a la información que tienen los estudiantes de este siglo XXI ha permitido que, en estas últimas décadas, utilicen con mayor naturalidad las TIC en su quehacer pedagógico como medio de elaboración de conocimiento más que como medio de obtención de información, como se ha podido contrastar en este estudio, al utilizar los foros temáticos en un 31\% ( $\mathrm{n}=1174)$, el correo electrónico en un 27\% ( $\mathrm{n}=1022)$ y, en el caso de los blogs, en un 33.6\% ( $n=1275)$; lo anterior permite suponer que éstos estudiantes se sienten capacitados para utilizar esta herramienta, debido a la importancia que han tomado al actualizarse de manera autodidacta en el uso de las TIC, por lo que los responsables de la calidad educativa y los encargados del proceso enseñanza aprendizaje deben tener en cuenta lo mencionado por Monereo y Pozo (2001) al afirmar que la educación debe comprometerse a desarrollar en los estudiantes competencias que hagan referencia a la utilización de las computadoras (hardware, redes, software, instalación de programas, actividades básicas de mantenimiento, etc.), el uso de programas básicos (procesadores de textos, editor gráfico, hoja de cálculo y base de datos), el manejo de la Internet (navegadores, buscadores, correo electrónico, foros, etc.) y las actitudes necesarias (control del tiempo, actitudes críticas, ética en los usos, etc.), ya que su apropiada utilización for- talece las posibilidades de manejar y gestionar el conocimiento en este siglo XXI, donde tenemos al alcance una infinidad de información de acceso libre y gratuita en aras de seguir mejorando la calidad educativa, lo cual se vincula con el conocimiento como lo refiere Pérez (2012) al estar esté involucrado aceleradamente en el mundo, trabajar dentro y fuera de comunidades sociales, con el objetivo de relacionarse y conocer otras formas de actuar y aprender, dado que la calidad del aprendizaje depende de los contextos en el que se genera el conocimiento y la tecnología no está exenta de esta.

Asimismo, en este estudio se ha podido contrastar las hipótesis planteadas respecto a que existe una correlación positiva entre actitud y uso hacia las TIC y dominio de las mismas en los estudiantes del nivel medio superior de la muestra estudiada, con mayor énfasis en los hombres: como también se contrastó la asociación positiva en el uso y dominio del blog, correo electrónico y foros temáticos en esta misma muestra; criterios que se deben considerar como lo estipula Graue (2017) al proponer que las TIC impacten en todos sus ámbitos, incluyendo la forma como se enseña y en la que aprenden los estudiantes, para aprovechar el enorme potencial que tienen estas herramientas tecnológicas vinculándolas con la comunidad universitaria; asimismo se resalta lo indicado por Pozo y Monereo (2001), quienes exponen que los cambios que se originan en la educación, mantienen relevancia en el siglo XXI, a partir de reconocer cómo impactan en los docentes, los estudiantes y los contenidos, ubicando ello como relevante para establecer procesos de enseñanza y aprendizaje que se correspondan.

Si bien en este estudio se han presentado resultados desde la percepción de los estudiantes, a futuro sería relevante tener la opinión de los docentes involucrados en este nivel de estudio y como ellos están aplicando estas herramientas en su programación de aula. Asimismo, si ellos no tienen problema en el manejo de dichas tecnologías o desconocen como producirlas o manejarlas de manera óptima.

Otro aspecto a considerar es conocer si estos medios o recursos que brinda las TIC pueden ser 
Blog, Correo Electrónico y Foros Temáticos: Su Uso, Dominio y Actitud en Estudiantes de Educación Medio Superior de México

considerados por los docentes como parte de las estrategias didácticas dentro de la programación de sus sesiones.

\section{REFERENCIAS BIBLIOGRÁFICAS}

ADI (2017). Estudio sobre los Hábitos de los Usuarios de Internet en México 2017. Asociación de Internet. Recuperado de https://goo.gl/Rw1TLY

Alonso, R. (19 de marzo de 2017). ¿Cómo usamos los mexicanos la tecnología? El Economista. Recuperado de: http:// eleconomista.com.mx/tecnociencia/2017/03/19/como-usamos-mexicanos-tecnologia

Álvarez O., Martínez G., Rojas R., Olivos R. y García V. (2016). El uso de las Tecnologías de la Información y la Comunicación en el desarrollo académico de los alumnos universitarios: Caso Facultad de Enfermería y Obstetricia. Revista Dilemas Contemporáneos: Educación, Política y Valores. Recuperado de: http://ri.uaemex.mx/handle/20.500.11799/32638? show=full

Blasco, R. (2010). El uso del correo electrónico como herramienta de enseñanza aprendizaje. III Jornadas de Formación de profesores de ELE en China, suplemento SinoELE. Revista de Enseńanza de ELE a hablantes de Chino, 3, 1-21. Recuperado de: http://www.sinoele.org/images/Revista/3/ iiijornadasP_Rocio.pdf

Carrasco, P., Carrillo, M., Basley, K., Vergara, A. y Contreras, A. (2017). Foros virtuales y construcción de conocimiento en profesionales de la salud. Enfermería Universitaria, 14 (3), 184-190. Recuperado de: https://doi.org/10.1016/j. reu.2017.06.002

Cuenca, V. (2015). El foro virtual como estrategia de enseñanza en la educación superior. Revista Hamut'ay, 2 (1), 23-31. Recuperado de: https://doi.org/10.21503/hamu. v2i1.827

Díaz-Barriga, F. (2008). Educación y nuevas tecnologías de la información: ¿Hacia un paradigma educativo innovador? Sinéctica. Revista Electrónica de Educación, 30, 1-15. Recuperado de: https://sinectica.iteso.mx/index.php/SINECTICA/article/view/192

Díaz-Barriga, A. (2013). TIC en el trabajo del aula, impacto en la planeación didáctica. Revista Iberoamericana de Educación Superior, 10 (4), 3-21. Recuperado de:

https://ries.universia.net/article/download/105/163

DOF (2013). Programa Sectorial de Educación 2013-2018. Diario Oficial de la Federación. Recuperado de: http:// www.dof.gob.mx/nota_detalle.php?codigo $=5326569 \&$ fecha $=13 / 12 / 2013$

Escofet, R. y Rodríguez, I. (2013). Internet y competencias básicas: Aprender a comunicarse a través de Internet. Barcelona: Graó.

Graue, L. (2017). Plan de Desarrollo Institucional 2015-
2019. Universidad Nacional Autónoma de México. Recuperado de http://www.rector.unam.mx/doctos/PDI-20152019.pdf

INEHRM (2015). Derecho de acceso y uso de las Tecnologías de la Información y la Comunicación. Instituto Nacional de Estudios Históricos de las Revoluciones de México. Recuperado de: https://goo.gl/F3WkSM

Larreal, B. (2015). Herramientas de comunicación para el desarrollo de la inteligencia lógica matemática. Revista Opción, número especial 3, 715-734. Recuperado de: http:// www.redalyc.org/html/310/31045567037/

López, J. (6 de mayo del 2015). México, entre países que más escalan en uso de tecnología. El Financiero. Recuperado de: http://www.elfinanciero.com.mx/wef-cancun/mexicoentre-paises-que-mas-escalan-en-uso-de-tecnologia.html

Monereo, C. y Pozo, J. (coord.) (2001). Competencias para sobrevivir en el siglo XXI. Cuadernos de Pedagogía, 298 (tema del mes, enero).

Noel, L. (2015). Using blogs to create a constructivist learning environment. Procedia-Social and Behavioral Sciences, 174, 617-621. Recuperado de: https://doi.org/10.1016/j. sbspro.2015.01.591

Orantes, L. (2009). Actitudes, dominio y uso de las tecnologías de la información y la comunicación (TIC) de los docentes de las universidades privadas de El Salvador. Universidad Tecnológica del El Salvador. Recuperado de: http:// www.redicces.org.sv/jspui/bitstream/10972/260/1/56175. pdf

Pérez, G. (2012). Educarse en la era digital. Ediciones Morata. ISBN: 978-968-867-925-8

Pozo y Monereo (2001). El aprendizaje estratégico. Docencia Universitaria, 2. Recuperado de: https://goo.gl/dNGeMr Puerta, C. y Sánchez, A. (2010). El correo electrónico: herramienta que favorece la interacción en ambientes educativos virtuales. Revista Virtual Universidad Católica del Norte, 30, 1-27. Recuperado de: http://www.redalyc.org/articulo. oa?id=194214476003.

SEP (1987). Proyecto COEEBA-SEP: introducción de la computación electrónica en la educación básica de México, como apoyo didáctico y para la enseñanza de la computación. Revista Tecnología y Comunicación Educativas, 2 (6) p. 15-24.

SEP (2001). Informe de labores 2000-2001. Secretaria de Educación Pública. Primera Edición. México: SEP. ISBN 970-18-6212-0.

UNESCO (2017). Las TIC en la educación. Organización de las Naciones Unidas para la Educación, la Ciencia y la Cultura. Recuperado de: https://es.unesco.org/themes/ tic-educacion. 


\title{
Juegos online: una mirada desde el juego patológico
}

\section{Online games: a view from the pathological game}

\author{
Daniel Uchuypoma Canchumani ${ }^{1}$ \\ Universidad Alas Peruanas, Perú
}

Recibido: $15-08-2017$

Aceptado: 12-12 -2017

\section{Cita Recomendada}

Uchuypoma, D. (2017) Juegos online: una mirada desde el juego patológico. Hamut'ay, 4 (2), 55-64. Recuperado de: http://dx.doi.org/10.21503/hamu.v4i2.1472

\section{RESUMEN}

Se presenta una revisión bibliográfica de la adicción a los juegos online, desde la perspectiva de la psicología y psiquiatría, realizada entre los años 2011 y 2017 en países de la Unión Europea, Asia y Latinoamérica, en los cuales existe una mayor prevalencia en este tema, por lo que ha recibido la atención creciente por parte de los expertos en ludopatía, de los clínicos e investigadores de diversas disciplinas y partes del mundo.

Siendo el objetivo de este estudio el análisis documental para la caracterización de la adicción a los juegos online: juego patológico, jugador patológico, características del juego patológico y el juego online. El método utilizado fue una exploración de la revisión de la literatura de trabajos de investigación en esta línea, en base de datos, repositorios, bibliotecas virtuales y otras fuentes especializadas. Los resultados sugieren que es fundamental proponer acciones preventivas en jóvenes y adultos hacia los juegos online, así como concientizar a esta población acerca del riesgo de estos, ya que puede repercutir en problemas psicosomáticos, de salud y además asociarse a un gran número de complicaciones sociales, personales, laborales y familiares, al haberse observado que los individuos del género masculino y con un mayor nivel de estudios son más propensos al juego patológico.

Palabras Clave: Adicción, Juegos en línea, Internet, Trastorno por Juego en Internet.

\section{Abstract}

A bibliographic review of addiction to online games is presented, from the perspective of psychology and psychiatry. It was carried out from 2011 to 2017 in countries of the European Union, Asia and Latin America, where

there is a higher prevalence of this matter. Hence, it has received increasing attention from gambling experts, clinicians and researchers from various disciplines and parts of the world.

The objective of this study is the documentary analysis for the characterization of addiction to online games: pathological game, pathological player, characteristics of pathological game and online game. The method we used was an exploration of the literature review of research works on this topic, in databases, repositories, virtual libraries and other specialized sources. The results suggest

1 Licenciado en Psicología Humana por la Universidad Alas Peruanas, psicoterapeuta freelance. E-mail: daniel5770@hotmail.com 
that it is necessary to propose preventive actions on young people and adults coping online games, as well as to make this population aware of the risks, since it can have repercussions in psychosomatic and health problems and also be associated with a large number of social, personal, work and family complications; it has been discovered that men with a higher level of education are more prone to pathological gaming.

Keywords: Addiction, Online games, Internet, Internet Gaming Disorder.

\section{INTRODUCCIÓN}

La adicción a los juegos online como trastorno del comportamiento se ha identificado en distintas partes del mundo, así como el perfil de quienes lo experimentan. En el año 2013 se incluyó la adicción al juego online en la quinta sección del Manual Diagnóstico y Estadístico de los Trastornos Mentales o DSM V (Carbonell, 2014). La inclusión de esta adicción dentro del manual de trastornos psiquiátricos más utilizado en el mundo tiene implicaciones sociales muy importantes, ya que es un reflejo de los grandes cambios de la última década en el desenvolvimiento de la sociedad mundial y los avances en el diagnóstico de trastornos mentales ligados a los desarrollos tecnológicos (Pontes \& Griffiths, 2014). Desde la aparición del Internet y la legalización de los juegos online, se han incrementado las consecuencias sobre la salud y en particular sobre el equilibrio mental de hombres y mujeres adolescentes (Olason et al, 2011; Estévez et al, 2013), así como de personas adultas y mayores (Festl et al, 2013). En la actualidad, las Tecnologías de la Información y la Comunicación (TIC), y especialmente la Internet, desempeñan un papel fundamental en la vida cotidiana de las personas, de tal forma que los trastornos de la salud mental también irrumpen el ciberespacio, provocando nuevas patologías como la dependencia a Internet $\mathrm{o}$ la adicción a los juegos online. El incremento de la disponibilidad de dispositivos móviles, las redes sociales y la difusión de publicidad que realizan los operadores de juego en todos los medios de comunicación contribuyen de manera importante en aumentar la problemática (Yanke, 2014). La conceptualización de las denominadas adicciones conductuales es un paso fundamental para el campo de los juegos de azar y para la investigación de las adicciones en general, en especial las que están ligadas al uso de Internet y las TIC. Esto lo convierte en un tema actual de investigación para los expertos en el estudio y atención de la ludopatía en psiquiatría, psicología y otras disciplinas (Albero, 2002; Wood \& Williams, 2011; Brunelle et al, 2012; Castilla et al. 2013; Gentile et al, 2013; Echeburúa et al, 2014; Luengo, 2014; Chóliz, 2017 y Gómez, 2017).

El establecimiento de centros de tratamiento especializados en diversas partes del mundo, como el sudeste asiático, Japón, China, Estados Unidos, México y Europa, refleja la creciente necesidad de ayuda profesional. En los países de Asia sudoriental, los efectos negativos de la adicción al juego online han llevado a los gobiernos y a los proveedores de servicios de salud a tomar el problema en serio y a desarrollar una serie de iniciativas para frenar y mitigar el problema; se han realizado investigaciones (Cía, 2013; Starcevic, 2012; Ko, Yen y Yen, 2012) para obtener más información sobre estos trastornos psiquiátricos coexistentes, ya que se considera esencial entender el mecanismo de la adicción a los juegos online. En China y Corea del Sur, la adicción al juego online se considera una preocupación importante para la salud pública. Su prevalencia ha sido estimada en $8.4 \%$ en varones y $4.5 \%$ en mujeres (Cía, 2013), por lo que el gobierno de ese país ha reconocido el problema, a consecuencia de un estudio realizado por el Ministerio de Educación, y para revertir esta situación crearon campos de abstinencia, con la finalidad de que las personas que sufren de adicción al juego sean ayudadas, donde los aíslan de la tecnología por completo (Majumdar, 2013). En México, existe la Comisión Nacional Contra 
Adicciones y una de sus áreas se orienta hacia el juego patológico (CNCA, 2012). En Europa, en los últimos años, han surgido centros de atención a la adicción a los juegos online en países, como Alemania (Centro de atención ambulatoria para adicciones conductuales, en Mainz), Reino Unido (Hospital Capio Nightingale, en Londres) y recientemente en España donde existen dos unidades de atención: Hospital de Bellvitge, en Barcelona y el Hospital Ramón y Cajal, en Madrid; lo anterior refleja la creciente necesidad de ayuda profesional en esta área. En este país, el mercado de los juegos online ha experimentado un auge económico importante desde su aparición y legalización en junio del 2012. El sector de los juegos online es una actividad económica en fase de crecimiento, solamente en el año 2016 se movieron capitales por más de 700 millones de euros. No obstante, a la par de este crecimiento económico se ha dado un importante incremento de los problemas y trastornos psicológicos relacionados con la adicción al juego online. Según la Dirección General de Ordenación del Juego de España, en el año 2016 se registraron 1.38 millones de personas que participaron con juegos online: juegos de rol, juegos de simulación, juegos de estrategia, juegos de azar. El análisis demográfico de los jugadores activos reveló que los jugadores son mayoritariamente hombres (83\%) y menores de 46 años (87\%). El perfil de edad más representativo, tanto en hombres como en mujeres, es el que está entre 26 y 35 ańos, 37\% del total (DGOJ, 2016a; DGOJ, 2016b). Según Echeburúa, et al. (2013) en su artículo Nuevos retos en el tratamiento del juego patológico encontraron que:

Mientras las motivaciones de los hombres para jugar son la obtención de un dinero fácil y la búsqueda de excitación, las mujeres juegan más para aliviar el malestar emocional y para hacer frente a la soledad. Las mujeres comienzan a jugar a una edad más tardía que los hombres, pero la adicción se desarrolla más rápidamente (Echeburúa et al., 2014, p.32).

El informe del Proyecto Europeo de Encuesta Escolar sobre el alcohol y otras Drogas (ESPAD, 2015) realizado entre 600000 mil estudiantes procedentes de 35 países europeos, 24 de ellos de los Estados miembros de la Unión Europea (UE), reportó que más de uno de cada cinco estudiantes (23\%) usaban Internet para jugar online regularmente ( 4 veces por semana). Casi la mitad de los estudiantes de Dinamarca jugaron regularmente en línea (45\%). Los juegos online regulares no eran tan comunes en Georgia (13\%), la ex República Yugoslava de Macedonia y Moldova (16\% cada uno). Los juegos online eran mucho más comunes entre las personas de género masculino (39\%) que entre las del género femenino (7\%). Entre los niños, las cifras más elevadas para el juego online se registraron en Dinamarca (64\%), Suecia (58\%), Estonia (55\%), Noruega (52\%) y Finlandia (51\%), la menor frecuencia de uso fue en Georgia y Mónaco (23\% cada uno). Dinamarca $(28 \%)$ y Mónaco (18\%) son los países con la mayor proporción de niñas que informan regularmente el uso de juegos online.

En el 2016 se realizó la II Jornada de Adicciones Comportamentales y Patología Dual, dentro de este marco de referencia el presidente de la Fundación Patología Dual de España, Néstor Szerman, señaló que en el $96 \%$ de los casos de adicción al juego patológico está asociado con otros trastornos mentales, como el trastorno por déficit de atención, la hiperactividad (TDAH), la fobia social, el trastorno obsesivo compulsivo o la psicosis, entre los de mayor prevalencia (Szerman, 2016).

En Latinoamérica, es importante resaltar la importancia que se le ha brindado también a conocer las implicancias que tiene el juego patológico en la actualidad, es el caso de Perú, Colombia y Chile. Rojas (2013), realizó un estudio en el Centro de Información y Educación para la prevención del abuso de Drogas (CEDRO) en Perú, con la finalidad de conocer esta problemática realizó el estudio "Epidemiológico nacional del Juego, uso de Internet y Redes Sociales virtuales en el Perú y fundamentos clínicos", en el 2010; la muestra estuvo conformada por 1200 viviendas de Lima Metropolitana y 400 viviendas en cuatro ciudades de la costa, de la sierra y selva de Perú, haciendo un total $n=6000$ viviendas, siendo este un aproximado de 12000 personas a nivel nacional. Las características de la población el $54.5 \%$ eran mujeres y el $45.5 \%$ varones, el mayor porcentaje 
de edad fue entre 30 y 39 ańos, el 52.8\% tiene educación secundaria y el $37 \%$ es de educación superior, dentro de los resultados obtenidos resaltan que a mayor nivel de instrucción hay una mayor prevalencia de vida de los juegos de azar, siendo las personas del nivel universitario con mayor prevalencia $27 \%$, de la ciudad de la selva $37.6 \%$ seguido de la Sierra con $29 \%$, siendo los varones con mayor incidencia a diferencia de las mujeres; asimismo, reportó que el inicio al juego de azar se está dando en promedio a los 22 años en Lima Metropolitana a diferencia que en las otras ciudades del interior del Perú, a los 20 años. También se observó que el juego en esta muestra tiene una relación con los criterios diagnósticos en la evaluación de la ludopatía, como es la necesidad de gastar más dinero en juegos de azar del que tenían pensado, al incrementar el monto de dinero en las apuestas, siendo los varones, en $8.3 \%$, los que tienen una mayor prevalencia y las edades estaban en un rango de 25 a 29 años (10.1\%) y con un nivel de educación superior, procedentes de la región de la selva. Otras de sus principales conclusiones, es lo relacionado al uso de Internet ya que se observó que los varones con un nivel de instrucción superior y en su mayoría residentes en Lima Metropolitana, con edad promedio entre 12 a 18 ańos, son quienes tienen una mayor preponderancia al uso de esta tecnología. Asimismo, refieren que, de los 1500 casos atendidos durante un periodo de 11 años, el $15 \%$ de los pacientes tienen problemas asociados a ludopatía y juegos online, lo cual se expone en la Figura 1.

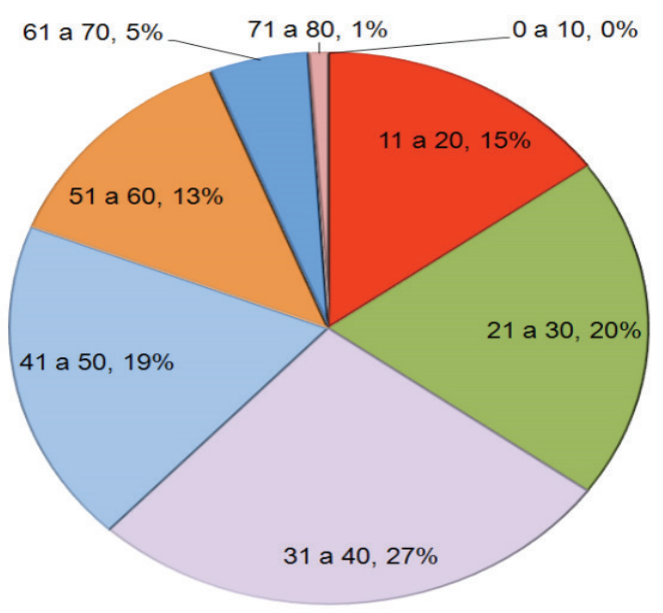

Figura 1. Ludopatía 1999-2010, por grupos de edad, $\mathrm{N}=995$.

Fuente: Rojas (2013)
En Chile, un estudio realizado por Giacaman, Nancupil y Jobet (2016) sobre "prevalencia estimada del juego patológico en estudiantes de la universidad Austral de Chile", en una muestra de 1254 estudiantes, con el 53.9\% de hombres y $46.09 \%$ de mujeres y una edad promedio de 21 años, detectaron que el $6.38 \%$ son potenciales jugadores patológicos, siendo los varones los de mayor prevalencia. Similares estudios realizados en Colombia coinciden en que las personas con mayor nivel de estudios, del género masculino (57.33\%), tienen una mayor prevalencia en ludopatía o juego patológico (Gonzáles, Flórez y Franco, (2013); Ruiz-Pérez, 2009 y Zapata; Torres y Montoya, 2011).

Toda vez que se incrementa la oferta de juegos online y se ha identificado que la incursión a ellos puede llegar a afectar a la creciente población de sus usuarios, el objetivo de este trabajo es aportar fundamentos para la definición y caracterización de la adicción a los juegos online.

\section{MÉTodo}

Este es un trabajo de revisión descriptiva y exploración sistemática bibliográfica, un meta análisis. Se exploraron diversas fuentes primarias, secundarias y otras de trabajos de investigación en el campo de la psicología y la psiquiatría relacionados con la temática Juegos online. En la primera etapa se realizó una búsqueda e identificación de documentos expuestos en sociedades científicas dedicadas a salud, así como de revisiones sistemáticas y estudios científicos de la Unión Europea, Asia y Latinoamérica y de otros países. Adicionalmente se realizó una búsqueda en Google Scholar de documentos y guías de práctica clínica publicados por asociaciones profesionales; esta búsqueda se hizo tanto en español como en inglés. Además, se recurrió a varias bases de datos electrónicas como el MEDLINE, The Cochranre Library Plus y el INDEX MEDICUS. En esta etapa se identificaron 110 artículos completos. En la siguiente etapa se seleccionaron aquellos documentos que incluían referencia exclusivamente al tema, quedando un total de $n=46$ artículos de los que se rescataron los antecedentes, definiciones y carac- 
terísticas relacionadas con la adicción a los juegos online e investigaciones relacionadas.

El producto del análisis documental permitió la integración de los siguientes temas principales relacionados con la adicción a los juegos online: juego patológico, jugador patológico, características del juego patológico, el juego online y resultados.

\section{Juego patológico}

El juego patológico se reconoció por primera vez como un trastorno psiquiátrico en los ańos 80 y se agrupó inicialmente en los trastornos de control de impulsos (OMS, 1992). La comprensión de las consecuencias adversas del juego excesivo ha sufrido un cambio profundo. Durante la mayor parte de esta historia, los individuos que experimentaron consecuencias adversas del juego fueron vistos como jugadores con problemas; hoy, se consideran como personas con problemas psicológicos y trastornos comportamentales. Este cambio es análogo a la trasformación del tema de estudio en los alcohólicos y el alcoholismo, y se ha reflejado o estimulado por la evolución de la clasificación y descripción clínica del juego patológico en las distintas ediciones del Diagnóstico y Estadístico de los Trastornos Mentales (DSM) publicado por la Asociación Americana de Psiquiatría desde 1980. El juego patológico es una de las primeras formas de dependencia sin consumo de drogas que ha sido estudiada desde la psicología y la psiquiatría, pero también desde los medios de comunicación y otras disciplinas en general (Ortiz-Tallo, Cancino y Cobos, 2011). La Organización Mundial de la Salud, en su Clasificación Internacional de Enfermedades versión 10 (CIE10, 2013), clasifica el juego patológico, como una enfermedad crónica que genera un trastorno del control de impulsos, que se caracteriza porque las personas dedican gran parte de su atención y sus recursos para mantenerse jugando, ya sea en centros de juego o más actualmente en escenarios virtuales en línea. Aunque a algunas personas les gusta jugar de vez en cuando, el jugador patológico generalmente avanza de juego ocasional a juego habitual. Una serie de investigaciones en la última década ha revelado múltiples similitudes entre el juego patológico y los trastornos por uso de sustancias, incluyendo la superposición neurobiológica (Dong et al, 2014; Potenza y Dong 2014; Potenza et al. 2013).

El jugador patológico se presenta ansioso de una gratificación inmediata y no repara en las posibles consecuencias negativas de esa conducta. Cuando la adicción conductual avanza, los comportamientos se vuelven automáticos, son activados por las emociones e impulsos, con pobre control cognitivo y autocrítica sobre ellos. Un papel fundamental en el diagnóstico de esta adicción se puede determinar por la cantidad de horas que la persona dedica a los juegos online. Chóliz y Saiz (2016) en su artículo Regular el juego para prevenir la adicción: hoy más necesario que nunca señalan que la justificación dada por la APA para definir el trastorno de juego como un trastorno adictivo no puede ser más explícita, ya que

...los comportamientos de juego patológico activan los sistemas de recompensa de manera semejante a las drogas de abuso y porque éste produce síntomas conductuales similares a los de los trastornos por consumo de sustancias... (APA, 2013, p. 481).

Además de esto se suma que, al igual que la adicción a las drogas, el juego patológico es considerado un trastorno crónico que tiende a empeorar sin un tratamiento adecuado. En el Manual Diagnóstico V (APA, 2013) se incluye el juego patológico en la clasificación de adicciones debido a las similitudes del tratamiento con otras adicciones. Hoy en día, las adicciones no están limitadas a las conductas generadas por el consumo de drogas, ya que las personas también pueden generar hábitos de conducta que en principio pueden ser normales y que luego pueden convertirse en adictivos según la frecuencia, intensidad o tiempo que invierten en el hecho, generando problemas en sus actividades cotidianas y también de salud mental. Los jugadores online requieren un alto grado de compromiso y tiempo de inversión en detrimento de otras actividades de tipo social, ocupacional y recreativo. En la actualidad la identificación del juego online patológico, como un problema de salud, ha dado paso a diversos estudios que han llegado a un consenso sobre algunas de las carac- 
terísticas clínicas, su prevalencia y consecuencias negativas en la salud mental de las personas jugadoras (Gómez et al, 2017; Echeburúa, Salaberría y Cruz-Sáez, 2014; Brunelle et al, 2012; Castilla et al, 2013).

\section{Características del Juego Patológico}

Cuando un individuo juega compulsivamente puede resultar de una combinación de distintos factores biológicos, genéticos y ambientales. El juego patológico a menudo implica comportamientos repetitivos. La Asociación Psiquiátrica Americana (APA, 2014), en el DSM-V, clasifica el juego patológico dentro de la categoría de trastornos relacionados con el consumo de sustancias adictivas. Según el DSM-V, un comportamiento de juego patológico puede diagnosticarse en una persona si están presentes cuatro o más de los siguientes síntomas: i) Preocupación. La persona está preocupada por los juegos de azar y tiene pensamientos frecuentes sobre las experiencias de juego, perjudicando o pensando en las maneras de conseguir dinero con el cual de nuevo apostar, etc. ii) Tolerancia. Similar a la tolerancia a los fármacos, la persona necesita apostar de manera compulsiva y aumentan las cantidades de dinero para lograr nuevas emociones o satisfacciones. iii) Pérdida de control. La persona ha realizado repetidos intentos infructuosos para controlar, reducir o detener el juego, pero es incapaz de hacerlo por sí mismo. iv) Retirada. La persona se inquieta o irrita al intentar reducir o detener el juego. v) Escape. La persona juega para evadirse de los problemas o para aliviar un estado de ánimo desagradable vi) Persecución. Después de perder dinero al jugar, la persona intenta recuperar las pérdidas. vii) Mentir. La persona miente para intentar ocultar el grado de implicación en el juego. viii) Actividad ilegal. La persona comete actos ilegales como falsificación, fraude, robo o malversación de fondos para financiar el juego y ix) Relaciones riesgosas. La persona arriesga su trabajo o las relaciones personales y familiares debido al juego (Garrido et al, 2017); lo cual conlleva a consecuencias psicológicas que incluyen sacrificar las relaciones de la vida real, privarse de dormir, agresividad, estrés, soledad, hostilidad, afrontamiento disfuncional, empeoran los logros académicos y problemas con la memoria verbal. El juego patológico también puede estar asociado con trastorno bipolar, trastorno obsesivo-compulsivo (TOC) o trastorno de déficit de atención / hiperactividad (TDAH).

\section{El juego online}

El juego online tiene una serie de características que le confieren un componente adictivo mayor, ya que la facilidad de acceso a través de Internet, redes sociales y otras herramientas tecnológicas, hace posible que las personas puedan estar conectadas y jugar durante las 24 horas del día. Así mismo, la privacidad de jugar sin tener que asistir a ningún establecimiento de manera presencial es otra característica que incide en el desarrollo de la adicción de los jugadores en línea. Si un jugador pasa dos o tres días jugando en un casino, alguien probablemente lo notará (por ejemplo, familia, amigos, personal del casino, etc.); en contraste, los jugadores online pueden jugar en el trabajo, en casa, o incluso en teléfonos inteligentes sin que nadie sea consciente de que son en realidad adictos al juego. La facilidad de acceso a través de cualquier dispositivo tecnológico (tablet, móvil, portátil, teléfono, etc.) lo hace más tentador para el jugador. Además del típico juego patológico, el ordenador o computadora añade otra dimensión. $\mathrm{El}$ juego por Internet es una actividad sedentaria, las computadoras e Internet crean aislamiento y un sentido de la fantasía. Esta combinación pone a un individuo en mayor riesgo de problemas de salud mental, según afirman Kuss y Griffiths, 2012 y Kuss et al, 2013.

El juego online exacerba y aumenta la velocidad de los efectos negativos de la adicción. Los autores Hilgard, Engelhardt \& Bartholow (2013) en su artículo Individual differences in motives, preferences, and pathology in video games: the gaming attitudes, motives, and experiences scales (GAMES) señalan que, cuando una adicción al juego está ya presente en la vida de una persona, no suele aparecer como el único trastorno psicológico; algunos otros trastornos psicológicos están altamente correlacionados con ésta. Las repercusiones sobre la salud tanto psicológica como fisiológica pueden ser muy graves y las personas que lo 
sufren tienden a no darse cuenta de la seriedad del problema. Estos autores destacan que son tres los factores que están relacionados significativamente con el uso patológico del juego online: el uso de juegos para escapar de la vida cotidiana, el uso de juegos como salida social y las actitudes positivas hacia la acumulación constante de recompensas en el juego. Los juegos de azar patológicos online se asocian con una salud mental deficiente en general. Las preocupaciones parecen basarse en un número creciente de estudios, como los que reportan Jeong y Kim (2011), Hellström, et al. (2012), Kuss \& Griffiths (2012) y Cia (2013), que indican que la adicción al juego online está asociada con varias consecuencias negativas, la depresión, la ansiedad, las fobias, la somatización, el trastorno de la personalidad antisocial, el alcoholismo, etc.

Para Basile (2011), la adicción al juego online debe ser vista desde una perspectiva holística, integrando los factores neurobiológicos, individuales, relacionados con el juego y culturales que contribuyen a la patogénesis y a la experiencia de los síntomas, la cual puede denotar una enfermedad neurobiológica crónica que es menos estigmatizante porque no sugiere que los pacientes que requieren medicación se vuelven "adictos" a su requerido tratamiento psicofarmacológico. La adicción, a diferencia de la dependencia, lleva a perseguir compulsivamente comportamientos gratificantes independientemente de los problemas biológicos, psicológicos y sociales asociados. Hellström et al. (2012) realizaron un estudio para examinar la relación entre tiempo de juego, motivos para jugar, y las consecuencias negativas debido a jugar en línea; la muestra fue sobre un total de 7757 adolescentes suecos (3 872 niños y 3 885 niñas) entre 13 y 18 ańos, los cuales completaron un cuestionario durante las horas de clase. Los resultados indicaron que el tiempo dedicado al juego estaba asociado con consecuencias negativas. El juego por motivos sociales y de diversión se asoció con un riesgo reducido, mientras que los juegos para escapar, ganar estatus o debido a demandas de otros se asociaron con un mayor riesgo de consecuencias negativas; los motivos para jugar deben ser considerados como un indicador principal de las consecuencias negativas, incluso más que el tiempo dedicado a los juegos. Los resultados de la investigación mostraron que el aumento del tiempo de juego online durante los días de semana aumenta la probabilidad de tener síntomas depresivos, músculo-esqueléticos y psicosomáticos, pero si el juego fuera por diversión o tenía motivos sociales, la probabilidad de enfermedad disminuía.

\section{Conclusiones}

Esta revisión bibliográfica ha demostrado que la investigación sobre la adicción al juego online ha aumentado en calidad y cantidad, particularmente durante la última década. La definición de la adicción al juego online es cada vez más comprensible, así como sus consecuencias. Sin embargo, se requieren investigaciones futuras para superar las limitaciones de la investigación actual, incluyendo un escrutinio más detallado del contexto del juego (incluyendo el individuo, el juego y la cultura) y mayor acervo documental. Los factores contextuales juegan un papel importante en la comprensión de la adicción al juego online como un fenómeno holístico. Se sugiere que un diagnóstico oficial de la adicción al juego online debe considerar la incorporación de la conducta problemática en el contexto del individuo, el juego y las prácticas de juego, así como el entorno sociocultural más amplio y cómo el significado de la conducta de juego se deriva de su contexto. En última instancia, una comprensión holística beneficiará a las personas que buscan ayuda profesional para su conducta problemática ante los juegos en línea, así como a los enfoques de tratamiento para que se vuelvan más específicos y, por lo tanto, más eficaces.

La presente revisión desde las perspectivas actuales sobre la adicción al juego online conduce a una mayor base de evidencia que incluye hallazgos importantes que se apoyan en la perspectiva actual de entender la adicción al juego online desde un marco de enfermedad. Además, se sugiere explorar la causalidad de la relación entre las alteraciones neurobiológicas y las anormalidades neuro-estructurales y los síntomas de adicción al juego en línea. La exploración adicional de estas cuestiones mejorará nuestra comprensión de este problema de salud mental. 
La base de investigación actual sobre la adicción al juego online ha llevado a la American Psychiatric Association a incluir juegos de Internet como desorden en el apéndice del DSM-5 como la segunda adicción de comportamiento junto con el juego patológico, lo que sugiere que el problema está demandando mayor interés a nivel mundial y como se ha podido observar en este estudio que existe el problema de los juegos online habiendo una mayor prevalencia en los individuos con mayor nivel de estudios y del género masculino los más propensos a sufrir de este trastorno.

Lo expuesto en este documento sugiere que los problemas con el juego online deben ser tomados en serio, ya que pueden afectar negativamente al individuo de varias maneras. Algunos de los problemas van desde la comorbilidad con otros trastornos psiquiátricos hasta los graves problemas que pueden tener a nivel familiar, en su entorno de trabajo y la probabilidad de tener síntomas negativos a nivel fisiológico y psicológico como la depresión, la ansiedad, trastornos cardiovasculares, trastornos del sistema nervioso, trastornos del sueño, problemas de espalda, problemas dentales $\mathrm{u}$ orales, obesidad crónica cansancio, músculoesqueléticos etc., afectaciones que han de comprobarse en estudios colaterales.

\section{REFERENCIAS BIBLIOGRÁFICAS}

Albero, M. (2002). Adolescentes e Internet. Mitos y realidades de la sociedad de la Información. Revista de estudios de comunicación, 7, 177-191. Recuperado de: www.ehu.es/ zer/hemeroteca/pdfs/zer13-10-albero.pdf

APA. (2013). Diagnostic and statistical manual of mental disorders (5th Edition). American Psychiatric Association. Washington, DC: American Psychiatric Association.

APA. (2014). DSM-5. Manual Diagnóstico y Estadístico de los Trastornos Mentales. American Psychiatric Association, Espa-a, Editorial Panamericana.

Basile, H. (2011). Adicción a Internet: ciberadicción. Bogotá: Universidad de los Andes.

Brunelle, N., Leclerc, D., Cousineau, M., Dufour, M., Gendron, A. \& Martin, I. (2012). Internet gambling, substance use, and delinquent behavior: An adolescent deviant behavior involvement pattern. Psychology of Addictive Behaviors, 26, 364-370. Recuperado de: https://doi. org/10.1037/a0027079
Carbonell, X. (2014). La adicción a los videojuegos en el DSM-5. Adicciones, 26 (2), 91-95. Recuperado de: https:// doi.org/10.20882/adicciones. 10

Castilla, C., Berdullas, S., Vicente, A. y Villamarín, S. (2013). Apuestas online: el nuevo desafío del juego patológico. Infocop, 61, 3-6.

Chóliz, M. (2017). Prevención de las adicciones tecnológicas en la adolescencia. Journal of Parents and Teachers. 369, 53-59. Recuperado de: https://dialnet.unirioja.es/servlet/ articulo?codigo $=5883019$

Chóliz, M. y Saiz, J. (2016). Regular el juego para prevenir la adicción: hoy más necesario que nunca. Revista de socidrogalcohol 28 (3), 174-181. Recuperado de: https://dialnet.unirioja.es/servlet/articulo?codigo $=5838610$

Cia, A. (2013). Las adicciones no relacionadas a sustancias (DSM-5, APA, 2013): un primer paso hacia la inclusión de las Adicciones Conductuales en las clasificaciones categoriales vigentes. Revista Neuropsiquiatria 76 (4), 210-217. Recuperado de: https://doi.org/10.20453/rnp.v76i4.1169

CIE-10 (2013). F60-F69 Trastornos de la personalidad y del comportamiento del adulto. Psicomed.net. Recuperado de: http://www.psicomed.net/cie_10/cie10_F63.html

CNCA. (2012). Consideraciones Generales hacia la Prevención y la Atención del Juego Patológico en México. Comisión Nacional contra las Adicciones. Secretaria de Salud. México D.F.

DGOJ. (2016a). Análisis del perfil del jugador online. Edición Dirección General de Ordenación del Juego, Espańa. Recuperado de: https://www.ordenacionjuego.es/es/ otros-informes-estudios

DGOJ. (2016b). Memoria anual 2016. Dirección General de Ordenación del Juego, España. Recuperado de: http:// www.dgojuego.minhap.gob.es/es/memorias-informe-anual

Dong, G., Lin, X., Zhou, H. \& Lu, Q. (2014). Cognitive flexibility in Internet addicts: fMRI evidence from difficult-to-easy and easy-to-difficult switching situations. Addict Behav. 39, 677-68. Recuperado de: https://doi.org/10.1016/j.addbeh.2013.11.028

Echeburúa, E., Salaberría, K., y Cruz-Sáez, M. (2014). Nuevos Retos en el Tratamiento del Juego Patológico. Terapia Psicológica, 32 (1), 31-40. Recuperado de: https://doi. org/10.4067/S0718-48082014000100003

ESPAD. (2015). European School Survey Project on Alcohol and Other Drugs. EMCDDA, ESPAD. Recuperado de: http://www.espad.org/report/home/

Estévez, A., Herrero, D. y Sarabia, I. (2013). Factores facilitadores de conductas adictivas de juego patológico en jóvenes y adolescentes. ONCE: Juego en adolescentes: nuevas formas, mismas consecuencias. Universidad de Deusto. Recuperado de: http://www.jugarbien.es/cmis/browser?i$\mathrm{d}=$ workspace://SpacesStore/6fa8e6d7-514a-4536-951f-1c7 433 be6a66

Festl, R., Scharkow, M. \& Quandt, T. (2013). Problematic computer game use among adolescents, younger and older 
adults. Addiction,108, 592-599. Recuperado de: https:// www.ncbi.nlm.nih.gov/pubmed/23078146

Garrido, M., Del Moral, G y Jaén, P. (2017). Antecedentes de juego y evaluación del sistema familiar de una muestra de jóvenes jugadores patológicos. Healt and Addictions. 17 (2), 25-36.

Gentile, A., Coyne, M. y Bricolo F. (2013). Pathological technology addictions: what is scientifically known and what remains to be learned, en The Oxford Handbook of Media Psychology, ed. Dill K. E., editor New York, NY: Oxford University Press. 382.

Giacaman, I. Nancupil, W. y Jobet, J. (2016). Prevalencia estimada del juego patológico en estudiantes de la Universidad Austral de Chile, Valdivia. Revista Anacem, 9 (2), 1-14. Recuperado de: http://www.revistaanacem.cl/wp-content/ uploads/2016/11/1.-EPUB-16-TC-002.pdf

González, P., Flórez, M. y Franco, G. (2013). Ludopatia y estrategias de afrontamiento en personas que asisten a los casinos en el municipio de Dosquebradas. Universidad Nacional Abierta y a Distancia (UNAD). Recuperado de: http://repository.unad.edu.co/bitstream/10596/2178/1/ Ludopata.pdf

Gómez, J. (2017). La transformación del juego problemático en España, Revista Española de Sociología, 26, 219-252. Gómez, J., Cases, J., Gusano, G. y Lalanda, C. (2017). Percepción social sobre el juego de azar en Espa-a. Instituto de Política y Gobernanza IPOLGOB-Universidad Carlos III de Madrid.

Hellström, C., Nilsson, W., Leppert, J. \& Aslund, C. (2012). Influences of motives to play and time spent gaming on the negative consequences of adolescent online computer gaming. Comput. Human Behav. 28, 1379-1387. Recuperado de: https:/www.ncbi.nlm.nih.gov/pubmed/26072677

Hilgard, J., Engelhardt, C. \& Bartholow, B. (2013). Individual differences in motives, preferences, and pathology in video games: the gaming attitudes, motives, and experiences scales (GAMES). Frontiers in Psychology, 4, 608. Recuperado de: http://journal.frontiersin.org/article/10.3389/ fpsyg.2013.00608/full

Jeong, J. \& Kim D. (2011). Social activities, self-efficacy, game attitudes, and game addiction. Cyberpsychol Behav Soc Netw, 14, 213-22. Recuperado de: https://www.ncbi. nlm.nih.gov/pubmed/21067285

Ko, H., Yen Y. \& Yen, F. (2012). The association between Internet addiction and psychiatric disorder: A review of the literature. European Psychiatry, 27, 1-8. Recuperado de: https://www.ncbi.nlm.nih.gov/pubmed/2215373

Kuss, D. \& Griffiths, D. (2012). Internet gaming addiction: a systematic review of empirical research. Int J Ment Health Addict, 10, 278-296. Recuperado de: https://www.ncbi. nlm.nih.gov/pmc/articles/PMC4061797/

Kuss, D., Griffiths, D., Karila L. \& Billieux J. (2013). Internet addiction: a review of epidemiological research for the last decade. Curr Pharm Des, 20(25), 4026-52. Recuperado de: https://www.ncbi.nlm.nih.gov/pubmed/24001297
Luengo, A. (2014). Adicción a Internet: conceptualización y propuesta de intervención. Revista Profesional Espa-ola de Terapia Cognitivo - Conductual, 2, 22-52. Recuperado de: http://www.jogoremoto.pt/docs/extra/BL5L6u.pdf

Majumdar A. (2013). Japan plans 'fasting camps' for Web-addicted children. Tech, 2, 20. Recuperado de: http:// www.firstpost.com/tech/news-analysis/japan-plans-fastingcamps-for-web-addicted-children-3635073.html

Olason, D. T., Kristjansdottir, E., Einarsdottir, H., Haraldsson, H., Bjarnason, G. \& Derevensky, J. (2011). Internet gambling and problem gambling among 13 to 18 year old adolescents in Iceland. International Journal of Mental Health and Addiction, 9, 257-263. Recuperado de: https:// goo.gl/Xhy5z2

OMS. (1992). Clasificación Internacional de Enfermedades. Organización Mundial de la salud. CIE-10. Descripciones Clínicas y Pautas para el Diagnóstico. Madrid: Meditor. Ortiz-Tallo, M., Cancino, C. y Cobos, S. (2011). Juego patológico, patrones de personalidad y síndromes clínicos. Adicciones, (23) 3, 189-197. Recuperado de: https://doi. org/10.20882/adicciones. 143

Pontes, H. \& Griffiths, M. (2014). Measuring DSM-5 Internet Gaming Disorder: Development and Validation of a Short Psychometric Scale. Computers in Human Behavior, 45. 137-143. 10.1016/j.chb.2014.12.006. Recuperado de: https://doi.org/10.1016/j.chb.2014.12.006

Potenza, M. \& Dong, G. (2014). A cognitive-behavioral model of Internet gaming disorder: Theoretical underpinnings and clinical implications. Plum X metrics, 58,7-11. Recuperado de: http://www.journalofpsychiatricresearch. com/article/S0022-3956(14)00202-7/fulltext

Potenza, M., Balodis, M., Franco, A., Bullock, S., Xu, J. \& Chung, T. (2013). Neurobiological considerations in understanding behavioral treatments for pathological gambling. Psychol Addict Behav: J Soc Psychol Addict Behav, 27, 380-392.PMid:23586456. Recuperado de: https://doi. org/10.1037/a0032389

Rojas, M. (2013). Epidemiologia Nacional del Juego, uso de Internet y Redes Sociales Virtuales en el Perú y Fundamentos Clínicos. Área de investigación y monitoreo de CEDRO-Centro de Información y Educación para la prevención del abuso de drogas. Perú; CONCYTEC. Recuperado de: http://www.repositorio.cedro.org.pe/bitstream/ CEDRO/343/1/2974-DR-CEDRO.pdf

Ruiz-Pérez, J. (2009). Juego patológico en usuarios de casinos en Bogotá: Prevalencia y relaciones con consumo de alcohol, búsqueda de sensaciones y patrones de juego. Revista Colombiana de Psicología, 18 (2), 145-156. Recuperado de: https://revistas.unal.edu.co/index.php/psicologia/ article/view/9993/36344

Starcevic, V. (2012). Is Internet addiction a useful concept? Aust N Z J Psychiatry, 47, 16-19. Recuperado de: http:// journals.sagepub.com/doi/10.1177/0004867412461693

Szerman, N. (2016). Adicciones comportamentales y Trastorno Bipolar, conferencia. II Jornada de Adicciones Com- 
portamentales y Patología Dual, Madrid, 23 de junio.

Wood, R. \& Williams, R. (2011). A comparative profile of the Internet gambler: Demographic characteristics, game-play patterns, and problem gambling status. New Media \& Society, 13(7), 1123-1141. Recuperado de: https://doi. org/10.1177/1461444810397650

Yanke, R. (30 de octubre de 2014). Atrapados por el juego 'on line'. El Mundo. Recuperado de: http://www.elmundo. es/espana/2014/10/30/54515869268e3e23258b4571.html Zapata, M., Torres, Y. y Montoya, L. (2011) Riesgo de juego patológico. Factores y trastornos mentales asociados en jóvenes de Medellín - Colombia. Revista adicciones, 23 (1), 17-25. Recuperado de: http://www.redalyc.org/ $\mathrm{html} / 2891 / 289122829003 /$ 


\title{
Propuesta de práctica investigativa con la Webquest. Estrategia pedagógica de comprensión del concepto e importancia del "bosque"1
}

\author{
Magda Julissa Rojas Bahamón ${ }^{2}$ \\ Lillyam López de Parra ${ }^{3}$ \\ Universidad de la Amazonia, Colombia
}

A proposal of a research practice using a webquest. A pedagogical strategy of comprehension of the concept and importance of "forests"

Recibido: 25-10-2017

Aceptado: 16-12-2017

\section{Cita recomendada}

Rojas, M. y López, M.. (2017) Propuesta de práctica investigativa con la Webquest. Estrategia pedagógica de comprensión del concepto e importantica del "bosque". Hamut'ay, 4 (2), 65-79.

Recuperado de: http://dx.doi.org/10.21503/hamu.v4i2.1473

\section{RESUMEN}

Ante la problemática presentada por la degradación de un ecosistema ubicado en una Institución Educativa en Florencia Caquetá, Colombia, este artículo tiene como objetivo presentar la propuesta del diseño de una práctica investigativa mediante el uso de la Webquest para la compresión del concepto e importancia del bosque. Se realizó una indagación previa desde el enfoque cualitativo. Se trabajó con estudiantes del último grado y profesores de la Institución. Se aplicó una entrevista semi-estructurada para identificar la comprensión e importancia del concepto bosque y su restauración ecológica. Los datos se sistematizaron |con el software NVivo y su análisis arrojó que uno de los factores de la degradación de los bosques obedece a la falta de educación ambiental de las personas, quienes conciben que el bosque es un conjunto de árboles y desestiman los beneficios y servicios que proveen estos ecosistemas a las comunidades. Los resultados han permitido elaborar el diseño de la Webquest siguiendo los postulados desarrollados por Dodge para la estructuración y diseño de la práctica investigativa, en la perspectiva de promover la autonomía y participación del estudiante en el proceso. Se concluye con una propuesta de Webquest como una estrategia pedagógica importante para la educación ambiental y para propiciar actitudes de conservación.

Palabras Clave: Restauración ecológica, práctica investigativa, Webquest, bosque.

\footnotetext{
1 Este trabajo es uno de los resultados del proyecto de investigación: Representaciones Sociales de la Investigación. Programas: Lengua Castellana y Literatura, Administración de Empresas y Maestría en Ciencias de la Educación; auspiciado por la Vicerrectoría de Investigaciones de la Universidad de la Amazonia. Florencia Caquetá. Colombia.

2 Profesora Institución Educativa Antonio Ricaurte. Florencia Caquetá. Magíster en Educación. Estudiante del Doctorado en Educación y Cultura Ambiental. Universidad de la Amazonia.

3 Profesora Titular Universidad de la Amazonia. Doctora en Educación Universidad Distrital “Francisco José de Caldas". Bogotá. D.C.
} 


\begin{abstract}
Given the problems presented by the degradation of an ecosystem located in an Educational Institution in Florencia, Caquetá, Colombia; this article aims to present the proposal of a research practice design through the use of a WebQuest to understand the concept and importance of forests . A preliminary inquiry was made using the qualitative approach. We worked with students of the last grade and teachers of the Institution. A semi-structured interview was applied to identify the comprehension and importance of the concept of forest and its ecological restoration. The data was systematized with NVivo software and its analysis showed that one of the factors that impact forest degradation is the lack of environmental education of people, who conceive that the forest is a set of trees and disregard the benefits and services that these ecosystems provide to communities. The results have allowed to design a WebQuest following the protocol developed by Dodge to structure and design a research practice, aimed to promote students' autonomy and their participation in the process. It concludes with a WebQuest proposal as an important pedagogical strategy for environmental education and to promote conservation attitudes.
\end{abstract}

Keywords: Ecological restoration, research practice, WebQuest, Forest.

\section{INTRODUCCIÓN}

La transformación de los ecosistemas naturales, como el caso de la deforestación, es una de las problemáticas existentes en el ámbito de la educación y cultura ambiental que provoca amplia preocupación. Ellis (2015) plantea que el 75\% de la tierra del planeta ha sido transformado hacia biomas de tipo antropogénico que no existían en el pasado. Así mismo, Dirzo et al. (2014) manifiesta que esta transformación ha impactado en la biodiversidad de los ecosistemas; con serias consecuencias en cascada sobre las interacciones entre sus organismos en el funcionamiento y en los servicios ecosistémicos que proveen.

Esta situación de degradación de los ecosistemas acontecida en diversas latitudes del planeta se ha presentado de manera concreta en zonas donde aparentemente la vegetación es abundante. Al sur de Colombia, en diversas zonas de la ciudad de Florencia, conocida como la puerta de oro de la Amazonia, se evidencian alarmantes pérdidas de la cobertura boscosa. Un caso puntual ocurre en la zona nororiental de la ciudad en un bosque ubicado en la Institución Educativa denominada Antonio Ricaurte como se ilustra en la figura 1.

El bosque objeto del estudio tiene una extensión aproximada $172 \mathrm{~m} 2$ y ocupa cerca del $25 \%$ del

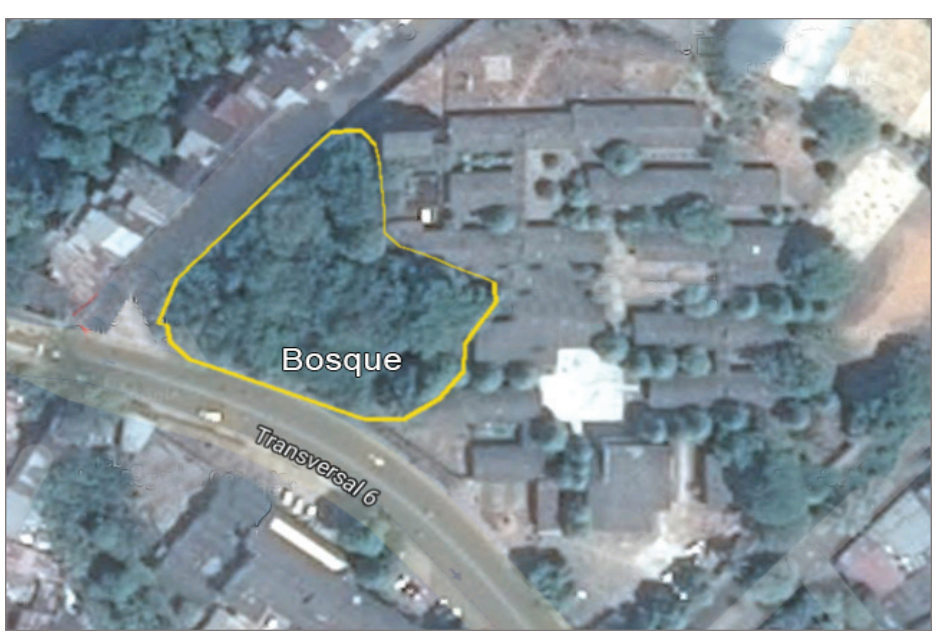

Figura 1. Ubicación del bosque en la Institución Educativa Antonio Ricaurte.

Fuente: Google Maps (2015).

territorio de la institución. Este bosque está tipificado como bosque húmedo tropical, por estar ubicado en la región de piedemonte amazónico a $242 \mathrm{msnm}$, cuenta con más de 100 especímenes, algunos con más de 45 años de antigüedad.

De acuerdo con lo manifestado por los profesores con más antigüedad en la Institución, el bosque tenía una extensión más amplia; sin embargo, el plan de ordenamiento territorial de Florencia en el año 2004, estableció quitar una parte del bosque para ampliar la vía de acceso hacia los barrios del Norte, debido a problemas de movilidad en la 
zona. Para la época, no hubo manifestación alguna por el recorte de esta zona boscosa. Esta degradación de los ecosistemas obedece a causa de la intensa actividad humana en el aprovechamiento con enfoques de manejo del territorio como el ordenamiento territorial (SER $\left.{ }^{4}, 2004\right)$.

Adicionalmente, el bosque en mención carece de una planeación sistemática debido a la falta de acciones de renovación dirigidas que permitan su conservación y evitar su pérdida en los próximos 20 años; esto se evidencia porque el crecimiento de especímenes nuevas obedece a procesos naturales por propagación de semillas.

Aunque el bosque reviste importancia como generador de servicios a la población estudiantil y a los pobladores de las zonas aledańas, en la observación realizada se evidenció que a nivel interno se presentan procesos de degradación del hábitat porque la zona es utilizada para arrojar escombros y almacenar elementos desechados en las oficinas. También, se presenta la invasión de la zona de bosque por la construcción de pequeñas eras de trabajo para la ubicación de huertas escolares transitorias, actividad que obliga a limpiar el terreno y cortar árboles con el fin de obtener más espacios para las prácticas. Esta situación se agrava porque son pocas las personas (estudiantes y profesores) que comprenden el valor del bosque para la población humana de la zona.

Respecto a la realización de prácticas investigativas realizadas en la Institución Antonio Ricaurte acerca de la importancia y manejo del bosque, en la indagación de los archivos, no se encontraron registros acerca de estudios que se hayan efectuado sobre el mismo, ni sobre ningún tipo de caracterización de fauna o flora. Se estableció que en el año 2015 se realizaron dos proyectos en el marco de la convocatoria de proyectos de investigación Ondas Colciencias 5 . Uno de los proyectos, trataba sobre el cultivo de plantas aromáticas, utilizó zona de bosque para la construcción de eras para la siembra de las plantas; el otro, relacionado

4 SER: Society for Ecological Restoration. International, Grupo de trabajo sobre Ciencia y Políticas

5 El Programa Ondas es la estrategia fundamental de Colciencias (Departamento Administrativo de Ciencia, Tecnología e Innovación de Colombia) para fomentar la cultura ciudadana de Ciencia, tecnología e Innovación en la población infantil y juvenil colombiana, a través de la investigación como estrategia pedagógica (Tomado de: legadoweb. colciencias.gov.co/faq/qu-es-el-programa-ondas) con la enseñanza de la filosofía, ejecutó la construcción de un quiosco para favorecer la concentración de los estudiantes en la lectura filosófica. También se encontraron reportes de la realización de caminatas dentro del bosque en el marco de actividades académicas propias de la especialidad ambiental de la Institución.

Por otra parte, en la revisión del estado del arte sobre la investigación como alternativa para la recuperación del bosque, se identificó que la Webquest es una estrategia educativa que ha promovido el interés de varios investigadores. Por ejemplo, en la indagación realizada por Sosa (2013) plantea las ventajas de la Webquest expuestas en diversos trabajos y se asume que estas son variadas y están enfocadas según los actores: estudiantes (protagonismo en el aprendizaje, fuente de motivación, reflexión, pensamiento crítico, autoestima, trabajo colaborativo, etc.), profesores (espacios de creación, problemátiza la realidad y abordaje interdisciplinario de los problemas, beneficio para toda la comunidad educativa, educa en valores) y los procesos como la evaluación. Asimismo, presenta los inconvenientes analizados en las investigaciones.

En lo referente al diseño e implementación de la Webquest en el campo de la educación existen diversos documentos e investigaciones, como la propuestas de Molebash \& Dodge (2003), Kennedy (2004), VanFossen (2004), Strickland (2005), entre otros.

Orientado hacia el tema del presente trabajo está la aportación del estudio realizado por Martínez y Salas (2015) en la que se implementó y desarrolló una Webquest en la Institución Educativa Marco Fidel Suárez del municipio de Ciénaga de Oro Córdoba, en la que durante tres sesiones los estudiantes pudieron rescatar los relatos de los abuelos acerca de la historia sobre las manifestaciones culturales y rescatar así, su legado cultural para valorarlo y respetarlo.

En esta misma línea se encontró el trabajo de Goig (2012) en el que se analiza el uso de la Webquest como un recurso didáctico y como complemento a la metodología aplicada en el proceso educativo de la educación vial para estudiantes del $2^{\circ}$ ciclo de Educación Infantil, con la participación de los 
Propuesta de práctica investigativa con la Webquest. Estrategia pedagógica de comprensión del concepto e importancia del "bosque"

profesores y otros agentes sociales intervinientes. Pese a los avances obtenidos, una de las conclusiones enfatiza en la importancia fundamental de la configuración de equipos pedagógicos en los centros educativos para implementar este tipo de estrategia pedagógica. Ejemplos de WebQuest que atraen la atención hacia temas relacionados con la biodiversidad pueden encontrarse en Washingtonville (s/f), ANBG (2007), Kpinkleton (2011), Ulloa et al. (2012), Condal, F. (2012), Mrsclarke (2013), Dean (2015) y Zunal (2015), entre otros.

No obstante, los desarrollos investigativos con el empleo de la Webquest, son pocos los trabajos que aborden la problemática ambiental. Al respecto, García (2014) sostienen que los procesos de educación ambiental requieren la formación de profesores, para que a través de ellos, se incorpore esta como eje transversal del proceso de enseñanza aprendizaje; así mismo, el equipamiento de recursos tecnológicos y seguimiento pedagógico de estas estrategias.

De manera específica, se evidencia una carencia de conocimiento en relación con el uso de la Webquest como estrategia de investigación para la conservación del bosque. En este sentido, el interrogante a resolver es ¿Cuál práctica investigativa se puede implementar con la Webquest para la compresión del concepto e importancia del bosque?

Responder este cuestionamiento tiene como objetivo diseñar una práctica investigativa mediante la implementación de la Webquest para la compresión del concepto e importancia del bosque.

La realización de esta investigación se justifica porque la restauración ecológica se ha planteado como una de las soluciones de vital importancia para la recuperación de los ecosistemas naturales y el equilibrio natural del entorno, en el que el ser humano, como parte fundamental y mayor beneficiario de los recursos ecosistémicos juega un papel relevante como actor y ejecutor. Las proyecciones de los impactos descritos anteriormente podrían ser abrumadoras si se considera que en muchas partes del planeta ya se ha perdido más del 30\% de la biodiversidad original (Newbold, et al., 2015), aspecto que hace pensar que la edu- cación puede brindar alternativas que permitan reducir estas devastadoras cifras.

Desde esta perspectiva, el trabajar en lugares alterados por la actividad humana, la restauración ecológica expande el campo de acción de la conservación biológica, la cual no queda restringida a las áreas protegidas y, además, no sólo se protegen los hábitats remanentes, sino que se recuperan superficies de hábitat degradados (Primack y Massardo, 2001).

Por esa razón, se hizo la indagación acerca de estrategias educativas innovadoras que puedan articular fácilmente aspectos de la restauración ecológica para mitigar las situaciones planteadas anteriormente. Las acciones implican el desarrollo de técnicas y la realización de procedimientos experimentales que, junto con el conocimiento pertinente y confiable de los ecosistemas, cumplan las expectativas de las comunidades o de un contexto social necesariamente consensuado.

\section{ACERCA DE UNA WEBQUEST}

Para Dodge (2002) la Webquest, es una actividad de investigación en donde la información con la que interactúan los estudiantes proviene total o parcialmente de recursos de la Internet. Yoder (1999) afirma que es un tipo de unidad didáctica que incorpora vínculos a la World Wide Web. A los estudiantes se les presenta un escenario y una tarea, normalmente, un problema para resolver o un proyecto para realizar; descripción que confirmó y consolidó Kennedy (2004). Los estudiantes disponen de recursos Internet y se les pide que analicen y sinteticen la información y lleguen a sus propias soluciones creativas. Los estudiantes disponen de información específica y resuelven la Webquest en grupos de trabajo y adoptan cada uno una perspectiva o rol determinado. El eje es la realización de diversas actividades con la información como:

Analizar, sintetizar, comprender, transformar, crear, juzgar y valorar, crear nueva información, publicar, compartir, etc. La tarea debe ser algo más que simplemente contestar preguntas concretas sobre hechos o conceptos (como en una Caza del Teso- 
ro) o copiar lo que aparece en la pantalla del ordenador a una ficha ("copiar y pegar" e "imprimir" son los peores enemigos de “comprender"). (Adell, 2004, pp. 3-4)

En este sentido, la Webquest igualmente se enlaza con las propuestas de desarrollo de competencias investigativas y de manera muy específica, con las competencias informacionales o competencias en el manejo de la información; es decir, con las competencias relacionadas con los procesos de planificación (preparación o planteamiento), acceso (adquisición, recepción, búsqueda y recuperación, elaboración, creación...), manejo (gestión, procesamiento, tratamiento, organización, interpretación, elaboración, revisión...) y uso de información (aplicación, expresión, presentación, comunicación, difusión, transferencia...) que de acuerdo a lo señalado por Roblizo y Cózar (2015) corresponde a las competencias en Tecnologías de la Información y la Comunicación (TIC).

Los fundamentos y referentes psicopedagógicos de las Webquest, tanto explícitos como implícitos, se encuentran básicamente en las teorías del procesamiento de la información; sin embargo, desde la perspectiva de la presente propuesta, se abordará estratégicamente desde los postulados de lo que Gimeno y Pérez (2000) clasifican como psicología dialéctica, para abordar planteamientos que incidan en los procesos de aprendizaje mediados tanto personal, como instrumental y contextualmente.

En los procesos de la actividad con la Webquest se busca la obtención y análisis crítico de la información para apoyar el desarrollo del pensamiento en los niveles de análisis, síntesis y evaluación (Dodge, 2002); en esta perspectiva, se realiza la indagación y la investigación con la mediación de la Web para solucionar problemas de interés de los estudiantes en el método de aprendizaje por descubrimiento (Baro, 2011).

En conclusión, una Webquest es un tipo de actividad didáctica que consiste en una investigación guiada; de ahí, su importancia como estrategia pedagógica para fomentar los procesos y competencias investigativas. Con recursos principalmente procedentes de Internet se promueve el desarrollo de habilidades cognitivas superiores, el traba- jo cooperativo, la autonomía de los estudiantes y la evaluación con criterios bien definidos. Una Webquest se concreta siempre en un documento para los estudiantes, el cual puede ser accedido de manera física, aunque es normalmente accesible a través de la Web.

\section{Estructura de una Webquest}

En este trabajo se retoman los aportes de la estructura propuesta por Dodge (1997) y las aportaciones de Kennedy (2004) la cual contiene los apartados: a) introducción, b) descripción de la tarea, c) proceso (aspectos que permiten guiar su realización), d) evaluación y e) conclusión, indicados en la figura 2.

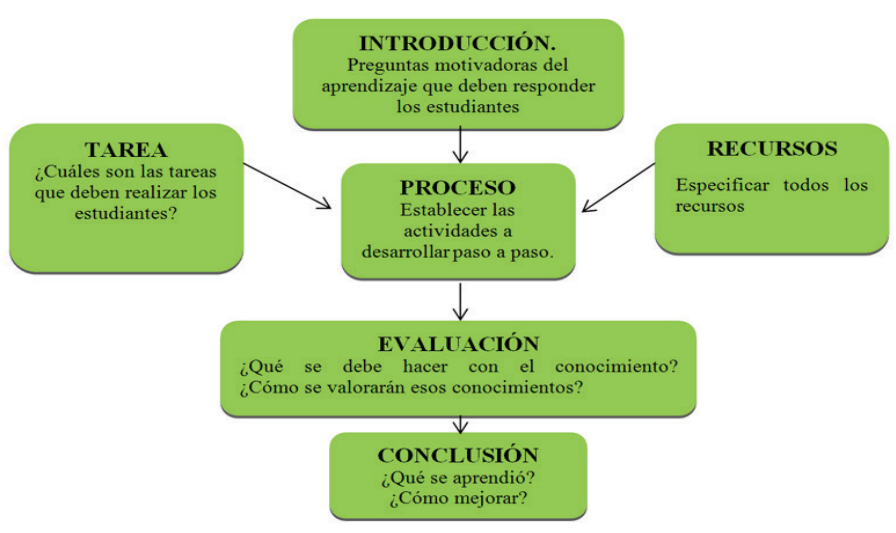

Figura 2. Estructura de una Webquest según Dodge (1997) Fuente: Elaboración propia acorde con los planteamientos de Dodge (1997).

El desarrollo de las etapas de la Webquest, se realiza de manera guiada, cada etapa está concebida con apartados estructurados para que el estudiante las lleve a cabo. La primera es la introducción, la cual provee la información básica y orienta sobre lo que se espera. La meta de la introducción es hacer la actividad atractiva y divertida para despertar el interés de los estudiantes y mantenerlo a lo largo de toda la actividad.

La tarea es una de las partes más importante de una Webquest. Existen muchas formas de asignar una tarea, Dodge (2002), describe los 12 tipos de tareas más comunes, véase la figura 3 . 


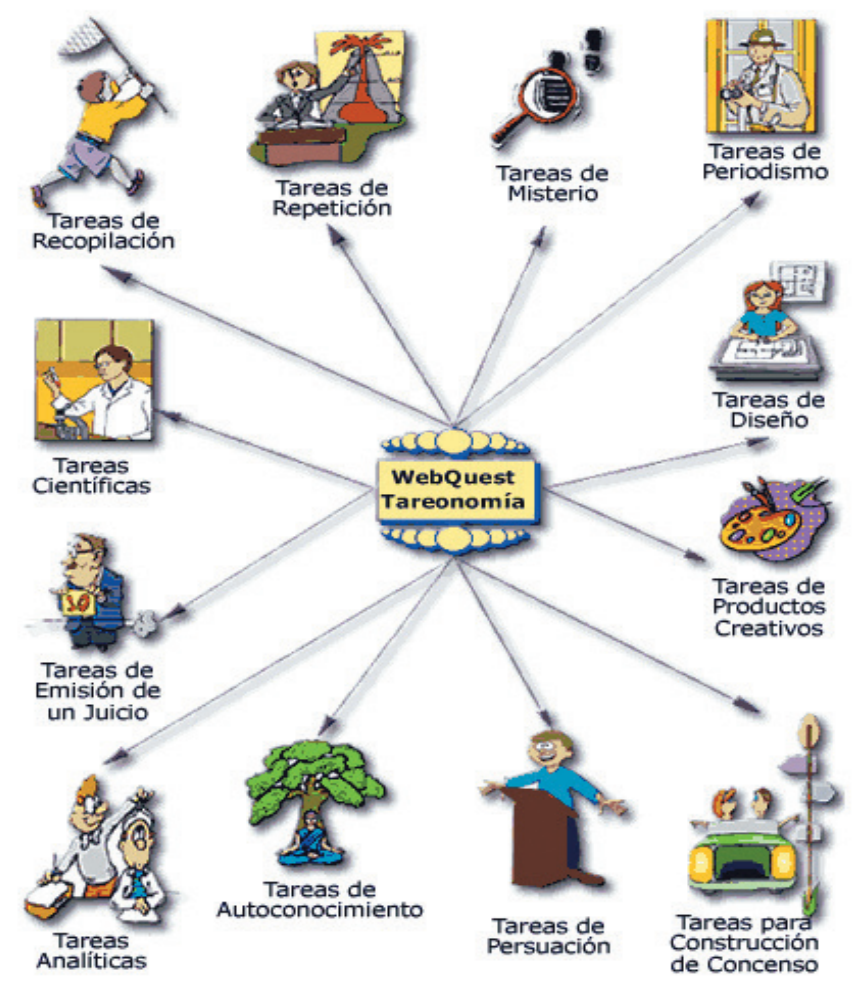

Figura 3. Tareonomía de la Webquest (Dodge, (2002).

Fuente: Eduteka (2002). Recuperado de http://www.eduteka.org/Tema11.php

Las tareas pueden ser múltiples y variadas entre otras: a) de recopilación (información de varias fuentes), b) repetición (fuentes de información alternativas a las ofrecidas en clase), c) de misterio o de acertijo (responder preguntas a partir de buscar información en webs concretas), d) periodísticas para actuar como reporteros (diseño de una muestra representativa, la construcción de instrumentos de investigación (cuestionarios, entrevistas, etc.), e) recogida de datos a través de esos instrumentos de investigación y la organización de la información resultante, su interpretación y presentación en forma de informe sintético de las conclusiones), f) de diseño (crear un producto o plan de acción que cumpla con una meta predeterminada y funcione dentro de restricciones pre-establecidas), g) creativas (producir algo dentro de un formato determinado, por ejemplo, una obra de teatro), h) construcción de consenso (articular, considerar y acomodar diferentes puntos de vista sobre un tema concreto), i) persuasión (desarrollar una argumentación convincente que se base en lo aprendido), j) autoconocimiento (exploración guiada de recursos en línea y fuera de ella, sobre sí mismo), k) analíticas (observar y encontrar similitudes y diferencias con el objeto de descubrir las implicaciones que tienen esas similitudes y diferencias), 1) emisión de un juicio (clasificar, valorar o tomar una decisión informada entre un número limitado de opciones), 1l) científicas (incluye el planteamiento de preguntas que el estudiante debe contestar con base en información previamente definida, a la cual se accede generalmente desde internet).

La tarea y el proceso están estrechamente relacionados. El proceso es la explicación del trabajo a realizar; se caracteriza porque es una etapa clara y bien definida que se debe desarrollar; consta de una serie de actividades estructuradas y de unos recursos que se proporcionan al estudiante; tiene por finalidad que los estudiantes puedan construir el conocimiento necesario y alcanzar de este modo las metas esperadas; permite que el estudiante realice una construcción del conocimiento en función de las preguntas planteadas, desarrolle estrategias de búsqueda, procesamiento de la información y fomente la colaboración y la discusión.

En esta investigación se consideró que, el enriquecimiento de la estrategia puede darse en la medida que se dé autonomía al estudiante para responder a cuestionamientos de manera abierta y busque distintas posibilidades, las cuales dependerán del tratamiento de la información; también, cuando el estudiante pueda sugerir cambios en la estructura de las actividades al agregar, modificar o sugerir información adicional para enriquecer la actividad. Esto conllevaría a afianzar el sentido propositivo del estudiante para permitirle ser autónomo; es decir, tener la oportunidad de participar en la construcción de las actividades de la Webquest, para analizar los contenidos, avanzar en su desarrollo y sugerir nueva información relevante para incluir.

Por su parte los recursos, consisten en una lista de sitios web que el profesor ha localizado para ayudar al estudiante a completar la tarea. Estos son seleccionados previamente para que el estudiante pueda enfocar su atención en el tema en lugar de navegar a la deriva. Se considera desde esta investigación, que los recursos pueden sufrir variables 
en el sentido de comprender tanto listas de sitios web como referencias a fuentes físicas (libros, revistas, etc.); es decir, que los recursos puedan ser producto de la propuesta de los participantes.

Luego se encuentra la evaluación, la cual constituye una característica distintiva de este tipo de propuesta didáctica puesto que al estudiante se le presenta, desde el inicio del proceso, los criterios con los que va a ser evaluado su trabajo. Dichos criterios aparecen en forma de escala de valoración con diferentes indicadores. Sin embargo, si bien la Webquest establece criterios puntuales en la evaluación, en esta investigación se consideró vincular procesos de autoevaluación de manera que los participantes puedan involucrar al proceso evaluativo, aspectos que le permitan contextualizar, desde su punto de vista personal, cómo se desarrolló el proceso. Calatayud (2008) considera que la autoevaluación es la estrategia por excelencia para educar en la responsabilidad y para aprender a valorar, criticar y reflexionar sobre el proceso de enseńanza y aprendizaje individual realizado por el estudiante. De esta manera, el participante puede tomar conciencia de cuál es su progreso personal y le permite reflexionar individualmente sobre su proceso de enseńanza y aprendizaje.

Finalmente, la conclusión proporciona la oportunidad de resumir la experiencia, animar a la reflexión sobre el proceso y generalizar lo aprendido. Constituye el cierre del proceso y suele tener un carácter motivador para seguir trabajando en esa línea.

\section{Materiales y MéTodo}

\section{Participantes}

Para la realización de este trabajo se contó con la participación de funcionarios de la Institución Educativa Antonio Ricaurte de Florencia Caquetá: dos (2) profesores de asignaturas del área ambiental (un docente de la especialidad ambiental y un docente retirado que hizo parte de la especialidad en el área ambiental durante la década de los 80 ), el rector y el coordinador académico de la Institución Educativa. Igualmente, se tuvo la participación de diez estudiantes de educación básica que determinaron aspectos relacionados con la importancia del bosque para la institución.

\section{Instrumento}

Con el propósito de evidenciar el pensamiento de los diversos actores (directiva, profesores y de los estudiantes) acerca del bosque circundante de la Institución en estudio, se diseñó y aplicó como instrumento para recoger la información, una entrevista semiestructurada, la cual se organizó acorde con las siguientes dimensiones relacionadas con el bosque como objeto de conocimiento:
a. concepto,
b. importancia,
c. servicios,
d. aspectos para la conservación.

En cada dimensión se formularon tres preguntas para un total de doce interrogantes.

Previamente a la aplicación, se hizo el pilotaje con un profesor y dos estudiantes, para tener un juicio de valor del instrumento; lo cual permitió identificar la falta de claridad de algunas preguntas; estas pequeńas observaciones indicadas a algunos ítems fueron corregidos, para poder aplicar posteriormente el instrumento a la muestra del estudio.

\section{Tipo y Diseño}

Este estudio es de enfoque cualitativo y de diseño descriptivo - interpretativo, porque busca identificar, describir y determinar los aspectos inherentes a la problemática de degradación de un ecosistema bosque, a partir de la indagación de actores que han tenido vínculo con él.

\section{Procedimiento}

Para presentar la propuesta de práctica investigativa con la Webquest. Estrategia pedagógica de compresión del concepto e importancia del "bosque" se ha seguido el diseño como se muestra en la figura 4, el cual presenta varias fases. 


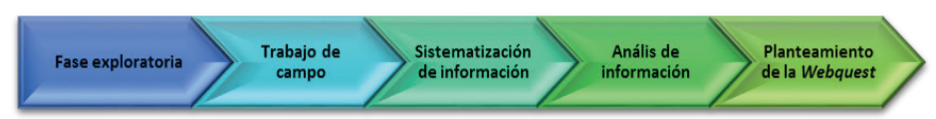

Figura 4. Fases del estudio

Fuente: elaboración propia.

1. Fase exploratoria. Esta fase comprendió la búsqueda de información inherente al bosque de la Institución Educativa Antonio Ricaurte. Se consultaron informes académicos que hacen referencia al bosque; y se realizó la contextualización del escenario o ámbito de la indagación; para esto se determinaron las características del bosque mediante la búsqueda de información en los archivos de la Institución y los profesores con más tiempo de antigüedad en ella. Se les hizo una entrevista semiestructurada en la que se indagó acerca de aspectos relacionados con uso del bosque, descripción y actividades educativas realizadas en el bosque. Como resultado se elaboró la descripción geográfica mediante la toma de fotografía y una caracterización del bosque con base en la información obtenida.

2. Fase Trabajo de campo. En esta fase se hizo el proceso de recolección de datos. De esta manera, para obtener la información inherente al bosque se contactaron a los participantes, que fueron profesores de la especialidad ambiental, directivos y estudiantes para que con su colaboración voluntaria accedan a la aplicación de la entrevista semiestructurada, para recoger datos relacionados con el bosque como concepto, importancia, servicios que provee un bosque, aspectos para la conservación de un bosque, previo a lo cual se acordo la fecha y hora de la entevista.

3. Fase Sistematización de la información. Esta fase tuvo como objetivo examinar la informacion obtenida de las entrevistas aplicadas, las cuales fueron grabadas, para consolidar la información inherente al bosque. Para la sistematización, se hizo previamente la transcripción de las entrevistas, digitalizandose los audios, para luego obtener los resultados en el software de análisis cualitativo NVivo; considerando para el análisis e interpretación de los datos los criterios de uso, importancia, significado para la institución.

4. Fase de análisis e interpretación de los datos. Con la información obtenida en la fase anterior, se realizó el análisis en un escrito de corte cualitavo para encontrar los aspectos semejantes, relevantes y diferencias sobre la concepción de bosque por parte de los actores.

5. Elaboración de la Webquest. De acuerdo con el análisis efectuado, se realizó una propuesta preliminar y pertinente para la comprensión del concepto bosque, su importancia y conservación. En la elaboración de la propuesta del Webquest se tuvo en cuenta la estructura propuesta por Dodge (1997).

\section{Resultados}

En el desarrollo de las fases propuestas previas a la propuesta de la Webquest, se obtuvieron los siguientes resultados:

Concepto e importancia del bosque. Con base en la sistematización de los datos obtenidos mediante el programa NVivo, se obtuvo la siguiente información:

Importancia del bosque. La valoración dada al bosque aledaño a la Institución tiene diferente valoración según los actores indagados. En la figura 5 se presentan los términos más representativos de la valoración dada por los estudiantes.

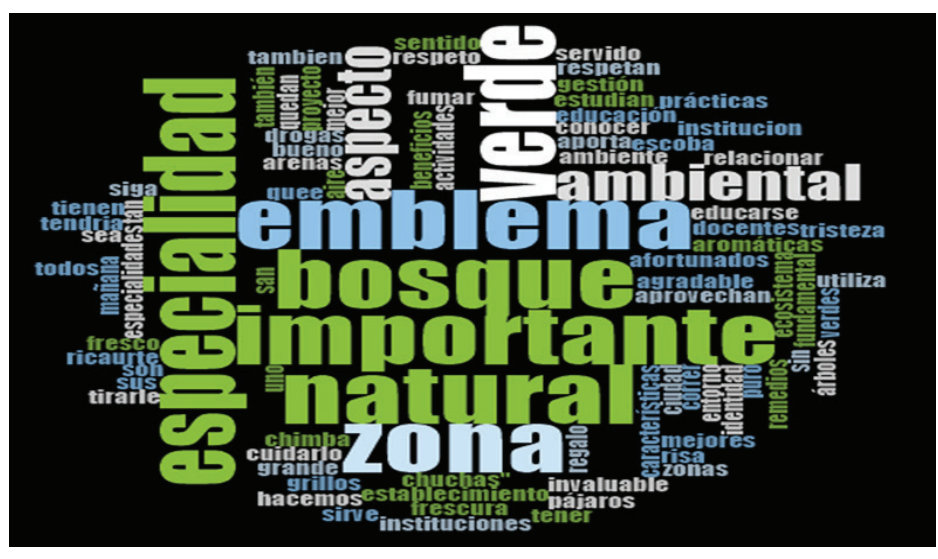

Figura 5. Mapa de nube. Términos de valoración del bosque por parte de los estudiantes.

Fuente: elaboración propia. 
Los estudiantes valoran el bosque como un emblema institucional y fuente de las prácticas de la especialidad ambiental de la Institución. También se evidencia la importancia del componente faunístico, dado que, determinaron el goce y el disfrute por observar aves y grillos. De igual manera, la valoración del bosque se comprende en términos de proveedor de frescura; así mismo como merecedor de respeto y cuidado.

De acuerdo con la gráfica de nube aparece de la figura 5, aunque con menos frecuencia, pero no menos importante y crítico, el hecho de entender el bosque como espacio para el consumo de drogas, debido a que tiene poca vigilancia y no hay tránsito frecuente de personas. Este aspecto podría determinarse como un elemento de convivencia importante de analizar y supervisar por parte de la directiva de la Institución.

Por parte de los profesores, la valoración fue más homogénea. Tienen en cuenta el bosque como un factor generador de biodiversidad y aprendizaje. Así mismo, es concebido como un ecosistema que provee aire puro no solo a los estudiantes, sino también a los habitantes aledaños a la institución (Ver figura 6).

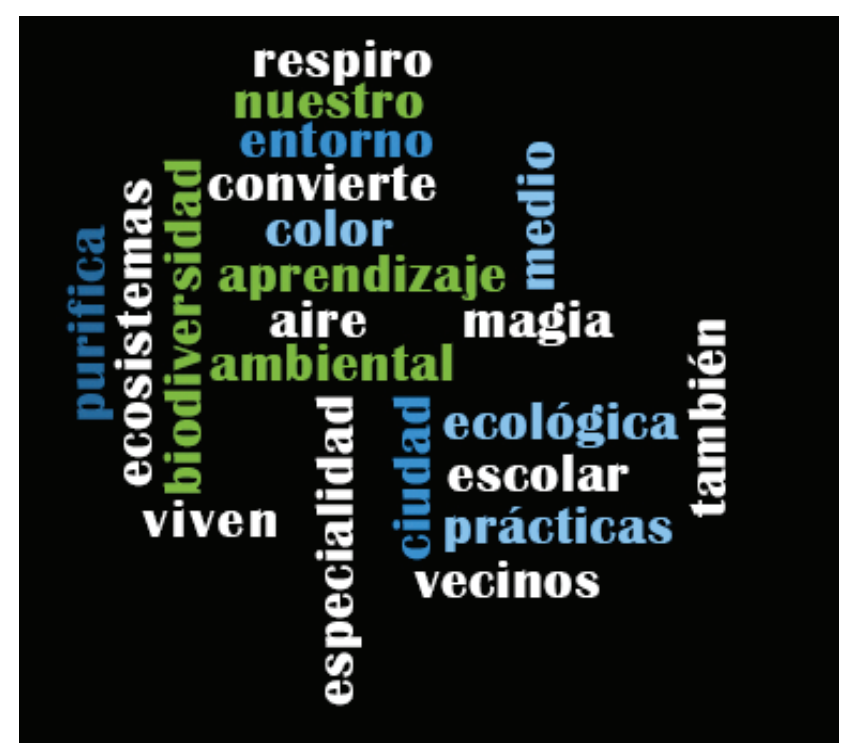

Figura 6. Mapa de nube. Términos de valoración del bosque por parte de los profesores.

Fuente: elaboración propia.
La indagación permitió determinar que no se han efectuado proyectos relacionados con la conservación o restauración del bosque, los que se han realizado pretendieron ganar espacio físico en este sector; no obstante, desde el punto de vista ecológico se han producido impactos importantes que han afectado al bosque. Algunos de ellos son: disminución de la cobertura boscosa, daños sobre la diversidad de pequeños animales, disminución de la capacidad de absorción de dióxido de carbono y disminución de la producción de oxígeno.

Dentro de las amenazas que se pudieron determinar, una de las principales que inciden sobre el ecosistema bosque de la Institución Educativa se origina por la vejez de los árboles que lo constituyen, aspecto que afectaría la perdurabilidad del mismo por la inminente muerte en un corto período de tiempo. Otro aspecto que amenaza la integridad del boque y la biodiversidad que sobre él emerge, obedece a procesos de degradación del hábitat, por la acumulación de escombros y desechos y por la utilización del terreno para las prácticas de la huerta casera.

Por otra parte, respecto al concepto de bosque, algunos de los entrevistados piensan que un bosque involucra un conjunto de árboles y que el espacio que ocupa en la institución podría dedicarse a la construcción de aulas que pueden ser beneficiosas para mitigar el hacinamiento en los salones de clase.

Por lo anterior se establece dentro de los aspectos críticos a vincular a la estrategia, la comprensión del concepto bosque y su importancia para el ser humano. Ante esta necesidad, identificada en el análisis de los datos arrojados con la aplicación de la entrevista semi-estructurada, se revisaron $\mathrm{y}$ analizaron varios documentos para generar de manera participativa una práctica investigativa a través del diseńo de una Webquest como una alternativa de respuesta para la conservación del bosque ubicado en las instalaciones de la Institución educativa Antonio Ricaurte.

En síntesis, los términos más reiterativos o que representaron mayor frecuencia fueron: natural, emblema e importante, como se muestra en la figura 7. 


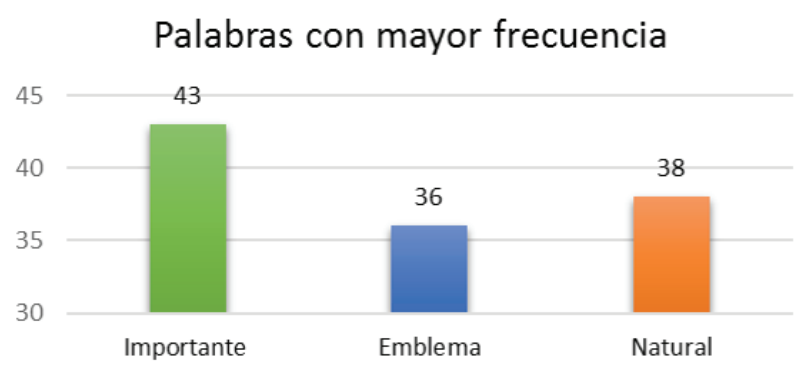

Figura 7. Gráfica de frecuencia. Términos de valoración con mayor frecuencia.

Fuente: elaboración propia (2015)

Los datos evidencian que la sensibilización de los actores respecto al significado del bosque, emergen en su discurso, de ahí que el término importancia en referencia al bosque se manifieste como un término representativo e intrínseco en sus argumentos. Seguidamente, se encuentran los calificativos de natural y emblema, con una frecuencia de 38 y 36 respectivamente.

Por otra parte, los conceptos que pocas veces emergieron fueron: educación y educarse; lo cual indica que pese a la actitud positiva frente a la temática aún hay una fuerte debilidad en la conciencia de los actores para asumir los procesos de formación como fundamentales para la conservación y restauración del bosque. No obstante, consideraron las prácticas como actividades novedosas para integrarlas a la Webquest, aunque no especifican qué clase de prácticas, por lo cual la valoración es nocional.

Propuesta Práctica Investigativa con la Webquest: El bosque es más que un grupo de árboles.

Para proponer una práctica investigativa como una alternativa para la sensibilización de estudiantes y profesores acerca de la importandcia del bosque se diseñó la Webquest con base en los resultados arrojados en las entrevistas y en la información recolectada en los documentos de los archivos de la Institución.

Para la propuesta de la Webquest se ha seguido la estructura indicada por Dodge (1997), Göktepe (2014), Pierce, (2013) Trovato, (2013), la cual consta de los siguientes componentes, las cuales se describen a continuación.

1. Introducción: Es la que debe guiar a los estudiantes hacia el tema propuesto y proporcionar la información y los objetivos de lo que va a realizar, motivándolos hacia la tarea a través de la pregunta o preguntas provocadoras de aprendizaje.

2. Tarea: Es el centro de la webquest, esta debe ser interesante, motivadora y creativa, con objetivos específicos y la entrega de un producto al finalizar, relacionada a un contexto social y del entorno de interés del estudiante.

3. Proceso: En la cual se indica de manera detallada toda la información para la realización de cada una de las actividades que tiene como fin la ejecución de las tareas.

4. Recursos: Se presentan todos los medios, herramientas, material bibliográfico y otras fuentes necesarias, que servirán de apoyo para la realización de la tarea, enfocados en el objetivo de la misma.

5. Evaluación: Es un proceso mediante el cual se verifica los conocimientos, destrezas y actitudes adquiridas, siendo la rúbrica el instrumento que recoge toda esta información, considerando criterios e indicadores específicos en una escala de calificación.

6. Conclusión: Es la que finaliza todo el proceso de la Webquest y permite hacer procesos de metacognición sobre el motivo de aprendizaje y los logros obtenidos por los estudiantes.

La estructura de la Webquest, se indica en la Tabla 1 , los componentes con las principales actividades de la propuesta. 


\section{Tabla 1}

Propuesta práctica investigativa Webquest El bosque más que un conjunto de árboles

\begin{tabular}{|c|c|}
\hline $\begin{array}{l}\text { Grupo de } \\
\text { resultado }\end{array}$ & Resultados \\
\hline Introducción & $\begin{array}{l}\text { - Resolución preguntas provocadoras del } \\
\text { aprendizaje: } \\
\text { - ¿Para Ud. qué es un bosque? } \\
\text { - ¿Qué importancia le otorga al bosque? } \\
\text { - ¿Cuál es el concepto de diferentes autores } \\
\text { sobre el bosque? } \\
\text { - ¿Qué estudios hablan de la importancia del } \\
\text { bosque?, } \\
\text { - ¿Cuáles son sus principales contribuciones } \\
\text { al respecto? }\end{array}$ \\
\hline Tarea & $\begin{array}{l}\text { - De autoevaluación y reflexión: Comprender } \\
\text { qué constituye un bosque. } \\
\text { - De reportaje: Identificar los beneficios que el } \\
\text { bosque provee a los estudiantes de la IEAR. } \\
\text { - Científica: Comprender la interacción del } \\
\text { bosque con la comunidad. } \\
\text { - Reto-Misterio: ejecutar acciones encamina- } \\
\text { das hacia la conservación y restauración del } \\
\text { bosque } \\
\text { - Nuestro granito de área para lograr la con- } \\
\text { servación del bosque } \\
\text { - Elaboración de juego didáctico }\end{array}$ \\
\hline Proceso & $\begin{array}{l}\text { - Información detallada para la realización de } \\
\text { cada una de las actividades que conlleva la } \\
\text { ejecución de las tareas: } \\
\text { - Observación de videos sobre el bosque. } \\
\text { - Reflexión sobre los videos: Mesa redonda. } \\
\text { Luego de la proyección de los videos se } \\
\text { realiza discusión/reflexión sobre cada video } \\
\text { visto con base en las siguientes preguntas: } \\
\text { ¿Cómo concibes el concepto de bosque? } \\
\text { ¿Qué servicios te puede ofrecer un bosque? } \\
\text { ¿Por qué se destruyen los bosques? ¿Qué } \\
\text { pasaría si no existieran los bosques? ¿Argu- } \\
\text { mente si se podría decir que un bosque es } \\
\text { solo un conjunto de árboles? } \\
\text { - Revisión documental. Trabajo individual. En } \\
\text { la herramienta CmapTools, elaborar un mapa } \\
\text { conceptual para las siguientes temáticas: } \\
\text { ¿Qué es un bosque?, servicios que nos } \\
\text { ofrecen los bosques } \\
\text { - Preparación, diseño de entrevistas semi-es- } \\
\text { tructuradas relacionadas con el bosque para } \\
\text { ser aplicadas a los compañeros. } \\
\text { - Sistematización de los datos en un programa } \\
\text { informático. } \\
\text { - Análisis e interpretación de la información. } \\
\text { - Práctica de campo: visita al bosque, zona } \\
\text { de bosque húmedo tropical ubicada en el } \\
\text { campus de la Institución Educativa Antonio } \\
\text { Ricaurte de Florencia. Recorrido sobre } \\
\text { terreno plano aproximado de } 50 \text { minutos. } \\
\text { Durante el recorrido se realizará observa- } \\
\text { ción faunística y florística. Se hará registro } \\
\text { fotográfico y de video. }\end{array}$ \\
\hline
\end{tabular}

Proceso

- Autorreflexión del recorrido en el bosque: discusión en mesa redonda, en torno a las preguntas: ¿Por qué son importantes los bosques? ¿Qué sensación le produce su recorrido por el bosque? ¿Cuáles animales pudieron observar en la zona por la presencia del bosque? ¿Qué le pasaría al lugar visitado si estuviese deforestado? ¿Cuáles son las razones de la deforestación? ¿Cuáles son las consecuencias de la deforestación para el modo de vida de las comunidades, el clima y los peligros naturales? ¿Qué actividades proponen para ayudar a conservar el bosque y administrarlo mejor?

- Presentación animada de la visita al bosque (diapositivas en Power Point, presentación en prezi o flash) con los registros fotográficos y filmes recopilados durante el recorrido. La exposición de la presentación se realizará en función de la importancia de los bosques para los seres humanos, los animales, las plantas y el ambiente.

- Trabajo grupal (3 personas). Elaborar una lista de mínimo diez (10) acciones de la vida diaria que cada persona puede ejecutar para ayudar a la conservación de los bosques. Para cada acción se elaborará una cartelera o póster que será expuesto en la institución educativa.

- Cada grupo elaborará un juego didáctico que involucre aspectos relacionados con conservación de bosques. Estos juegos didácticos serán expuestos en la jornada de la ciencia de la institución.

- Presentación del informe a través de la elaboración y proyección de un video (Concepto e importancia de los bosques, biodiversidad, servicios ecosistémicos).

Recursos - Videos: - la importancia de los bosques (https://www.youtube.com/watch?v=3IRJVyalzwc), - ¿Qué significa el bosque para una comunidad local? (https://www.youtube.com/ watch?v=ZPrmy0B5Hko), - ¿Qué es biodiversidad? ((https://www.youtube.com/watch?v=Rh4txXeKIME); - servicios ecosistémicos, nuestra conexión vital con la biodiversidad (https://www.youtube.com/watch?v=2h6rOS$8 \mathrm{NvkQ}$ ), - hombre y biodiversidad (https:// www.youtube.com/watch?v=bR2X6sqsAiY), aprender a proteger la biodiversidad (https:// www.youtube.com/watch?v=RVnkkJaCuRo).

- Links de páginas Web para indagar sobre temas como: - importancia de los bosques/ Biodiversidad/Cuentos: http://bosquehumedo.blogspot.com.co/; http://www.ecologistasenaccion.org/article6296.html; http://www. inecc.gob.mx/con-eco-biodiversidad; http:// www.ecologistasenaccion.org/article6296. html; http://www.conmishijos.com/ocio-en-casa/cuentos/cuentos-infantiles/cuento-el-bosque-encantado.html 
Propuesta de práctica investigativa con la Webquest. Estrategia pedagógica de comprensión del concepto e importancia del "bosque"

\begin{tabular}{ll}
\hline Evaluación & Mapas conceptuales de los documentos, \\
& carteleras, juego didáctico, presentación de \\
& los resultados de la indagación en un video. \\
& Los cuales se verificarán con la rúbrica. \\
\hline Conclusiones & - \\
& Resolución preguntas de reflexión y \\
& metacognición: ¿Cómo se sintieron?, ¿Qué \\
& aprendieron y cuáles fueron sus vivencias?, \\
& ¿Cómo les pareció la experiencia?, ¿Qué \\
& dudas o sugerencias les surgieron? ¿Qué \\
& acciones podemos llevar a cabo para cuidar \\
& el bosque? \\
& La conclusión se realiza de manera grupal en \\
& una plenaria una vez terminadas todas las \\
& actividades de la Webquest.
\end{tabular}

Fuente: elaboración propia (2015)
Teniendo en cuenta que la propuesta mencionada debe permitir una practica investigativa idónea se ha tenido en cuenta que se realice una evaluación para determinar si el estudiante demuestra interés en las actividades programadas, participa activamente en las actividades individuales y grupales, evidencia trabajo colaborativo y participa en las discusiones sugeridas, por lo que se ha elegido a la rúbrica, como instrumento de evaluación del tema, formando parte de la propuesta de la Webquest, por lo que en la Tabla 2 se describe los criterios.

\section{Tabla 2}

Rúbrica de las actividades en la Webquest.

\begin{tabular}{|c|c|c|c|c|c|}
\hline $\begin{array}{l}\text { Notas } \\
\text { Indicadores }\end{array}$ & 5.0 & 4.0 & 3.0 & 2.0 & 1.0 \\
\hline $\begin{array}{l}\text { Mapas } \\
\text { conceptuales }\end{array}$ & $\begin{array}{l}\text { El estudiante entrega } \\
\text { el mapa conceptual } \\
\text { de cada lectura. }(3 \\
\text { mapas). Los mapas } \\
\text { son coherentes con los } \\
\text { documentos. }\end{array}$ & $\begin{array}{l}\text { El estudiante entrega } \\
\text { el mapa conceptual } \\
\text { de cada lectura. Pero, } \\
\text { algunos mapas no son } \\
\text { coherentes con los } \\
\text { documentos. }\end{array}$ & $\begin{array}{l}\text { El estudiante entrega } \\
\text { el mapa conceptual de } \\
\text { cada lectura. Pero, los } \\
\text { mapas no son coheren- } \\
\text { tes con los documentos. }\end{array}$ & $\begin{array}{l}\text { El estudiante no entrega } \\
\text { los mapas completos. } \\
\text { Los mapas no son cohe- } \\
\text { rentes con los documen- } \\
\text { tos. }\end{array}$ & $\begin{array}{l}\text { El estudiante no entrega } \\
\text { mapa conceptual de nin- } \\
\text { guna lectura. }\end{array}$ \\
\hline $\begin{array}{l}\text { Presentación } \\
\text { Video/Animada }\end{array}$ & $\begin{array}{l}\text { Aborda el tema con } \\
\text { claridad. Tiene fotogra- } \\
\text { fías, sonidos, videos, es } \\
\text { llamativa, tiene textos } \\
\text { claros, coherentes y con } \\
\text { buena ortografía. }\end{array}$ & $\begin{array}{l}\text { Aborda parcialmente los } \\
\text { temas. Tiene fotografías } \\
\text { sonidos, videos, es } \\
\text { llamativa, tiene textos } \\
\text { claros, coherentes y } \\
\text { con buena ortografía. }\end{array}$ & $\begin{array}{l}\text { Aborda escasamente } \\
\text { los temas. Tiene foto- } \\
\text { grafías, pero no tiene } \\
\text { sonidos ni videos, es } \\
\text { llamativa, tiene textos } \\
\text { claros, coherentes y } \\
\text { algunas fallas ortográ- } \\
\text { ficas. }\end{array}$ & $\begin{array}{l}\text { No aborda claramente los } \\
\text { temas. Tiene pocas foto- } \\
\text { grafías, no tiene sonidos } \\
\text { ni videos. Es poco atracti- } \\
\text { va, no tiene textos claros, } \\
\text { presenta mala ortografía. }\end{array}$ & $\begin{array}{l}\text { No se entregó presen- } \\
\text { tación. }\end{array}$ \\
\hline $\begin{array}{l}\text { Exposición de } \\
\text { la presentación }\end{array}$ & $\begin{array}{l}\text { El expositor domina el } \\
\text { tema, es claro en su } \\
\text { argumentación contesta } \\
\text { preguntas de sus com- } \\
\text { pañeros }\end{array}$ & $\begin{array}{l}\text { El expositor domina el } \\
\text { tema, es claro en su } \\
\text { argumentación, pero } \\
\text { no contesta claramente } \\
\text { las preguntas de sus } \\
\text { compañeros. }\end{array}$ & $\begin{array}{l}\text { El expositor domina el } \\
\text { tema medianamente, } \\
\text { responde vagamente } \\
\text { las preguntas de sus } \\
\text { compañeros. }\end{array}$ & $\begin{array}{l}\text { El expositor no domina el } \\
\text { tema, titubea. }\end{array}$ & No hizo exposición \\
\hline $\begin{array}{l}\text { Cartelera o } \\
\text { póster }\end{array}$ & $\begin{array}{l}\text { El estudiante presenta } \\
\text { las carteleras o posters } \\
\text { completos (10), cada } \\
\text { una con una acción de } \\
\text { conservación de la bio- } \\
\text { diversidad. El material } \\
\text { presenta textos claros, } \\
\text { imágenes y buena } \\
\text { ortografía. }\end{array}$ & $\begin{array}{l}\text { El estudiante presenta } \\
\text { las carteleras o posters } \\
\text { completos (10)- Pero, } \\
\text { no todas presentan } \\
\text { acciones de conserva- } \\
\text { ción de la biodiversidad. } \\
\text { El material presenta } \\
\text { textos claros, imágenes } \\
\text { y buena ortografía. }\end{array}$ & $\begin{array}{l}\text { El estudiante presenta } \\
\text { las carteleras o posters } \\
\text { completos (10). Pero, } \\
\text { no todas presentan } \\
\text { acciones de conserva- } \\
\text { ción de la biodiversidad. } \\
\text { El material presenta } \\
\text { textos claros, imágenes } \\
\text { y algunos errores de } \\
\text { ortografía. }\end{array}$ & $\begin{array}{l}\text { El estudiante no entrega } \\
\text { el material completo. Las } \\
\text { carteleras o los posters } \\
\text { no abordan acciones cla- } \\
\text { ras para la conservación } \\
\text { de la biodiversidad. Pre- } \\
\text { senta textos incoherentes } \\
\text { y errores de ortografía }\end{array}$ & $\begin{array}{l}\text { El estudiante no presen- } \\
\text { ta cartelera o poster. }\end{array}$ \\
\hline Juego didáctico & $\begin{array}{l}\text { El juego aborda aspec- } \\
\text { tos de la conservación, } \\
\text { uso o promoción de } \\
\text { recursos naturales. Es } \\
\text { entretenido y divertido. }\end{array}$ & $\begin{array}{l}\text { El juego aborda par- } \\
\text { cialmente aspectos de } \\
\text { la conservación, uso o } \\
\text { promoción de recursos } \\
\text { naturales. Es entreteni- } \\
\text { do y divertido. }\end{array}$ & $\begin{array}{l}\text { El juego aborda par- } \\
\text { cialmente aspectos de } \\
\text { la conservación, uso o } \\
\text { promoción de recursos } \\
\text { naturales, sin embargo, } \\
\text { no es entretenido ni } \\
\text { divertido. }\end{array}$ & $\begin{array}{l}\text { El juego no aborda as- } \\
\text { pectos de la conserva- } \\
\text { ción, uso o promoción de } \\
\text { recursos naturales. }\end{array}$ & $\begin{array}{l}\text { El grupo no presenta } \\
\text { juego didáctico. }\end{array}$ \\
\hline
\end{tabular}

Fuente: elaboración de las autoras. 


\section{Discusión y Conclusiones}

La importante transformación que han sufrido los ecosistemas naturales en todo el planeta plantea necesidades imperantes de restauración ecológica. Lo acontecido en el bosque ubicado en las instalaciones de la Institución Educativa Antonio de Florencia, Colombia, corresponde a afectaciones que obedecen a distintos enfoques de manejo del territorio; particularmente, en lo relacionado con el ordenamiento territorial y a aspectos de degradación como consecuencia de las actividades humanas (SER, 2004). Este tipo de degradación no sólo responde a los modelos económicos imperantes, sino que también tiene un origen en las percepciones y actitudes humanas hacia el medio ambiente (Barraza, 2001), aspecto que pudo contrastarse en este estudio.

Por lo anterior y con base en la información obtenida, se propone el uso de la Webquest como alternativa para esta problemática, dado que es considerada una estrategia útil para ser incluida en iniciativas educativas que promuevan la conservación y el desarrollo sostenible y promover la inclusión de la restauración ambiental en las perspectivas y estrategias educativas. De esta manera, se podría contribuir al logro de los objetivos globales para la restauración forestal formulados en las iniciativas del Reto de Bonn y la Declaración de los Bosques de la Cumbre sobre el Cambio Climático $\left(\mathrm{ONU}^{6}, 2014\right)$, los cuales persiguen la restauración de 150 y de 350 millones de hectáreas de bosques, para los años 2020 y 2030, respectivamente.

Por otra parte, es necesario recalcar que la indagación de la fase diagnóstica en esta investigación, se constituye en una etapa importante para el diseńo de estrategias educativas inherentes a educación ambiental, dado que posibilita la ampliación de los horizontes de aplicación; esto se traduce en la creación de herramientas que permitan el diálogo entre las diferentes visiones de la naturaleza a través de prácticas investigativas, así como la adaptación del ser humano a los retos de las problemáticas ambientales y hacia a formación de recursos humanos orientados hacia la conservación del entorno natural.
Asimismo, la primera fase de la investigación de este estudio también demostró que la Webquest se constituyó en una estrategia potencial de educación ambiental porque su carácter de búsqueda, indagación y análisis de información facilitan el planteamiento de prácticas investigativas de restauración ecológica. La flexibilidad de su estructura permite la fácil vinculación de diversos procesos y además la incorporación de otros elementos mediadores importantes como los contenidos, el contexto institucional, los materiales y los profesores.

Los anteriores aspectos coinciden con Goig (2012) al enfatizar que la Webquest es una potente herramienta didáctica que se puede usar en todas las áreas de conocimiento y en cualquier nivel educativo. En este propósito, se espera realizar en una segunda fase de la investigación, la implementación de la webquest para determinar si efectivamente la estrategia incrementa la motivación de los estudiantes y además desarrolla la capacidad de resolución de problemas, así como la de selección, análisis y síntesis de la información. Asimismo, para corroborar si la estrategia Webquest contribuye a lograr los objetivos de la educación ambiental en razón a lo propuesto por Hungerford (2010) en relación con la contribución respecto a la generación de actitudes responsables para tomar decisiones relativas a medio ambiente.

Para investigaciones futuras, se considera necesario avanzar en el desarrollo de proyectos de investigación en los que se establezcan relaciones interdisciplinares entre lo educativo, lo cultural, lo ambiental y lo tecnológico para plantear y desarrollar estrategias pedagógicas mediadas por la investigación y la TIC como es el caso de la Webquest.

Estas estrategias educativas deben buscar promover el diálogo y el consenso; por lo que también sería pertinente conocer la perspectiva del docente en la aplicación de estas estrategias para la educación ambiental, si realmente fomenta el desarrollo de actitudes de conservación de los entornos naturales y si puede considerarse una renovación metodológica con el uso de las TIC en la escuela. 
Propuesta de práctica investigativa con la Webquest. Estrategia pedagógica de comprensión del concepto e importancia del "bosque"

\section{REFERENCIAS BIBLIOGRÁFICAS}

Adell, J. (2004). "Internet en el aula: las WebQuest”, Edutec. Revista Electrónica de Tecnología Educativa, 17. Recuperado de: http://www.uib.es/depart/gte/edutec-e/revelec17/adell_16a.htm

ANBG (2007). Webquest: Mununja the Butterfly. Australian National Botanic Gardens. Recuperado de: https:// www.anbg.gov.au/apu/webquest.html

Baro, A. (2011). Metodologías activas y aprendizaje por descubrimiento. Innovación y experiencias educativas, 40. 1-11. Recuperado de: https://archivos.csif.es/archivos/andalucia/ensenanza/revistas/csicsif/revista/pdf/Numero_40/ ALEJANDRA_BARO_1.pdf

Barraza, L. (2001). Perception of social and environmental problems by English and Mexican school children. Canadian Journal of Environmental Education, 6, 139-157.

Calatayud, M. (2008). La autoevaluación como estrategia de aprendizaje para atender a la diversidad. Recuperado de http://www.educaweb.com/noticia/2008/01/28/autoevaluacion -como-estrategia-aprendizaje-atender-diversidad-12752.html

Condal, F. (2012). The Webquest for marine biodiversity study. Tesis de maestría. Recuperado de: https://www.researchgate.net/publication/255679361_The_Webquest_for_ marine_biodiversity_study.

Dean, R. (2015). Biodiversity and sustainability WebQuest. Recuperado de: http://www.createwebquest.com/webquest/ biodiversity-and-sustainability-webquest

Dirzo, R. H. S., Young, M., Galetti, G., Ceballos, N. J. B. \&. Collen, I. B. (2014). Defaunation in the Anthropocene. Science, 345, 401-403. Recuperado de:

https://doi.org/10.1126/science.1251817

Dodge, B. (1997). Some Thoughts About WebQuests. Recuperado de: http://mennta.hi.is/vefir/danska/webquest1/ Some\%20Thoughts\%20About\%20WebQuests.htm

Dodge, B. (2002). WebQuest taskonomy: a taxonomy of tasks. Recuperado de: http://webquest.org/sdsu/taskonomy. html

Ellis, E. (2015). Ecology in an anthropogenic biosphere. Ecological Monographs, 85, 287-331. Recuperado de: https://doi.org/10.1890/14-2274.1

García, A. (2014). Tratamiento de la educación ambiental en la educación secundaria obligatoria. El uso de la Webquest como recurso didáctico. (Tesis de maestría). Recuperado de: http://reunir.unir.net/handle/123456789/2653

Gimeno, J. y Pérez, A. (2000). La función y formación del profesor en la enseńanza para la comprensión. Diferentes perspectivas. Comprender y transformar la enseńanza. 9a edición. Madrid: Morata. PMCid:PMC14825

Goig, R. (2012). El uso de la Webquest como recurso didáctico innovador en el $2^{\circ}$ ciclo de Educación Infantil. Revista Electrónica de Investigación y Docencia (REID), 7, 73-89. Recuperado de: http://www.revistareid.net/revista/n7/REI-

\section{D7art4.pdf}

Göktepe, S. (2014) A webquest example for mathematics education. Procedia-Social and Behaviral Sciences, 1 (16), 2175-2179. Recuperado de: https://doi.org/10.1016/j.sbspro.2014.01.539

Hungerford, H. (2010). Environmental Education (EE) for the 21st Century: Where have we been? Where are we now? Where are we headed? Journal Environmental Education, 41, 1-6. Recuperado de: https:/doi. org/10.1080/00958960903206773

Kpinkleton (2011). Biodiversity/extinction Webquest. Recuperado de: https://www.livebinders.com/play/ play?id=246421

Kennedy, S. (2004). The well-constructed WebQuest. Social Studies and the Young Learner, 16(4), 17-19.

Martínez, E. y Salas, Z. (2015). Aplicación de una Webquest, como estrategia pedagógica para que los niños de grado tercero (30) de la Institución Educativa Marco Fidel Suárez de Ciénaga de Oro, Córdoba se apropien de la historia del Departamento. (Trabajo de Especialización). Fundación universitaria los Libertadores. Facultad de Ciencias de la Educación. Especialización en Informática y Multimedia en educación.

Molebash, P., \& Dodge, B. (2003). Kickstarting inquiry with WebQuests and Web inquiry projects. Social Education, 67, 158-162.

Mrsclarke (2013). Grade 5/6 Biodiversity Webquest. Recuperado de https://mrsclarkeblog.wordpress.com/2013/09/30/ grade-56-biodiversity-webquest/

Newbold, T., Hudson, L. N., Hill, S. L. L. et al. (2015). Global effects of land use on local terrestrial biodiversity. Nature, 520, 45-50. Recuperado de: https://doi.org/10.1038/ nature 14324

ONU (2014). FORESTS. Action Statements and Action Plans. Recuperado de: http://www.un.org/climatechange/ summit/wp-content/uploads/sites/2/2014/07/New-YorkDeclaration-on-Forest-\%E2\%80\%93-Action-Statementand-Action-Plan.pdf

Primack, R. y Massardo, F. (2001). Restauración Ecológica. En: Primack, R., Rozzi, R., Feinsinger, P., Dirzo, R. \& Massardo, F. (Eds.). Fundamentos de conservación biológica perspectivas latinoamericanas. México: Fondo de Cultura Económica, pp. 559-582.

Pierce, J. (2011) La aplicación de la teoría del constructivismo al aprendizaje de lenguas para fines específicos a través de la webquest. Innovación educativa, 21, 279-288. Recuperado de: http://www.usc.es/revistas/index.php/ie/article/ download/39/156.

Pinantoan, A. (2013, marzo). Webquests - An Introductory Guide and Resources. InformEd. Recuperado de: https:// www.opencolleges.edu.au/informed/teacher-resources/webquests/

Roblizo, M., \& Cózar, R. (2015). Usos y Competencias En Tic En Los Futuros Maestros De Educación Infantil Y 
Primaria: Hacia Una Alfabetización Tecnológica Real Para Docentes. Pixel-Bit. Revista de Medios y Educación, (47), 23-39. Recuperado de:

https://doi.org/10.12795/pixelbit.2015.i47.02

SER (2004). Principios de SER International sobre la restauración ecológica. Recuperado de: www.ser.org y Tucson: Society for Ecological Restoration International.

Sosa, M. J. (2013). La WebQuest: ventajas e inconvenientes como recurso educativo. V Simposio Pluridisciplinar sobre Diseño y Evaluación de Contenidos Educativos Reutilizables. Recuperado de: http://www.web.upsa.es/spdece08/ contribuciones/146_poster_WEBQUESTdefinitiva.pdf

Trovato, G. (2013) Las nuevas metodologías didáctica en el aprendizaje del espa-ol L2: la webquest y sus aplicaciones en el ámbito del español del turismo. Revista de Lenguas modernas, 18, 299-311. Recuperado de: Yoder, M. B. (1999). The Student Webquest. Learning \& Leading with Technology. 26(7), 7-52. Recuperado de https://daretodifferentiate. wikispaces.com/file/view/webquest.pdf

Strickland, J. (2005). Using webquests to teach content: Comparing instructional strategies. Contemporary Issues in Technology and Teacher Education, 5(2), 138-148.

Ulloa, C., Rey, G., Sánchez, A. \& Cancela, A. (2012). Power Plants, Steam and Gas Turbines WebQuest. Educ. Sci, 2(4), 180-189. Recuperado de: https://doi.org/10.3390/educsci2040180

VanFossen, P. J. (2004). Using WebQuests to scaffold higher-order thinking. Social Studies and the Young Learner, 16(4), 13-16.

Washingtonville (s/f). Ecological Footprint Web Quest Activity. Washingtonville, Central School District. Recuperado de: http://www.ws.k12.ny.us/APESFiles.aspx

Yoder, M. B. (1999). The Student Webquest. Learning \& Leading with Technology. 26(7), 7-52. Recuperado de: https://daretodifferentiate.wikispaces.com/file/view/webquest.pdf

Zunal (2015). Species at Risk: Biodiversity Inquiry Project. Recuperado de: http://zunal.com/webquest.php?w=276337 


\title{
Despliegue de una Red Inalámbrica Libre Comunitaria: un ejercicio de soberanía digital en el barrio Villa del Río (Bogotá, Colombia)
}

\section{Deploying an Open Community Wireless Network: An exercise on digital sovereignty in Villa del Río neighborhood (Bogotá, Colombia)}

\author{
Leonardo Gonzalo Taborda Ángel ${ }^{1}$
}

Universidad Pedagógica Nacional, Colombia

Recibido: 01-10-2017

Aceptado: 21-12 -2017

\section{Cita Recomendada}

Taborda, L. (2017) Despliegue de una Red Inalámbrica Libre Comunitaria: un ejercicio de soberanía digital en el barrio Villa del Río (Bogotá, Colombia). Hamut'ay, 4 (2), 80-81. Recuperado de: http://dx.doi.org/10.21503/hamu.v4i2.1486

\section{RESUMEN}

En este estudio se presenta una revisión general de la literatura existente en el campo de las Redes Inalámbricas Comunitarias a nivel nacional e internacional, haciendo un paralelo con la experiencia desarrollada por Network Bogotá en el despliegue de este tipo de red en el barrio Villa del Río, que se localiza en Bogotá, Colombia. El objetivo del artículo es presentar la recopilación bibliográfica desde una investigación documental, para ello se han utilizado bases de datos especializadas en la temática y una serie de descriptores para su búsqueda.

Uno de los aspectos más relevantes a tener en cuenta entre la experiencia aquí descrita y la revisión de literatura, es que el éxito de una red comunitaria tiende a ser más favorable si en la difusión del proyecto participan las administraciones locales, ya que éstas generan confianza y credibilidad en los habitantes que utilizarán la red. De igual forma, las conclusiones establecen que es fundamental para el desarrollo de la red abordar un "diseño crítico" de la misma en el cual la comunidad se torna consciente de que la red no solo aporta a la transformación de problemáticas actuales, sino que también ostenta unas capacidades de expansión futuras donde las soluciones a situaciones o propuestas de nuevos servicios surgirán de la recursividad de sus usuarios. También, se concluye que impulsar la construcción de una red comunitaria como una labor tipo "hágalo usted mismo" permite el empoderamiento tecnológico en personas no expertas, es decir, que los habitantes de un lugar determinado pueden diseñar y desplegar sus troncales de comunicación sin tener que ser desarrolladores o técnicos en redes o informática.

Palabras Clave: Redes Inalámbricas Comunitarias, Redes en Malla, Soberanía Digital, Quick Mesh Project.

1 Licenciado en español y Lenguas Extranjeras de la Universidad Pedagógica Nacional (Colombia), Miembro del proyecto de Redes Inalámbricas Network Bogotá, Integrante del Semillero de Investigación KENTA de la Universidad Pedagógica Nacional (Colombia). E-mail: leonardotaborda@networkbogota.org 


\section{Abstract}

This study presents a general review of the existing literature in the field of Community Wireless Networks at a national and international level. It makes a parallel with the experience developed by Network Bogotá in the deployment of this type of network in Villa del Río neighborhood, which is located in Bogotá, Colombia. The aim of the article is to present a bibliographic compilation from a documentary research. Thus, specialized databases on the subject have been used as well as a series of descriptors for its search.

One of the most relevant aspects to take into account between the experience described here and the literature review, is that the success of a community network tends to be more favorable if local authorities participate in the diffusion of the project, since this generate trust and credibility in the inhabitants who will use the network. Likewise, the conclusions establish that it is fundamental for the development of the network to undertake a "critical design" of itself, through which the community becomes aware that the network not only contributes to the transformation of current problems, but it also has future expansion capabilities where solutions to situations or proposals for new services will arise from the resourcefulness of its users. It is also concluded that promoting the construction of a community network under the concept "do-it-yourself" makes possible the technological empowerment of non-expert people; that is, the inhabitants of a specific place can design and deploy their communication trunks without the necessity to be developers or technicians in networks or computer science.

Keywords: Community wireless Network, Mesh Networks, Digital sovereignty, Quick Mesh Project.

\section{INTRODUCCIÓN}

Internet es sin lugar a duda una de las más grandes invenciones en la historia de la Humanidad, porque ha permitido romper fronteras de espacio y tiempo en las comunicaciones e incursionar en los diversos ámbitos profesionales, académicos, económicos, de salud, empresariales, educativos y de la comunidad en general, pero a pesar de ello, es preocupante encontrar que alrededor de la mitad de la población mundial no cuenta aún con acceso a Internet a pesar de innumerables esfuerzos (Internet Society, 2016, p.32), siendo diversos factores que se confabulan, entre los que se destacan la inestabilidad en las conexiones a Internet, la situación política y económica de cada país o marcos regulatorios desactualizados sobre este tema (Chamorro \& Pietrosemoli, 2008, p. 10), además de la ausencia de contenidos locales relevantes en Internet para el usuario final, es decir, de información y servicios que guarden relación con su área geográfica más inmediata, el idioma y las necesidades que se tiene en el contexto (Kende, 2016). Sumado a esto, la separación que existe entre los que tienen y los que no poseen acceso libre a la información dan origen a una brecha digital, en cuya reversión pueden aportar las Redes libres (Gordillo, 2013, p.11), no solo entendidas como redes de computadoras interconectadas, sino como Redes Comunitarias implementadas en poblaciones vulnerables, donde el acceso a la información es una posibilidad, pero no una realidad.

La implementación de estas redes tiene la finalidad de brindar tecnología y contenidos de difusión libre, las cuales son autogestionadas al ser administrada por sus propios usuarios y abierta a toda la comunidad. Por su parte Forero (2012) refiere que los servicios de comunicaciones comunitarias no pueden ser impuestas, sino que estos deben ser el resultado de una necesidad sentida. Más aún, la comunidad a través de sus líderes democráticos debe ser partícipe en todo el proceso 
de gestación, instalación y gestión de los medios comunitarios. Complementando este aspecto, Rivera (2017), enfatiza "el derecho de los pueblos a acceso tecnológico, navegar por internet, recibir, transmitir y almacenar información de forma segura" (p. 68), así como "la capacidad de un pueblo de gestionar la producción y distribución tecnológica y digital que consume. Cabe recordar que el diseño de una red comunitaria difiere en gran medida del diseño de una red de comunicaciones empresarial o de telefonía móvil; factores económicos y de voluntad de los habitantes de un sector para participar en una red son los principales denominadores en su 'diseño'".

Para Kos, Jernej \& Milutinović, Mitar \& Čehovin, Luka. (2015):

"Las redes comunitarias difieren de las redes regulares debido a sus patrones de crecimiento orgánicos - no cuentan con un cuerpo central que pudiese decidir cómo la red es construida. En cambio, la red crece de manera vertical, de abajo hacia arriba, en cuanto más gente exprese interés en participar en la comunidad y conectarse con sus vecinos" (p.1).

Desde estas perspectivas, es donde una Red Inalámbrica Libre Comunitaria (RILC) entra a transformar y mejorar las situaciones previamente descritas, lo que permite el desarrollo en lo personal, comunitario, social, al ayudar a acortar la brecha digital y facilitar el analfabetismo digital, y apoyar en la difusión de cultura y negocios electrónicos, entre unidades educativas o comunitarias (Luzardo, 2016); así como la existencia de la Ley 1341 de 2009 como un marco legal que garantiza el derecho ciudadano a la comunicación y el acceso a la información en Colombia. Desde estas perspectivas, el objetivo de este artículo es presentar una revisión de la literatura existente en el campo de las RILC, vinculando la experiencia desarrollada por Network Bogotá en el despliegue de una Red Inalámbrica Libre Comunitaria en el barrio Villa del Río, que se localiza en Bogotá, Colombia.

\section{Método}

Para poder presentar la información documental, por ser este un estudio bibliográfico, se realizó la revisión de la literatura en bases de datos científicas en Internet, como Google Académico, Science Direct, Dialnet y base de datos de Publindex, repositorio de la Universidad Nacional de Colombia, e-ANAQUEL (Repositorio Colombiano en Ciencia, Tecnología e Innovación) bases de datos internacionales como web of science, en un periodo de casi una década desde el 2008 a la actualidad, para lo cual se utilizaron descriptores para la búsqueda utilizando como palabras claves: "Community Networking, Mesh Networks, MANET Networks, Point-to-Multipoint links, Guifinet, Freifunk, OLSR, OpenWRT, P2P Networking, Critical Design, Redes Comunitarias, Comunicación Comunitaria, Televisión Comunitaria en Colombia". Con la información obtenida se describió cualitativamente los aspectos relacionado a RILC y la experiencia de Network Bogotá.

\section{Redes Inalámbrica Comunitarias}

Una Red Comunitaria es una troncal o infraestructura alámbrica e inalámbrica que una comunidad o grupo de habitantes construye para satisfacer o mejorar necesidades en materia de comunicación o Tecnologías de la Información y la Comunicación (TIC). De acuerdo con Baig et al. (2015) y Cepeda (2014), estas redes se organizan, construyen y organizan de manera abierta, libre y neutral por parte de las comunidades. Este tipo de redes surge desde el "hágalo usted mismo" (DIY) que en palabras de Antoniadis (2016) se define como "una variedad de soluciones técnicas que facultan a los ciudadanos a construir y operar sus propias redes de comunicaciones". Por estas razones es evidente el potencial de una RILC no solo para dar solución a necesidades y carencias en TIC a nivel local, como puede ser la falta de una emisora comunitaria o un sistema de cámaras de vigilancia; sino desde el ejercicio local, desde lo micro, construir a escala global, hacia lo macro, es decir, hacia Internet. Por su parte, Chamorro \& Pietrosemoli (2008), refieren que "las redes inalámbricas comunitarias son redes que permiten el acceso inalámbrico a diferentes tipos de recursos 
y servicios disponibles, ya sea en internet o en una red local, y que se caracterizan por ser diseñadas e implementadas esperando contribuir al mejoramiento de la calidad de vida de las comunidades" (p. 3). Además, Albarracín (2008) comenta que una RILC permite que los habitantes de un barrio tengan acceso a contenidos educativos bajo licencia libre y herramientas groupware, y desde la gestión de la comunidad, generan la publicación de contenidos y fomentan el uso de herramientas virtuales educativas, sobre todo en los menos favorecidos (p.25). Desde estos enfoques nace el proyecto "Network Bogotá" como respuesta a este movimiento mundial de comunicaciones comunitarias, definiéndose como "un grupo de trabajo que busca fomentar y generar conciencia sobre la importancia de contar con redes o troncales de información libres y comunitarias, donde los usuarios de las redes sean ciudadanos digitales de primera mano" y considerando además a la red comunitaria como la construcción de una red humana y social de participaciones, alianzas, trueques y de reconocerse en el otro, como ocurrió en los ańos 90 con el nacimiento de la televisión comunitaria, así las RILC son la resignificación de dicho ejercicio.

\section{Experiencias de Redes Inalámbricas Comunitarias}

A continuación, se describirán algunas experiencias, que han sido un referente para la implementación de la Red Inalámbrica Libre Comunitaria en el barrio Villa del Río (Bogotá, Colombia) realizada por Network Bogotá.

\section{Guifinet - Cataluña (España)}

Con un transcurrir de al menos una década de existencia, GUIFINET es la red inalámbrica autogestionada más grande del mundo. Con 34.021 nodos operativos a la actualidad, su red se extiende a lo largo y ancho de Cataluña y otros lugares de la península ibérica. Según Baig et al. (2015) "guifi.net comenzó como un grupo de personas que se reunían regularmente para planificar y desplegar la red. Este grupo buscaba formas de crear infraestructura de red entre aficionados en zonas rurales remotas, zonas ignoradas o desatendidas por los ISP (Internet Service Providers) conven- cionales" (p. 2). El trabajo desarrollado por los integrantes de guifi.net ha sido tan extenso que el proyecto es supervisado por la "Fundació per a la Xarxa Oberta, Lliure i Neutral", donde han logrado establecer redes comunitarias no sólo inalámbricas sino alámbricas, basadas en conexiones de fibra óptica FFTH, (Fiber to Home) registrándose como un operador de telecomunicaciones, contando con su propio número de sistema autónomo (AS) y con conexión al punto neutro CATNIX (Catalunya Neutral Internet Exchange) (San Miguel Pérez, 2017, p.7), lo que permite entregar Internet simétrico de banda ancha.

Los principios fundamentales de guifi.net son totalmente incluyentes, giran en torno a i) la apertura de acceso (uso) de la infraestructura, y ii) la apertura de participación (construcción, operación, gestión) en el desarrollo de la infraestructura y su comunidad. Es a partir de estos principios que la mayoría de las redes comunitarias empoderan a sus beneficiarios hacia una soberanía y una alfabetización digital, sin olvidar las peculiaridades de cada espacio que hacen aún más relevante la presencia o no de una red comunitaria. Se puede decir que los principios hacen parte de unos mínimos irrenunciables al momento de construir cualquier red autogestionada.

\section{Altermundi (Argentina)}

Altermundi es quizás el más exitoso proyecto de comunicaciones comunitarias en América Latina (Britos et al. 2016, p. 145), que ha desarrollado la gran mayoría de sus redes en Argentina y ha logrado llevar adelante importantes avances para el continente, aportando conocimiento organizacional y técnico, software (Libremesh) y hardware (Librerouter) para facilitar el despliegue de redes comunitarias, eliminando la dependencia de hardware SOHO (small office and home) el cual requiere adaptaciones para operar adecuadamente en redes libres (Librerouter, 2016).

Los esfuerzos realizados por esta organización han aportado software, hardware, marcos de regulación y políticas adecuadas en el campo de las comunicaciones comunitarias a gran cantidad de personas, y evidencian el peso en el campo de las telecomunicaciones que se puede realizar desde lo local para transformar los modelos actuales de in- 
Despliegue de una Red Inalámbrica Libre Comunitaria: un ejercicio de soberanía digital en el barrio Villa del Río (Bogotá, Colombia)

terconexión y transmisión de información.

\section{Red Inalámbrica Comunitaria de Bogotá - RICB (Colombia)}

A nivel Colombia se han llevado iniciativas importantes para transformar la conectividad en áreas tanto rurales como urbanas. El proyecto RICB que surgió desde la Facultad Tecnológica de la Universidad Distrital Francisco José de Caldas, se interesó en desplegar una red inalámbrica comunitaria para mejorar el acceso a herramientas TIC por parte de los habitantes de la localidad de Ciudad Bolívar. Pedraza, Gómez y Mancilla (2014). refieren que, desde una perspectiva investigativa y académica, se despliega una red que vinculó a Juntas de Acción Comunal e instituciones distritales de educación, a la par que se empleaban instrumentos de recolección y análisis de información para poder ofrecer en la red servicios relevantes para sus usuarios.

Con el trabajo detallado y riguroso realizado, se generaron experiencias pedagógicas mediante el uso de la red por parte de los usuarios beneficiarios, dado que varios colegios públicos del sector se vincularon en el despliegue de la infraestructura. A través de encuestas en las instituciones educativas participantes, los líderes del proyecto RICB obtuvieron que el $70 \%$ de usuarios conocen los cursos virtuales ofrecidos en la red, el 30\% de encuestados pueden emplear satisfactoriamente los cursos diseñados y un $90 \%$ de beneficiarios afirma que se requieren instalar más antenas para expandir la red y alcanzar a más personas. (Pedraza, Gómez y Mancilla, 2014). Otro de los reportes de experiencia en Colombia lo expresan Pedraza, Gómez y Salcedo al haber trabajado con tecnología Mesh (2012).

\section{Redes comunitarias en África}

Sobre las redes comunitarias en África, afirma Rey-Moreno (2017, p.20) que "constituye un esfuerzo considerable cambiar una mentalidad impuesta tras generaciones de dominio colonial. Como resultado, muchos son reacios a actuar en algo completamente diferente", y continúa, "Zenzeleni Networks (Sudáfrica) luchó por meses para poder abrir una cuenta bancaria, ya que los gerentes de los bancos en la ciudad más cercana no podían creer que habitantes de las áreas rurales estuviesen creando su propia cooperativa de telecomunicaciones".

\section{Redes Inalámbricas Comunitarias y su aporte a lo social}

Los cambios que se han ido dando a nivel del tiempo en esta era de la globalización y del auge tecnológico y el deseo de querer acercar al uso y apropiación de la tecnología a los menos favorecidos y se revierta esta brecha digital que aún existe, ha dado paso a la coyuntura tecnológica actual, donde se ha dado un beneficio a la masificación de la electrónica de consumo, de la ingeniería inversa que libera capacidades ocultas en dispositivos SOHO (small office and home) para el beneficio de las comunicaciones comunitarias y de la gestión de políticas y regulaciones favorables para la difusión de Internet, el desarrollo del software libre y el "open Access", aspectos fundamentales que han permitido dar como alternativa la implementación de RILC, permitiendo aceptar está, dado que ya no es posible rechazarla, porque está presente en todo momento, incluyendo a su vez a los seres humanos en ella, provocando pensamiento crítico, creativo y ético (Bebea, 2015). La implementación de una RILC requiere un trabajo social con cada participante de la red, al estar destinado a compartir un servicio común para todos con apropiación de la tecnología, sin fines de lucro, en zonas rurales, urbano marginales y aquellas que carecen de la información, telecomunicaciones, desde un enfoque holístico, ya que no se trata solo de instalar puntos de acceso inalámbricos, sino es necesaria la creación de servicios relevantes y el manejo y superación de problemáticas arraigadas por años, de educación, desarrollo local, salud, contenidos e investigación, (González, Otero y Vecino, 2011). Reiterando ese aspecto social RILC constituyen una alternativa abundante en materia de servicios locales que responden a la propiedad y control de la infraestructura, la proximidad física sin que esto involucre revelar información personal sensible, la independencia de grandes proveedores de acceso a Internet y con un énfasis en la mejora de los servicios de videovigilancia, seguridad, servicios educativos, lo cual lo asevera Baig, Roca y Freitag, (2016, p. 3) al exponer que el desarrollo de una RILC es una producción social o una producción colabo- 
rativa, porque los participantes trabajan de forma cooperativa, a escala local, para desplegar una infraestructura y construir islas de redes. Complementando lo mencionado Baladrón (2017), en el reporte que hace de la experiencia en Buenos Aires, refiere que este tipo de redes comunitarias impulsan la apropiación popular de la tecnología, con una mirada que reivindica la comunicación como derecho humano, todo lo anteriormente mencionado ha conllevado a que Network Bogotá impulse esta iniciativa en el barrio Villa del Río, como se describe a continuación.

Desplegando una red inalámbrica libre comunitaria por Network Bogotá

El trabajo de Network Bogotá con la comunidad del barrio Villa del Río, la Junta de Acción Comunal (JAC), nace de la necesidad de contar con una red no como una imposición, sino por el deseo de satisfacer inicialmente carencias en seguridad y vigilancia local, a través de circuitos de televisión (CCTV) accesibles a lo largo de la red comunitaria, opuesto al despliegue comunitario tradicional de cámaras que se realiza en Colombia, en el cual el dispositivo de grabación (DVR) queda bajo el control de un único individuo.

Dentro de este proceso se constata que la legislación actual colombiana en materia de TIC justifica y avala aún más la existencia de iniciativas como la propuesta realizada por Network Bogotá y los esfuerzos puestos en comunicaciones comunitarias, de acuerdo con la Ley 1341 de 2009 del Congreso de Colombia (2009), en la que se establece que:

La investigación, el fomento, la promoción y el desarrollo de las Tecnologías de la Información y las Comunicaciones son una política de Estado que involucra a todos los sectores y niveles de la administración pública y de la sociedad para contribuir al desarrollo educativo, cultural, económico, social y político e incrementar la productividad, la competitividad, el respeto a los derechos humanos inherentes y la inclusión social. (p. 1)

Teniendo la aceptación de la comunidad en el barrio Villa del Río de la implementación de la RILC, a continuación, se describen las etapas para el desarrollo de esta.

\section{Primera etapa de despliegue.}

Este primer momento de despliegue de infraestructura de red comunitaria se desarrolló a partir del 19 de agosto de 2017, siendo el principal espacio intervenido el edificio de la Junta de Acción Comunal (JAC). Para poder establecer confianza en el proyecto por parte de los posibles beneficiarios del barrio Villa del Río, Network Bogotá y el organismo local tuvieron que dar el primer paso para demostrar la calidad de la infraestructura de red y de gestión del proyecto. Como lo recuerda Antoniadis et al. (2015) desde el diseńo participativo "la experiencia ha demostrado que es muy importante ganar el compromiso y confianza de la comunidad -si un proyecto es visto como una intervención foránea sin un beneficio duradero éste será rechazado" (p. 5). Por tanto, la iniciativa anterior se desarrolló de cara a la expansión futura de la red, para disipar dudas, inseguridades e incluso arraigos culturales que pueden estar presentes en los habitantes del sector.

Como resultado, se instaló el primer nodo de la red en la Junta de Acción Comunal, compuesto por una antena inalámbrica o CPE Ubiquiti $\mathrm{Na}$ nostation M5 que opera en la frecuencia de $5 \mathrm{Gi}$ gahercios y un alcance máximo de 15 kilómetros con la finalidad de tener enlaces punto a punto de larga distancia a lo largo y ancho del barrio. Este dispositivo se instaló 15 metros de altura. En la misma jornada se instaló un rúter TP-LINK WDR3600 como punto de acceso para usuarios y como dispositivo de expansión de red gracias a que este equipo trabaja con el firmware "qMp"2, que posibilita la construcción de redes en malla o "mesh", las cuales son redes con una topología descentralizada, tolerante a fallos y en la cual un protocolo interno decide dinámicamente cuál es el mejor camino o ruta para alcanzar un destino dentro de la red (Vega et al., 2012).

Finalizando las labores de este primer momento de despliegue, se completó la puesta en punto

2 qMp (2017) es un firmware o sistema operativo para dispositivos embebidos o rúters, que se basa a su vez en el sistema operativo OpenWRT. qMp proporciona una forma fácil de desplegar redes en malla. Sitio: http://www.qmp.cat 


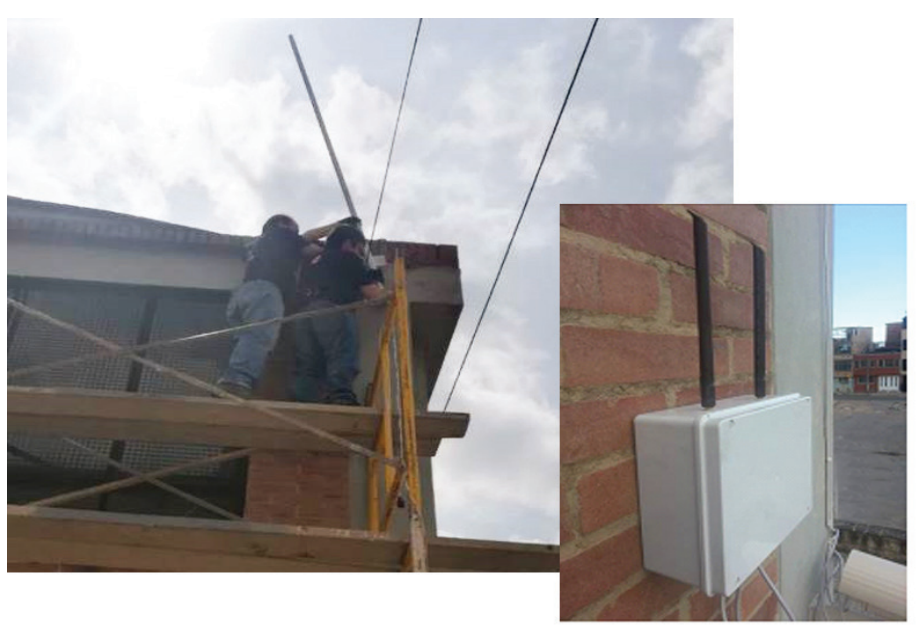

Figura 1. Izquierda: instalación de antena Nanostation M5 para enlaces troncales. Derecha: enrutador para redes en malla y punto de acceso.

Fuente: Elaboración propia.

de dispositivos en la Junta de Acción Comunal mediante la instalación de cableado Ethernet, cámaras de vigilancia análogas, DVR y un servidor comunitario con miras a la creación de la nube comunitaria de servicios o aljibe, donde se encuentran las aplicaciones y servicios que satisfarán las necesidades locales en el área de TIC.

\section{Segunda etapa de despliegue.}

Este momento de trabajo comunitario se ha venido desarrollando desde el 23 de septiembre de 2017 hasta la fecha y se espera concluir en la última semana de octubre del mismo año.

Con la presencia de la infraestructura instalada en la JAC, se citó una reunión con vecinos y autoridades pertinentes para explicar aquello que significa una red inalámbrica libre comunitaria y todas las posibilidades que ella puede ofrecer, recordando a Baig et al. (2015), quienes afirman que desde una apertura de participación se invita a la comunidad al desarrollo de la infraestructura, su construcción y gestión. El trabajo previamente desarrollado en la JAC sirvió de laboratorio viviente y muestra de confianza en el proyecto, como lo recomienda Antoniadis et al. (2015) acerca de la importancia de establecer confianza y beneficios en proyectos impulsados por agentes externos a la comunidad.

En esta ocasión, quienes financiaron esta etapa de la red fueron los habitantes de las carreras $67 \mathrm{y}$
68 con calle 55 A sur del barrio Villa del Río, siendo los primeros beneficiaros a gran escala del proyecto impulsado por Network Bogotá y la JAC. En una jornada de trabajo extenso y con apoyo directo de la comunidad, que comprendió que la infraestructura de red se construye como la infraestructura vial (Frankston, 2016) se instaló una segunda antena Ubiquiti Nanostation M5 para poder completar el primer enlace troncal entre dos ubicaciones del barrio (JAC y carrera 68). También se instalaron sobre esta misma ubicación dos rúters TP-LINK WDR3600, que actúan como puntos de acceso para usuario final, a través de los cuales se consumen y se producen los servicios locales relevantes. Más sin embargo estos rúters también aportan a la expansión de la red ya que cuentan con el mencionado firmware qMp para redes en malla.

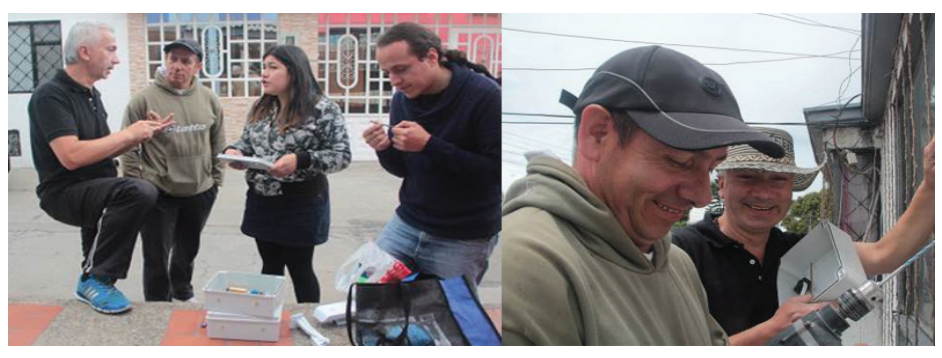

Figura 2. Izquierda: socializando con la comunidad el equipamiento de red y sus costos asociados por parte de la JAC y Network Bogotá. Derecha: residentes del sector liderando la instalación y despliegue de la red.

Fuente: Elaboración propia.

Terminada esta instalación en la carrera 68 del barrio Villa del Río se habilitó el primer tramo amplio de red comunitaria, ofreciendo cobertura para no menos de 100 residentes del sector beneficiado por la instalación local. El trabajo restante de esta etapa es la instalación de dos nodos para red en malla o mesh en la carrera 67. Como se puede constatar en la figura 3, la comunidad se empoderó en todos los niveles de despliegue de la red, tanto financieros como técnicos. Claramente, los principios básicos e irrenunciables en una red comunitaria definidos por Baig et al (2015) como "apertura de uso de la infraestructura y apertura de participación (construcción, operación y gestión" (p.3) son transversales en este proyecto liderado por Network Bogotá y la JAC Villa del Río. 
Una vez activado el suministro eléctrico para la red, los primeros servicios disponibles para sus beneficiarios fueron el circuito cerrado de televisión (CCTV) que se instaló en la primera etapa de despliegue de la red, con 7 cámaras de vigilancia alrededor del edificio de la JAC y un servidor web comunitario que contiene una página web a modo de presencia institucional del organismo local antes mencionado. Para finalizar la etapa también hace falta el despliegue de la emisora comunitaria, la instalación de Wikipedia offline y un servicio de telefonía IP básica.

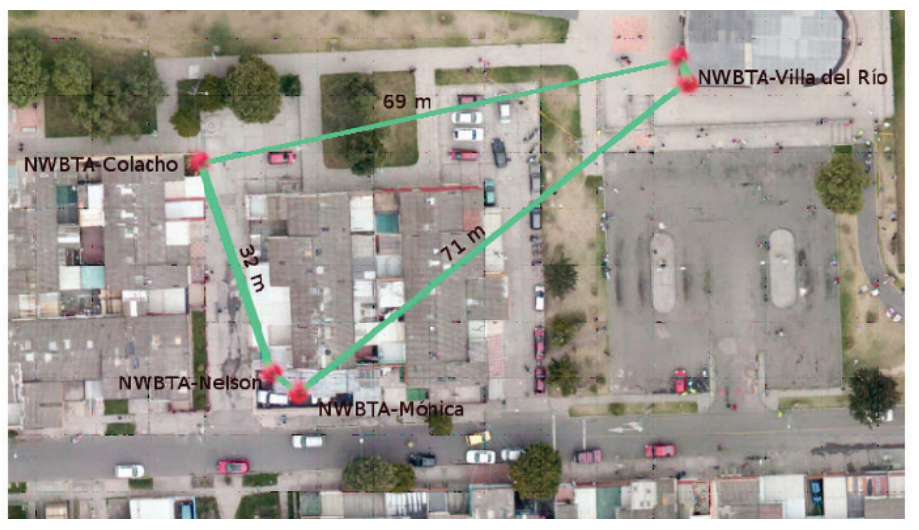

Figura 3. Estado actual de la red comunitaria del barrio Villa del Río, con las dos etapas de despliegue.

Es importante recordar que el proceso de despliegue de la red comunitaria en el barrio Villa del Río aún se encuentra inconcluso, con dos etapas restantes que deben ser terminadas en 2018. Más aún, existe la posibilidad de extender la red comunitaria aquí mencionada a otros barrios vecinos del sector, hecho que permitiría beneficiar un mayor número de habitantes.

\section{Discusión y Conclusiones}

Esta experiencia en RILC Villa del Río, ha podido contar con la participación concreta de la comunidad en el desarrollo de la red. Los habitantes del sector han aportado en la estructuración financiera y técnica de manera participativa, en la toma de decisiones en cuanto a la ubicación de equipos, tiempos de despliegue y montos de inversión, lo que se convierte en un factor de éxito para el desarrollo de la red desde el "diseño crítico", en el cual se dan a conocer de manera concreta y tangible a los posibles beneficiarios del proyecto local las posibilidades y capacidades futuras de la red (Antoniadis et al, 2015). Este diseño crítico permite evocar en los ciudadanos todo aquello que podrían estar realizando y mejorando en el ámbito local gracias a la red comunitaria. Por consiguiente, se contó con vecinos del sector juntando y administrando el dinero necesario para la compra de equipamiento de red, realizando cotizaciones de precios, dirigiéndose a las tiendas de electrónica a comprar los recursos adecuados y subiendo a los techos de las casas a instalar las antenas inalámbricas.

Por otra parte, la participación local en la construcción de la red comunitaria es una manifestación de la soberanía digital, por cuanto los residentes del barrio Villa del Río administran los recursos disponibles desde un escenario actual donde servicios tecnológicos vitales son controlados por grandes operadores (Rivera, 2017). Como consecuencia de este ejercicio comunitario, los usuarios beneficiarios de la red también sugirieron soluciones técnicas alternativas a las concebidas por el equipo técnico de despliegue (Network Bogotá), como en el caso de una conexión eléctrica más eficiente y administrable para un nodo particular de la red, donde un residente sugirió hacer una instalación eléctrica intercambiable entre los vecinos; independiente de la ubicación fija e inamovible de uno de los nodos, la conexión eléctrica se podría "rotar" entre los vecinos para un consumo eléctrico más justo. Por tanto, la "participación abierta" propuesta por Baig et al (2015) y evidente en la red liderada por Network Bogotá y la JAC, invita a la apropiación total de la red, aumentando el sentido de pertenencia y responsabilidad por la misma, propiciando un recurso "procomún" (p.3). De igual forma, estas actitudes esperadas en torno al despliegue de red obedecen al cariz o tono de "hágalo usted mismo", presente en la gran mayoría de proyectos de comunicaciones comunitarias. Para Antoniadis (2015), el "hágalo usted mismo" es una forma de empoderar a las personas en la construcción de recursos tecnológicos a la medida de las necesidades locales y personales y se basa en "el suministro de herramientas generales y metodologías que proveen la manera en que personas no expertas se 
conviertan en diseñadores de sus propias tecnologías sin la intervención de investigadores". (p. 5)

Acerca de los servicios de red comunitarios, estos son el vehículo o la manera de transformar situaciones locales. El aprovisionamiento de servicios comunitarios se hace a través del aljibe comunitario, más tangible y concreto que una nube comunitaria. La descentralización de servicios no se efectúa de manera tan dispersa como en una nube que se puede desplazar a la deriva; los servicios y aplicaciones de la red comunitaria son almacenados en servidores administrados por los propios usuarios "prosumidores" de la red. En el caso de la red de Villa del Río, el sistema de cámaras cuenta con un (1) DVR y un servidor web instalados en la JAC, mientras que cada calle beneficiada por el proyecto está estructurando financieramente sus propios DVR y servidores web de contenidos, es decir, sus propios aljibes de información.

También es importante mencionar algunos desaciertos, ya que se encuentran casos donde algunos residentes del sector tienen dificultades en comprender que el trabajo comunitario no significa trabajo gratuito. Como afirma Rey-Moreno (2017), gracias al arraigo cultural de desconfianza presente por generaciones es difícil comprender a veces que un trabajo de infraestructura local puede darse de manera honesta, desinteresada y altruista. En consecuencia, establecer paralelismos entre la infraestructura física de una ciudad y la infraestructura de comunicaciones que sugiere Frankston (2016, abril) tiene ciertas desventajas, ya que pervive la duda entre algunos potenciales beneficiarios del sector si las inversiones requeridas en equipamiento de red tienen sobrecostos o márgenes de utilidad ocultos.

Por lo tanto, como recomendaciones, en la medida de lo posible, el éxito de una red comunitaria será mayor si esta se promociona a través de un organismo local de administración. Como lo describen Baig et al (2015), "las administraciones públicas son responsables de la regulación de las interacciones entre el despliegue y la operación de la red y los bienes públicos, tales como la ocupación de dominio público. Todos los participantes que extraen conectividad deben contribuir con infraestructura" (p. 4). Sin embargo, en el escena- rio colombiano no se puede esperar a contar con el apoyo de la administración pública o que un organismo local de la magnitud que sea, reaccione ante la necesidad o no de proyectos de comunicaciones comunitarias, por ello, los residentes de un espacio geográfico cualquiera, pueden y deben organizarse para construir la red, y una vez esta se encuentre en operación, es posible contactar nuevamente al organismo público para que se integre en la red. El escenario más óptimo y deseado es la integración de todos y cada uno de los participantes de la comunidad, máxime cuando un organismo local puede aportar elementos de financiación y respaldo legal que de otra manera personas sin una existencia jurídica o de trayectoria pudiesen soportar.

En las etapas de socialización con las comunidades, sobre todo al momento de estructurar financieramente el proyecto es necesario incluir hasta los más mínimos costos, para evitar sorpresas al momento de instalar la red. Esto es requerido no solo por la falta de materiales que pueda darse, también es posible tener que cambiar equipamiento defectuoso o que no satisface las necesidades en el momento de su operación. En esta misma línea, se debe detallar minuciosamente qué puede y qué no puede hacer la red y la cantidad detallada de equipos, tanto para el despliegue actual como en expansiones futuras. Esto se hace con el ánimo de evitar desencuentros y dar a entender que la red es una unión de componentes, cada uno con tareas específicas a pesar de la existencia de equipos multiuso, como lo son los servidores web. La instalación de una red para mejorar la videovigilancia en un sector es de dos pasos, primero la instalación de la troncal o camino, y una segunda etapa es la instalación de las cámaras de seguridad y los equipos de registro de video o DVR.

El pedir consejo o palabra a otros proyectos de redes comunitarias alrededor del mundo, así como el tener como referentes otras experiencias previas, hace que el despliegue de una red en un país o ciudad sea más fácil. Estas comunidades están muy abiertas a la libre circulación de conocimiento e intercambio de saberes, por ejemplo, cómo se puede salvar una distancia de 1 kilómetro a través de dos puntos de acceso inalámbrico direcciona- 
les, esto ahorrará tiempo, dinero y esfuerzo en un proyecto de esta naturaleza.

En síntesis, la instauración de una Red Inalámbrica Libre Comunitaria responde a los derechos económicos, sociales y culturales de la población (Esterhuysen, 2017; Burch, 2017), y es posible cuando se identifica la necesidad específica de sus potenciales usuarios. El logro de los objetivos de dicha red se consolidará gracias a la participación activa y comprometida de los potenciales destinatarios; para ello es necesario que los conocimientos y experiencia de quienes dominan la parte tecnológica se pongan a disposición de la comunidad después de un análisis de sus necesidades, situación referida por diversos autores

\section{Agradecimientos}

Deseo dar un reconocimiento especial a todos los profesionales que han aportado al desarrollo y materialización de los objetivos propuestos por Network Bogotá.

A los miembros de Network Bogotá, Lic. Oscar Fabian Prieto y Luis Miguel Sánchez quienes han dado todo de si, sacrificando tiempo y esfuerzo para difundir a las Redes Comunitarias no solo desde una perspectiva técnica sino desde una perspectiva social y humana.

Al Ing. Erick Romero y Lic. Laura Barragán, miembros de la Junta de Acción Comunal del barrio Villa del Río (Bogotá) por creer en el proyecto Network Bogotá y ser la primera comunidad que abrió sus puertas para desarrollar Redes Inalámbricas Comunitarias.

\section{REFERENCIAS BIBLIOGRÁFICAS}

Antoniadis, P. (2016). Local networks for local interactions: Four reasons why and a way forward. First Monday, 21(12). Recuperado de: https://doi.org/10.5210/fm.v21i12.7123

Antoniadis, P., Apostol, I., Gaved, M., Smyth, M., \& Unteidig, A. (2015). DIY networking as a facilitator for interdisciplinary research on the hybrid city. Recuperado de: http:// nethood.org/publications/antoniadis_et_al_DIYnetworking_HybridCity2015.pdf

Albarracín, J. (2008). Redes inalámbricas comunitarias. Recuperado de: http://52.0.140.184/typo43/fileadmin/Revista_107/03.pdf

Baladrón, M. (2017). Redes comunitarias para la inclusión social y digital. Revista FIBRA, Tecnologías de la comunicación, abril n.14. Recuperado de: http://papel.revistafibra. info/redes-comunitarias-la-inclusion-social-digital

Baig, R., Roca, R., Freitag, F., \& Navarro, L. (2015). guifi.net, una infraestructura de red procomún gestionada de forma colectiva. Recuperado de: http://people.ac.upc.edu/ leandro/pubs/crowds-guifi-es.pdf

Bebea, I. (2015). Alfabetización Digital Crítica. Publicación online del proyecto. Ondula. Recuperado de: https://www. comunicacionabierta.net/wp-content/uploads/2016/03/alfabetizacion-digital-critica-version-web-72ppp.pdf

Britos, J., Vargas, L., Arias, S., Menzaque, F., Chalave, S., Echániz, N., \& Moreno, A. (2016, mayo). Evaluación del Enrutamiento y Acceso al Medio en Redes Mesh Auto-Configurables. En XVIII Workshop de Investigadores en Ciencias de la Computación (WICC 2016, Entre Ríos, Argentina). Recuperado de: http://hdl.handle.net/10915/52800

Burch, S. (2017). Internet y DDHH. América Latina en Movimiento, año 41, 1; Segunda época, número "Internet y derechos económicos, sociales y culturales".

Cepeda, M. (2014) Diseño e implementación de una red Mesh como alternativa de solución para redes comunitarias o rurales. (Tesis de grado) Facultad de Ingeniería, Universidad Libre, Colombia. Recuperado de: http://repository.unilibre.edu.co/bitstream/handle/10901/8422/Proyecto $\% 20$ de $\% 20$ Grado\%20Redes\%20Mesh\%20V3.pdf?sequence $=1$

Chamorro, L., y Pietrosemoli, E. (2008). Redes inalámbricas para el desarrollo en América Latina y el Caribe. APC. Recuperado de: https://www.apc.org/sites/default/files/APC_RedesInalambricasParaElDesarrolloLAC_20081223.pdf

Congreso de Colombia. (2009). Ley 1341 de 2009. Bogotá: Ministerio TIC. Recuperado de https://www.mintic.gov.co/ portal/604/articles-3707_documento.pdf

Esterhuysen, A. (2017). ¿Por qué enfocarnos en los derechos económicos, sociales y culturales? América Latina en Movimiento, año 41 2-5; Segunda época, número "Internet y derechos económicos, sociales y culturales".

Forero, N. (2012). Análisis De La Incidencia de la Televisión Comunitaria en Colombia en la conformación de espacios de participación ciudadana durante el periodo de 
Despliegue de una Red Inalámbrica Libre Comunitaria: un ejercicio de soberanía digital en el barrio Villa del Río (Bogotá, Colombia)

1995 - 2010 (Tesis de pregrado) (pp. 10-14). Recuperado de: http://repository.urosario.edu.co/bitstream/handle/10336/4204/1015417825-2012.pdf?sequence=1\&isAllowed $=\mathrm{y}$

Frankston, B. (2016). Infrastructure for a Connected World (p. 1). Recuperado de: http://rmf.vc/InfrastructureConnected?pdf=t

Frankston, B. (2016, abril). The Internet as our new infrastructure. Articulo presentado en la Conferencia Internacional sobre Conectividad Sostenible, Río de Janeiro, Brasil. Resumen recuperado de: http://rmf.vc/TalkInternetAsInfrastructure?pdf $=\mathrm{t}$

Gordillo, W. (2013) Redes Libres- Enlaces digitales con sentido social. ENGI. Revista electrónica de la Facultad de Ingeniería, 2 (1), 11-13. Recuperado de: http://revistas_electronicas.unicundi.edu.co/index.php/Revistas_electronicas/ article/view/71/pdf_12

González, B.; Otero, E. y Vecino, R. (2011). Wifi comunitaria para la distribución social del conocimiento: el caso de la Isla de La Juventud, Cuba. XV congreso de Investigación en Ciencias Administrativas, Universidad Veracruzana, Veracruz, México. Recuperado de: http://acacia.org.mx/busqueda/pdf/02_24_Wifi_Comunitaria.pdf

Internet Society. (2016). Global Internet Report 2016 (p. 32). Internet Society. Recuperado de: https:/www.internetsociety.org/globalinternetreport/2016/wp-content/ uploads/2016/11/ISOC_GIR_2016-v1.pdf

Kende, M. (2016, enero 23). Why is internet growth slowing down? [Weblog post] Recuperado de: https://www. weforum.org/agenda/2016/01/why-is-internet-growthslowing-down/

Kos, Jernej \& Milutinović, Mitar \& Čehovin, Luka. (2015). nodewatcher: A Substrate for Growing Your own Community Network. Computer Networks. 93, 2. Recuperado de: https://doi.org/10.1016/j.comnet.2015.09.021

Librerouter. (2016). Librerouter. Recuperado de: https:// librerouter.org/media/uploads/frida2016_librerouter_proposal.pdf

Luzardo, W. (2016). Propuesta de diseño de una red inalámbrica comunitaria libre mediante una red de malla (Mesh) para el desarrollo y comunicación digital de la parroquia rural Membrillal del Cantón Jipijapa Provincia de Manabí. (Trabajo de titulación) Facultad de Ingeniería Industrial Universidad de Guayaquil, Ecuador. Recuperado de:. http:// repositorio.ug.edu.ec/bitstream/redug/20559/1/LUZARDO\%20REYES\%20WALTER\%20JOS\%C3\%89.pdf

Pedraza, L., Gómez, C., y Mancilla Gaona, G. (2014). Red Inalámbrica de uso libre. Bogotá: Universidad Distrital Francisco José de Caldas. Recuperado de http://www.propiedadpublica.com.co/v2_base/file_downloader.php?id_file $=1351-\mathrm{m} 21-7 \mathrm{c} 08 \mathrm{aabb} 93 \mathrm{a} 26 \mathrm{fb} 3 \mathrm{f} 74 \mathrm{af2a} 88 \mathrm{dcde} 353$

qMp. (2017). Inicio - qMp. Qmp.cat. Recuperado de http://qmp.cat/Inicio

Rey-Moreno, C. (2017). Supporting the Creation and Scalability of Affordable Access Solutions: Understanding
Community Networks in Africa. Internet Society. Recuperado de: https://www.internetsociety.org/wp-content/ uploads/2017/08/CommunityNetworkingAfrica_report_ May2017_1.pdf

Rivera, C. (2017). Elaboración de un concepto de soberanía digital en base al estudio de los casos de Julian Assange y Edward Snowden (Tesis de maestría) (pp. 68-69). Quito: Instituto de Altos Estudios Nacionales. Recuperado de: http://repositorio.iaen.edu.ec/bitstream/24000/4622/1/TESIS\%20 DE\%20MAESTRIA\%20EN\%20RELACIONES\%20INTERNACIONALES.\%20CARLOS\%20RIVERA.pdf

San Miguel Pérez, E. (2017). Diseño del nodo de conexión a Internet de la red Guifi-Elx (Tesis de pregrado) (p.7). Recuperado de: http://hdl.handle.net/10045/67808

Vega, D., Cerda-Alabern, L., Navarro, L., \& Meseguer, R. (2012, octubre). Topology patterns of a community network: Guifi. net. In Wireless and Mobile Computing, Networking and Communications (WiMob), 2012 IEEE 8th International Conference on (pp. 612-619). IEEE. Recuperado de: http://dsg.ac.upc.edu/sites/default/files/1569633605.pdf 


\section{PARES REVISORES}

Hamut'ay 4(2). Julio - diciembre 2017

DSC. PhD. Rubén Darío Cárdenas Espinosa Ingeniería Electrónica, Tecnología de Información, Investigador Senior. Escritor, Mentor INNPULSA, Director Grupo de Investigación ReNuevaTe Ciencia, Tecnología e Innovación. Instructor SENA Distrito Capital Centro Metalmecánico. Catedrático en los CREAD Dorada, Anserma, Pereira y Manizales, Universidad de Caldas, Colombia

\section{Dr. Enrique Berra Ruiz}

Facultad de Estudios Superiores Iztacala. Docente Investigador Sistema de Universidad Abierta y de

Educación a Distancia. Universidad Nacional Autónoma de México. Profesor Investigador Titular B de T.C.

Universidad Autónoma de Baja California

\section{MSc. Elkin Durán Mancipe}

Magíster en Ingeniería Industrial. Especialista en Docencia Universitaria. Auditor Interno de Calidad en SGS Internacional. Par Académico MEN (Colombia) y SENA. Director de Planeación, Corporación Unificada Nacional de Educación Superior (CUN). Docente Posgrados a Distancia, Corporación Universitaria Minuto de Dios (UNIMINUTO).

\section{Dr. Gonzalo del Moral Arroyo}

Docente investigador. Facultad de Ciencias Sociales. Universidad Pablo de Olavide de Sevilla, Espańa

Ing. Magíster John Alexander Rojas Montero Especialista en Entornos Virtuales de Aprendizaje (OEI), y en Tecnologías de la Información Aplicadas a la Educación. Director del Grupo de Investigación KENTA. Universidad Pedagógica Nacional

\section{Dr. Javier Fombona Cadavieco}

Docente investigador. Facultad de Formación del Profesorado y Educación. Universidad de Oviedo, España

\section{Dr. Luis Picado}

Docente investigador. ISCE, Portugal

\section{Adriana Huertas PhD.}

Directora Investigación - UDCII. Facultad de Educación. Universidad Antonio Nariño, Bogotá, Colombia

\section{Dra. Ivanovnna Milqueya Cruz Pichardo}

Docente investigador. Pontificia Universidad Católica Madre y Maestra, República Dominicana
Dra. María de los Ángeles Alonso Lavernia Profesora Investigadora Titular B. Centro de Investigación en Tecnologías de Información y Sistemas. Universidad Autónoma del Estado de Hidalgo

Ing. MSc. Astrid Calderón Hernández

Orientador TI. Par evaluador de RedColsi y de REDA. Docente Universitaria y Asistente Ambientes Virtuales de Aprendizaje. Fundación Tecnológica Antonio de Arévalo TECNAR

\section{Dra. Alicia García Bejarano}

Especialista en Diseño de Ambientes Virtuales de Aprendizaje. Facultad de educación. Coordinadora Centro de Investigación Educativa y Pedagógica. Universidad del Bosque. Bogotá, Colombia

\section{Dr. Janio Lincon Jadán Guerrero}

Director del Instituto de Investigación, Innovación y Desarrollo. Universidad Tecnológica Indoamérica,

Ecuador. Director del Centro de Investigación en Mecatrónica y Sistemas Interactivos (MIST) Universidad Tecnológica Indoamérica, Ecuador.

\section{Dr. Wilson J. Sarmiento}

Profesor Asistente. Programa de Ingeniería en Multimedia. Universidad Militar Nueva Granada, Colombia

\section{Bell Manrique Losada, Ph.D.}

MSc. en Ingeniería. Profesora TC Facultad de Ingeniería. Universidad de Medellín, Colombia

\section{Dra. Mercedes Leticia Sánchez Ambriz}

Coordinadora académica del módulo de Educación a distancia, Instituto Latinoamericano de la Comunicación Educativa (ILCE). Miembro del Consejo Editorial de la Revista de la Academia de Educación abierta y a distancia. México. 


\section{INSTRUCCIONES PARA AUTORES}

La revista HAMUT'AY es una publicación semestral de la Coordinación de Investigación y Extensión Científica Tecnológica de la Dirección Universitaria de Educación a Distancia de la Universidad Alas Peruanas cuyo objetivo es divulgar artículos científicos a texto completo sobre tecnologías y virtualidad y se dirige a la comunidad universitaria nacional e internacional.

Todos los artículos son sometidos a un arbitraje por parte de pares evaluadores nacionales e internacionales de amplia trayectoria en la línea temática de la revista. Los pares no son miembros del Comité Editorial ni de la institución editora.

Los artículos que se remiten a la revista deben ser originales e inéditos, no se enviaron a otra revista para su publicación y no han sido publicados.

\section{TIPOS DE ARTÍCULOS A PUBLICAR}

La revista acepta tres categorías de artículos.

Artículos de investigación científica y tecnológica (López, 2013, Publindex, 2010). Son investigaciones originales que presentan resultados de uno o varios proyectos de investigación académico-tecnológica concluidos o en proceso.

Artículos de revisión (Fernández-Ríos y Buela-Casal 2009). Son síntesis de estudios bibliográficos de un tema determinado, en el que se analiza, sintetiza y discute la información publicada de una manera integrada.

Reportes de Casos (Publindex, 2010). Son presentaciones de resultados de un estudio de caso sobre una situación específica, que da a conocer las experiencias técnicas y metodológicas consideradas en el caso.

\section{ESTRUCTURA DE LOS TIPOS DE ARTÍCULOS}

Todos los artículos deberán ser redactados con el programa Microsoft Word, usando las siguientes normas de estilo de la revista digital: tamaño pa- pel A4 con márgen izquierdo de $3 \mathrm{~cm}$. y $2.5 \mathrm{~cm}$. en los demás márgenes; fuente Times New Román, tamaño 12 e interlineado a doble espacio.

En el encabezado deberá ir el título del artículo y los nombres completos de los autores, según el orden de participación. Cada una de las páginas del artículo debe estar numerada consecutivamente.

\section{Composición de los tipos de artículos}

Los artículos de investigación científica y tecnológica (López, 2013; Bobenrieth, 2002). Se componen del título, autor(es), resumen (abstract), palabras claves (keywords), introducción (objetivos), materiales y método (participantes, instrumento, diseño, procedimiento), resultados (interpretación tablas y figuras), discusión y conclusiones, referencias bibliográficas y agradecimientos y anexos (opcional). EFACYT.

Los artículos de revisión (Fernández-Ríos y Buela-Casal 2009, p.332). Están compuestos del título, autor(es), resumen (abstract), palabras claves (keywords), introducción, método (criterios de selección de la literatura), revisión de la literatura (marco teórico del tema de revisión), conclusiones (aspectos relevantes de la revisión de la literatura y sugerencias o recomendaciones a futuro) y referencias bibliográficas. EFAR

Tablas: El título será claro, conciso y descriptivo del contenido de la tabla. Solo la palabra inicial lleva mayúsculas y no se coloca punto al final del título. Veáse modelo siguiente:

Tabla 1

Tiempo transcurrido de arranque y consumo de CPU de las herramientas de virtualización

\begin{tabular}{lcc}
\hline $\begin{array}{c}\text { Herramientas de } \\
\text { virtualización }\end{array}$ & Tiempo (s) & CPU (\%) \\
\hline Xen & $109^{*}$ & 35.14 \\
VirtualBox & 87 & 0.88 \\
\hline
\end{tabular}

Nota: Tomada de García (2010)

* Las variables de control incluyeron tipo y modelo de fuente de poder 
En el contenido de la tabla las fracciones decimales se expresarán con una coma, excepto en el Abstract donde se usará el punto. Las cifras en miles y millones se separarán con un espacio simple, en vez de comas.

Figuras: Son gráficas, fotografías, diagramas y dibujos en formato JPG de calidad alta. El título será breve y conciso. Veáse el siguiente ejemplo.

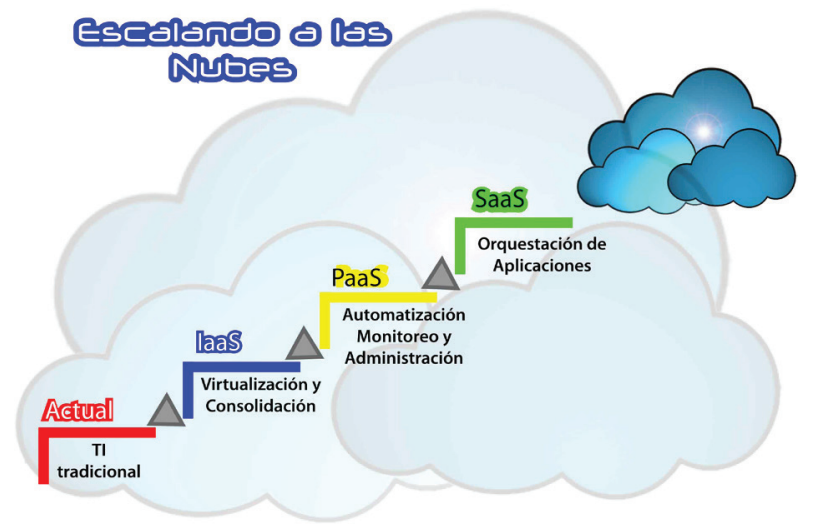

Figura 1. Escalando a las nubes. Fuente: http://www.eikonix.mx/?page_id=113

Referencias bibliográficas. Las referencias y citas bibliográficas deberán considerar las Normas APA, Sexta Edición. Veáse los siguientes ejemplos:

\section{Articulos publicados en revistas:}

Alcalde-Alvites, M. (2016) Software libre enfocados en diversos campos de las ciencias biológicas. Revista Hamut'ay, 3 (1) 59-70. Recuperado de: http://dx.doi.org/10.21503/hamu.v3i1.1000

Cabero, J. (2010). Los retos de la integración de las TICs en los procesos educativos: Limites y pósibilidades, Rev Perspectiva Educacional, 49 (1), 36-61

\section{Libros:}

Cabello, R. y Levis, D. (2007), Medios informáticos en la educación a principios del siglo XXI, (p.107) 1era. Edición. Argentina: Publicaciones Prometeo Libros

\section{Capitulos de libros:}

García, A., Cocero, D., Velázquez, J., Blanco, E., Grande, M., Núñez, M.V. y Tejera, R. Aplicación de la teledetección a la gestión silvopastoral (2006). En Camacho Olmedo, M., Cañete, J. y Lara, J. El acceso a la información espacial y las tecnologías geográficas. (pp.831-842). España Granada: Editorial universidad de Granada

Tesis:

Carmona, J. (2012) Aplicaciones de la simulación tridimensional para la detección precoz de consumo de sustancias y violencia escolar en ámbitos educativos entre los años 2011 y 2012. Tesis doctoral, Universidad de Almería, Almería, España

\section{Páginas electrónicas:}

Fernandez-Rios \& Buela-Casal, G. (2009) Standars for the preparation and writing of psichology, Internacional Journal of Clinical and Health Psychology (citado el 15 de febrero del 2014), 9 (2), 329-344. Recuperado de: http://www.aepc. es/ijchp/ref-es-326.pdf

\section{ENVÍO DE ARTÍCULOS}

Los autores enviarán el artículo científico acompañado de la declaración jurada de autoría y autorización (DEJA) al Editor jefe de la revista (Dra. Cleofé Genoveva Alvites Huamaní <revistahamutay@uap.edu.pe>. Los autores recibirán confirmación de la fecha de recepción de su trabajo.

\section{PROCESO DE EVALUACIÓN DE ARTÍCULOS}

La evaluación de los artículos tiene dos fases:

Primera fase: El grupo editorial verifica el cumplimiento de los aspectos estructurales y de forma según las indicaciones para autores, en los formatos establecidos, y de acuerdo al tipo de artículo.

Segunda fase: Los árbitros (pares revisores) determinan el valor del contenido del artículo y sus aspectos metodológicos, evaluando la calidad científica del artículo. Los pares evaluadores emiten uno de los siguientes criterios: No publica, Publica con condición (levantará observaciones previa a la publicación) y publica, considerando para ello los criterios estipulados en el PEAR o PEAO o PEEC, según sea el caso. Si se da el criterio de Publica con condición se remitirá al autor para que levante las observaciones, luego éste devolverá al editor para que lo envíe al par revisor nuevamente para su decision final. En el caso de que un artí- 
culo tenga la aceptacion de un par evaluador y del otro no, para dirimir se remitirá a un tercer evaluador.

\section{REFERENCIAS BIBLIOGRÁFICAS}

Asociación Americana de Psicología. (2010). Manual de Publicaciones. México: El Manual Moderno S.A.

Bobenrieth, M. (2002) Normas para revisión de artículos originales en Ciencias de la Salud. Revista Internacional de Psicología Clínica y de la Salud, 2 (4) 509-523.

Fernandez-Ríos, L. y Buela-Casal, G. (2009) Standards for the preparation and writin of Psychology review articles. Revista International Journal of Clinical and Health Psychology, 9 (2) 329-344.

López, S. (2013) El proceso de escritura y publicación de un artículo científico. Revista Electrónica Educare, 17 (1), 5-27. Recuperado de http://www.revistas.una.ac.cr/index. php/EDUCARE/issue/current.

Romani, F. (2010) Reporte de caso y serie de casos: una aproximación para el pregrado. Revista CIMEL 15 (1), 46-51 recuperado de http://www.redalyc.org/articulo. oa?id=71720941013.

Publindex (2010) Documento Guía, servicio permanente de indexación de Revistas de Ciencia, Tecnología e innovación Colombianas, Base Bibliográfica Nacional-BBN, Índice bibliográfico nacional Publindex-IBN. 